$$
\begin{aligned}
& \text { UNIVERSIDADE DE SÃO PAULO } \\
& \text { INSTITUTO DE GEOCIÊNCIAS }
\end{aligned}
$$

\title{
Avaliação biogeoquímica da contaminação do solo e água subterrânea na área do Parque Ecológico do Tietê - PET, Região Metropolitana de São Paulo - RMSP, SP.
}

\section{REJANE GONÇALVES DA ROCHA}

Orientadora: Profa. Dra. Rosely Aparecida Liguori Imbernon

\author{
DISSERTAÇÃO DE MESTRADO \\ Programa de Pós-Graduação em Recursos Minerais e Hidrogeologia
}

São Paulo 


\title{
UNIVERSIDADE DE SÃO PAULO \\ INSTITUTO DE GEOCIÊNCIAS
}

\section{Avaliação biogeoquímica da contaminação do solo e água subterrânea na área do Parque Ecológico do Tietê - PET, Região Metropolitana de São Paulo - RMSP, SP.}

\section{REJANE GONÇALVES DA ROCHA}

\begin{abstract}
Dissertação apresentada ao Programa de Pós-Graduação em Recursos Minerais e Hidrogeologia do Instituto de Geociências da Universidade de São Paulo, como parte dos requisitos para a obtenção do título de mestre.
\end{abstract}

Orientadora: Profa. Dra. Rosely Aparecida Liguori Imbernon

$$
\text { DISSERTAÇÃO DE MESTRADO }
$$

Programa de Pós-Graduação em Recursos Minerais e Hidrogeologia

São Paulo 
Ficha catalográfica preparada pelo Serviço de Biblioteca e Documentação do Instituto de Geociências da Universidade de São Paulo

\section{Rocha, Rejane Gonçalves}

Avaliação biogeoquímica da contaminação do solo e água subterrânea na área do Parque Ecológico do Tietê - PET, região metropolitana de São Paulo RMSP, SP / Rejane Gonçalves da Rocha. - São Paulo, 2011.

71 p. : il. + anexos.

Dissertação (Mestrado) : IGc/USP

Orient.: Imbernon, Rosely Aparecida Liguori

1. Contaminação do solo 2. Contaminação da água subterrânea 3. Áreas degradadas 4. Parques urbanos 5. Coeficiente de prospecção biogeoquímicos I. Título 
"A natureza pode suprir todas as necessidades do homem, menos a sua ganância".

Mahatma Gandhi 
As dificuldades apareceram, permaneceram e foram superadas, pela ajuda e apoio de pessoas que como anjos se fizeram presentes.

Ao curso de Pós-Graduação em Recursos Minerais e Hidrogeologia do Instituto de Geociências da Universidade de São Paulo, por toda infraestrutura disponibilizada e a CAPES, agradeço pela bolsa concedida;

A minha orientadora Prof. Dra. Rosely Aparecida Linguori Imbernon, pela orientação, pelo apoio, confiança, pelos ensinamentos passados e por me ajudar a realizar um sonho.

Ao Prof. Dr. Teodoro Ribeiro Isnard Almeida, pelo suporte e a confiança.

Ao Prof. Dr. Antonio Conceição Paranhos, grande amigo, pelos ensinamentos, conselhos, pela companhia nas noites de trabalho, pelo ombro, o abraço ou o olhar.

A Dra Sibele Ezaki, por quem tenho muita admiração, obrigada pelos ensinamentos de vida e profissionais, pelo apoio e pela amizade.

Ao Prof. Dr. José Domingos Faraco Gallas, pela ajuda com o software nos tratamentos de dados.

Ao Carlos Henrique Maldaner, com a efetivação nos campos, auxiliando e me tranquilizando.

Aos queridos amigos que fiz ao longo destes anos de IGC-USP, em meio às correrias, sucessos e frustrações do dia-a-dia: Aníbal Bem David Albino Muchimbane, Edson Luís Duarte dos Santos, Fernando Augusto Saraiva, Sandra Tereza Procel Guerra, Paula Amaral, Fabricio Baú Dalmás, Felipe van Enck Meira, Nick, Nicole Jasen Lazaro, Jordana Pianoski, José Paulo Sertek, Cibele Hummel do Amaral, Marcos Mondin, Robercal Asevedo Berrocal, Joaquim Matheus, Ariel Vieira da Silva, Thiago Roque, Maria Alexandra Aguja Bocanegra e Daniel Atencio.

A todos os funcionários do IGc - USP, que, de alguma forma, colaboraram para a concretização deste trabalho, em especial às funcionárias da biblioteca Maristela, Célia, Érica, Brenda e Sandra pelo auxilio nas pesquisas.

Aos técnicos dos Laboratórios, Sandra Andrade, Paulo Mori, Marinês Lopes de Silva, Ricardo Cardenete, José Vinicius Martins, Elaine Aparecida da Silva Sinfrônio, Suely dos Santos, estagiária Audrey Schon Rodrigues; que me auxiliaram na parte experimental. 
As secretárias Ana Paula, Magali, Rita e Denise sempre, pacientes e muito dispostas a ajudar.

Por último, mas não menos importante, agradeço a Maria Lúcia da Silva, Maria Bárbara Gonçalves, Aparecido Gonçalves (in memoriam) e a Iara Gonçalves da Rocha, pelas contribuições que proporcionaram em diferentes fases de minha vida, sendo, sem dúvida, responsáveis por quem sou hoje.

Obrigada! 


\section{Dedico}

A Malú pelo apoio incondicional. A todos aqueles que, desde o princípio, torceram e acreditaram em mim. 


\section{RESUMO}

O Parque Ecológico Tietê (PET), em Ermelino Matarazzo, a leste da região metropolitana de São Paulo, foi criado com o objetivo de preservar as várzeas do rio Tietê. Antes da criação do parque, a região foi palco de várias atividades antrópicas que levaram ao risco de contaminação do solo e águas subterrâneas. A recuperação iniciou-se com o plantio de espécies nativas, o que também promoveu a recolonização da fauna, composta essencialmente de espécies frugívoras. Dentre as espécies de plantas presentes no parque, a palmeira Jerivá (Syagrus romanzoffiana) é importante por sua ampla distribuição geográfica nos ecossistemas brasileiros. $\mathrm{O}$ presente estudo teve como objetivo compreender, através de coeficientes de prospecção biogeoquímicos, a interação entre os compartimentos solo, água subterrânea e planta, este último representado pela palmeira Jerivá. Os resultados indicaram que o Jerivá apresentou diferentes coeficientes de absorção entre suas folhas e pecíolos. O estudo também demonstrou que fatores como sazonalidade dentro de um período mínimo de um ano, idade e espécies de plantas devem ser levados em conta em abordagens biogeoquímicas.

Palavras-chave: áreas degradadas - coeficientes de prospecção biogeoquímicos parque urbano - contaminação do solo e água subterrânea - Syagrus romanzoffiana. 


\section{ABStRACT}

The Tietê Ecological Park (PET) in Ermelino Matarazzo, east of the metropolitan area of São Paulo city, was created with the purpose of preserving the floodplains of the Tietê River. Prior to the establishment of the park, the region was scene of several anthropogenic activities which led to high risk of soil and groundwater contamination. Subsequent recovery of the degraded area was aimed through the planting of native plant species, which also promoted the recolonization of the area by the fauna, essentially composed of frugivorous species. Among the plant species introduced in the park, the Jerivá palm tree (Syagrus romanzoffiana) is important for its wide geographical distribution in Brazilian ecosystems. The current study aimed to understand, through biogeochemical prospecting coefficients, the interaction between soil compartments, underground water and plant, the latter represented by the Jerivá palm tree. The results indicated that Jerivá presented different absorption coefficients among its leaves and petioles. The study also demonstrated that factors like seasonality within a minimum period of one year, age and plant species must be taken into account in biogeochemical approaches.

Keywords: degraded areas - biogeochemical prospecting coefficients - urban park - soil and groundwater contamination - Syagrus romanzoffiana. 


\section{ÍNDICE}

Agradecimentos iii

Dedicatória $\quad$ V

Resumo vi

Abstract vii

Capitulo 1 - Introdução 1

1.1 Objetivos 9

Capítulo 2 - Área de Estudo 10

2.1. Aspectos Fisiográficos 13

2.2. Hidrogeologia Local 18

Capítulo 3 - Materiais e Métodos $\quad 20$

3.1. Coleta e preparação das amostras de água subterrânea. 22

3.2. Coleta e preparação das amostras de solo 23

3.3 Coleta e preparação das amostras da espécie-tipo (Palmeira Jerivá) 27

3.4. Tratamento estatístico dos dados 29

Capítulo 4 - Resultados e Discussão 31

4.1. Amostras de solo 31

4.2. Amostras de água $\quad 37$

4.3. Amostras de Jerivá 53

Capítulo 5 - Conclusão $\quad 61$

Referências Bibliográficas 66

Anexos 


\section{Índice de Figuras}

Figura 1- Processos que envolvem a absorção de metais pelas plantas.

Figura 2 - Localização da área de estudo e áreas adjacentes

Figura 3 - Esquema do Parque Ecológico do Tietê-PET adaptado de Ross (1991). A Rodovia dos trabalhadores hoje é denominada Ayrton Senna. Destaque para área de estudo adaptado de Mondin (2005) com os poços selecionados, as espécies-tipo Palmeiras Jerivás e os locais de coleta de solo.

Figura 4 - Planície de inundação do Tietê e os componentes dos aspectos fisiográfico regionais.

Figura 5 - Perfil de solo do PET

Figura 6 - Carta de solo da planície aluvial do rio Tietê trecho Parque Ecológico do Tietê

Figura 7 - Dados pluviométricos da subprefeitura da Penha e temperatura média da cidade de São Paulo no ano de 2010

Figura 8 - Parque Ecológico do Tietê - vista aérea entre os anos 1977 e 2007

Figura 9 - Mapa topográfico dos poços de água subterrânea. Destacados em vermelho os poços onde foram coletadas as amostras utilizadas no presente estudo

Figura 10 - Esquemática da palmeira Jerivá - Syagrus romanzoffiana, destaque para os órgãos utilizados neste trabalho.

Figura 11 - Esquema da localização das palmeiras Jerivá, dos poços de monitoramento e dos pontos de coleta de solo no PET.

Figura 12 - Foto do procedimento de coleta do solo em destaque os horizontes A e B.

Figura 13 - Perfil do no solo identificando os horizonte A e B e seus respectivos limites.

Figura 14 - Foto do furo 3 (F3) indicando resíduos plásticos encontrados.

Figura 15 - Fotomicrografica da amostra de solo do PEIC com destaque para grão de Quartzo.

Figura 16 - Fluxograma dos ensaios realizados no solo

Figura 17 - Foto do procedimento de coleta do nomofilo e do pecíolo, com a poda sendo feita na bainha, rente ao estipe.

Figura 18 - Box-whisker plots para elementos maiores e elementos menores. 
Figura 19 - Classificação textural das amostras solo

Figura 20 - Análise de cluster no modo-Q. 33

Figura 21 - Representação gráfica da análise dos componentes 36 principais dois fatores rotacionados para o solo.

Figura 22 - Gráfico C.E Vs T dos meses de junho e outubro 37

Figura 23 - $a, b, d, e-$ Diagrama $p H=f(E h)$ dos micronutrientes. $\quad 40$

Figura 24 - a, b, c, d, e, - Diagrama $\mathrm{pH}=\mathrm{f}(\mathrm{Eh})$ dos macronutrientes. $\quad 41$

Figura 25 a - Curvas de isovalores para C.E e Cl', (junho e outubro). 43

Figura 25 b - Curvas de isovalores para Fe e Ca (junho e outubro). 44

Figura $25 \mathrm{c}$ - Curvas de isovalores para $\mathrm{K}$ e Na (junho e outubro).

Figura $25 \mathrm{~d}$ - Curvas de isovalores para Mg e Mn (junho e outubro). $\quad 46$

Figura 25 e - Curvas de isovalores para pH e Eh (junho e outubro).

Figura $25 \mathrm{f}$ - Curvas de isovalores para $\mathrm{NO}_{3}{ }^{-}$e $\mathrm{SO}_{4}{ }^{2-}$ (junho e 48 outubro).

Figura 26 - Box-whisker plots para os cátions, ânions e parâmetros físico-químicos da água subterrânea.

Figura 27 - - Matriz de correlações entre os dados analisados para cátions e ânions e parâmetros pH, Eh e CE. Coletas de Junho e Outubro.

Figura 28 - Representação gráfica da análise de componentes principais para dois fatores rotacionados

Figura 29 - Análise dos componentes principais dos elementos maiores e traços na espécie tipo para o mês de Junho.

Figura 30 - Análise dos componentes principais dos elementos maiores e traços na espécie tipo para o mês de Outubro

Figura 31 - Gráficos do coeficiente Temporal para os nomofilo e pecíolo.

Figura 32 - Gráficos do Coeficiente Acropetal do nomofilo e pecíolo 60 para os meses de junho e outubro 


\section{Índice de Tabelas}

Tabela 1 - Análise granulométrica das amostras de solo do PET e de ambiente referência não antropizado (F4)

Tabela 2 - Loadings e Comunalidades estimadas para cada variável em cada um dos fatores rotacionados (rotação Equamax) para solo.

Tabela 3 - Loadings e Comunalidades estimadas para cada variável em cada um dos fatores rotacionados (rotação Equamax) para água.

Tabela 4 - Interpretação do Coeficiente de Absorção Biológica (CAB).

Tabela 5 - Interpretação dos Coeficientes, Absorção Temporal (CAT) e Coeficiente Acropetal (CA).

\section{Índice de Siglas}

CA - Coeficiente Acropetal

CAB - Coeficiente de Absorção Biológica

CAT - Coeficiente de Absorção temporal

PET - Parque Ecológico do Tietê

PEIC - Parque Estadual da llha do Cardoso

DAEE - Departamento de águas e Energia Elétrica

CETESB - Companhia de Tecnologia de Saneamento Ambiental

CONAMA - Conselho Nacional do Meio Ambiente 


\section{INTRODUÇÃO}

Nos discursos ambientais, os termos poluição e contaminação são utilizados muitas vezes como sinônimos. Cabe ressaltar que, quando distinguimos poluição, nos referimos ao acréscimo de detritos no meio ambiente, que difere de contaminação, pois um ambiente contaminado está poluído e o inverso nem sempre ocorre. Podemos citar como exemplo uma árvore que apresenta linhas e tiras plásticas de pipas em seus galhos. Esta árvore está poluída, porém, não está contaminada, pois, contaminação pressupõe a presença de substâncias ou seres patogênicos num ambiente, que em determinadas concentrações provocam danos aos seres vivos.

Assim, os metais são substâncias contaminantes não biodegradáveis que se acumulam no ecossistema, formando diferentes tipos de compostos, com diversos efeitos nos organismos vivos. Araújo et al. (2010) relatam que os metais pesados ameaçam a saúde humana e a vida aquática, pois são bioacumulativos. Os processos naturais contribuem para a presença destas espécies químicas no solo. A lixiviação promovida pelo intemperismo das rochas solubiliza em água os metais presentes nas rochas.

Além dos processos naturais, outros fatores, como derivações das ações antrópicas, o crescente avanço tecnológico associado a hábitos de consumo e descarte excessivos, sem a destinação correta de alguns materiais, são também responsáveis pela origem dos metais pesados no solo (Kabata-Pendias e Pendias, 2001).

A contaminação do solo e da água por metais está relacionada a processos de acúmulo, transporte, adsorção, dessorção, precipitação, dissolução, complexação, oxirredução e à quantidade de matéria orgânica do meio. Segundo Pereira et al. (2002), os elementos químicos são redistribuídos no ar, na água, no solo e nos alimentos, obedecendo a ciclos bioquímicos e geoquímicos. Durante a passagem pela cadeia trófica, esses elementos podem sofrer um processo de acúmulo, produzindo efeitos à saúde humana. 
Os metais, em sua maioria, desempenham funções importantes para o equilíbrio do ambiente, tanto para plantas como para outros seres vivos. No entanto, merece atenção a concentração em que os mesmos estão disponíveis nos diferentes compartimentos do sistema Terra, uma vez que alguns metais só desempenham funções benéficas quando em concentrações baixíssimas. Estando em concentrações acima das toleráveis, ocasionam efeitos adversos (Paoliello et al., 2003; Araújo et al., 2010).

As plantas extraem do solo e da água os macro e micronutrientes que necessitam à sua sobrevivência. Cada espécie tem seus elementos essenciais característicos e suas respectivas concentrações. A elevada disponibilidade de metais no solo e na água gera maior oferta dessas substâncias à planta, que pode levar a processos de bioassimilação. Esse processo é ocasionado pela prédisposição da planta em reter o elemento, possibilitando concentrações destes elementos em taxas maiores no tecido vegetal do que no solo e/ou água.

De acordo com Zeitouni et al. (2007), os macronutrientes para espécies vegetais correspondem aos elementos $\mathrm{N}, \mathrm{P}, \mathrm{K}, \mathrm{Ca}, \mathrm{Mg}$ e $\mathrm{S}$. Os micronutrientes aos elementos $\mathrm{B}, \mathrm{Cl}, \mathrm{Cu}, \mathrm{Fe}, \mathrm{Mn}, \mathrm{Na}$, Mo e $\mathrm{Zn}$.

Faquim (2005) relata que os macronutrientes têm, em geral, seus teores expressos em percentagem e os micronutrientes em miligrama por grama $(\mathrm{mg} / \mathrm{g})$ ou parte por milhão (ppm), todos na forma elementar. A única distinção na classificação entre macro e micronutrientes é a concentração exigida pelas plantas. Os macronutrientes ocorrem em concentrações entre 10 a 5.000 vezes superior às dos micronutrientes. O mesmo autor afirma, ainda, que somente a análise química da planta não é suficiente para o estabelecimento da essencialidade de um elemento. As plantas absorvem do solo, sem muita discriminação, os elementos essenciais, os benéficos e os tóxicos, podendo estes últimos, levá-las à morte.

Faquim (2005) afirma que "todos os elementos essenciais devem estar presentes nos tecidos das plantas, mas nem todos os elementos presentes são essenciais". Malavolta (1980), refere-se a micronutrientes como "oligoelementos" ou "elementos traços", ainda que tais expressões não representem a realidade, pois, "oligo" significa "raro" e os micronutrientes são comuns a todas as plantas superiores. De fato, embora tais elementos ocorram em pequena proporção, o 
resultado pode ser quantificado - os teores estão acima do que se considera como traços. Da mesma forma, não são "menores" nas suas funções, o crescimento e a produção vegetal poderão ser limitados (diminuídos ou impedidos), tanto pela falta de um micronutriente (como o molibdênio), como pela carência de um macronutriente (como o nitrogênio).

A partir destas observações e características das plantas, encontramos na literatura estudos que utilizaram espécies vegetais como indicadores de mineralização em metais, desde o início do século passado, em trabalhos de prospecção de depósitos de vanádio, rádio e urânio realizados por Aleksandrov (1920) apud (Brooks, 1983 ${ }^{1}$ ).

Embora até o final da década de 1970 o principal foco da prospecção biogeoquímica concentrava-se na exploração de metais preciosos, a partir do início da década de 1980, áreas que envolvem o equacionamento de problemas ambientais, tais como contaminação de solo e aquíferos, demostraram crescente interesse na capacidade de algumas espécies de plantas hiperacumularem metais.

Biorremediação é o termo utilizado para designar o emprego de plantas, microorganismos e enzimas isoladas ou livres na mitigação de áreas contaminadas (Pletsch et al., 1999). Quando utilizamos especificamente sistemas vegetais para mitigar poluentes orgânicos e inorgânicos do meio, denominamos de fitorremediação. Segundo Pires et al. (2003) a fitorremediação possui vantagens quando objetiva a descontaminação de solo e água, por apresentar potencial de tratamento in situ e ser economicamente viável.

A absorção dos íons que estão no solo e na água pelas plantas ocorre, principalmente, pelo sistema radicular. Os metais pesados, frequentemente, sofrem acumulação nas camadas superiores do solo, tornando-se mais acessíveis à absorção pelas raízes das plantas (Henriques, 2005). Assim, a prospecção biogeoquímica pode prover informações geoquímicas sobre o substrato (solo) uma vez que a composição química das plantas tende a refletir a disponibilidade dos elementos ao redor do sistema radicular (Schützendübel et al., 2002; Lima \& Cunha, 2008).

\footnotetext{
${ }^{1}$ ALESKOVSKY, V.B., MOKHOV,A., SPIROV,V., 1959, Geokhimiya, No.3, 266.
} 
Os primeiros estudos sobre a hiperacumulação de metais por plantas foram descritos em 1814 por Desvaux, a partir dos estudos do botânico Andrea Cesalpino que reportou a presença do crescimento de Alyssum bertolonii sobre rochas ultramáficas na Toscana, Itália (Brooks, 1983).

Plantas hiperacumuladoras de metais pesados são usualmente endêmicas a um determinado substrato geológico, sendo sua presença indicativa de um litotipo específico ou mineralização presente (Brooks, 1983). Os procedimentos biogeoquímicos são descritos por Brooks (1983) a partir de trabalhos desenvolvidos por Tkalich, em 1938 na ex-União Soviética.

Brooks (2000) estabeleceu alguns princípios da hiperacumulação a partir de estudos fitoquímicos, mas somente a partir da publicação do trabalho de McGrath et al. (1993), descrevendo o potencial para utilização de plantas hiperacumuladoras de metal na descontaminação in situ de solos poluídos por metais pesados, foram definidos parâmetros para tal aplicação.

Os estudos têm se focado em identificar os complexos de metais pesados em plantas hiperacumuladoras, porém, deve-se atentar aos mecanismos pelos quais a acumulação e transporte ocorrem no sistema que envolve planta-solo-água. Essa característica da planta de absorver indiscriminadamente elementos tem sido explorada na recuperação de áreas degradadas, por se tratar de uma forma econômica de recuperação que envolve diferentes processos (Moreno et al., 2008), (Figura 1). 


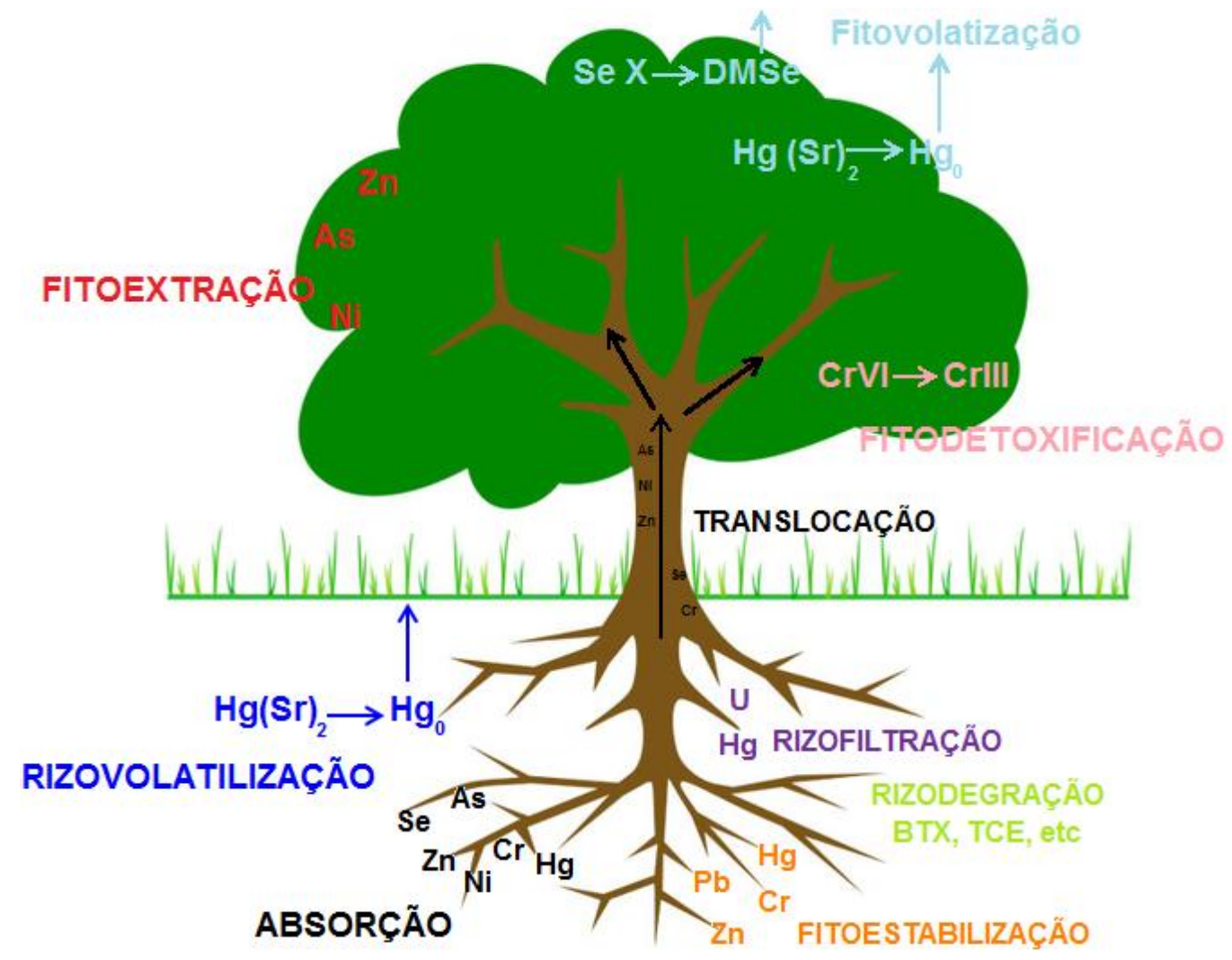

Figura 1 - Processos que envolvem a absorção de metais pelas plantas (modificada a partir de Moreno et al., 2007).

A fitoextração; como processo de bioacumulação pode ser limitada, se a área a ser mitigada apresentar baixa disponibilidade de elementos contaminantes no solo. Alguns autores (Davidson et al., 1994; Bertoncini et al., 1999; Aguiar et al., 2002; Carneiro et al., 2002) sugerem a utilização de agentes quelantes, que dissolvem o metal da matriz do solo para formar um complexo solúvel. Esse procedimento tem sido utilizado para aumentar a biodisponibilidade de metais pesados às plantas e facilitar o processo de fitoextração (Dos Anjos et al., 2001; Zeitouni et al., 2007; Andrade et al., 2009).

A remediação de ambientes contaminados por meio de sistemas e processos vegetais (fitorremediação) movimenta um mercado de 100 a 150 milhões de dólares nos EUA, o que corresponde a $0,5 \%$ do mercado total de remediação naquele país (Pilon-Smits, 2005).

Na última década, surgiram nos EUA e na Europa inúmeras empresas que exploram a fitorremediação como atividade lucrativa. Além disso, empresas têm aplicado a fitorremediação em suas próprias áreas industriais contaminadas, por 
meio do financiamento de pesquisas e colaborações com empresas menores e/ou grupos acadêmicos em projetos de pesquisa (Pletsch, 1999; Gonçalves et al., 2009; Lopes, 2010; Marques et al., 2011).

O Brasil apresenta grande potencial de uso, tanto para biorremediação como para fitorremediação, aplicadas na recuperação de áreas contaminadas, em face da grande biodiversidade vegetal e das características climáticas, que favorecem os processos biológicos no tratamento da poluição. Entretanto, a comercialização desta tecnologia é ainda incipiente, apesar da demanda por soluções mais econômicas e menos invasivas ao meio ambiente (Moreno et al., 2007; Marques et al., 2011).

Uma espécie de planta considerada como indicador biogeoquímico deve apresentar relação aproximadamente linear entre o teor do elemento na planta e a concentração do mesmo elemento no solo (Brooks, 1983). A utilização de espécies de plantas como bioindicadores tem apresentado crescente interesse, principalmente em áreas nas quais o uso e ocupação anteriores deixaram resíduos de contaminantes químicos no solo.

A contaminação diferencial e o rastreamento de metais pesados em solos e seus efeitos sobre as plantas dependem de diferentes fatores, tais como características do solo, condições de crescimento e espécies de plantas (KabataPendias \& Pendias, 2001). Plantas são consideradas como reservatórios intermediários, por meio dos quais o rastreamento de metais pesados no solo e parcialmente na água e no ar movem-se para o homem e os animais. No entanto, algumas espécies de plantas são seletivas na absorção de diversos metais do solo. Estas exercem controle sobre a aceitação ou rejeição de alguns elementos por reações fisiológicas adequadas (Coutinho et.al.; 2007; Ferraz, 2009).

Assim, o estabelecimento de coeficientes de absorção pode ser um parâmetro para avaliarmos o potencial de bioacumulação de uma espécie, bem como as interações que envolvem o sistema solo-água-planta.

Notadamente, não é o valor absoluto de um parâmetro que será importante para uma avaliação biogeoquímica, mas a variação e razão de mudança, assim como os fatores que promoveram tais mudanças.

O Coeficiente de Absorção Biológica - CAB (Biological Absorption Coefficient - BAC); o Coeficiente de Absorção Temporal - CAT (Temporal Absorption 
Coefficient - TAC) e o Coeficiente Acropetal - CA (Acropetal Coefficient - AC) são alguns parâmetros utilizados por Brooks (1983) para avaliar a absorção diferenciada de metais em diferentes espécies de plantas.

O Coeficiente de Absorção Biológica - CAB foi definido por Kovalevsky em 1969, como a relação entre a concentração de um elemento nas cinzas da planta (Cp) e a concentração do mesmo elemento no substrato (Cs) (solo) (Brooks, 1983).

O Coeficiente de Absorção Temporal - CAT foi também definido por Kovalevsky (1969) apud (Brooks, $2000^{2}$ ) e foi adaptado para exprimir a concentração de um elemento no órgão da planta $(\mathrm{Ct})$ em um tempo particular em relação à concentração de um mesmo elemento no mesmo órgão da planta num tempo correspondente a outro período (Cw) (estação seca e estação de chuvas, por exemplo).

O Coeficiente Acropetal - CA foi definido por Sabinin em 1955 (Brooks, 2000) e exprime a relação entre a concentração de um elemento de um órgão particular da planta (Co) e a concentração do mesmo elemento em um órgão referência da mesma espécie (Cx).

Assim, os parâmetros biogeoquímicos podem ser utilizados sazonalmente para avaliar as mudanças, e a partir de sua correlação com os dados geoquímicos do solo e água, obter uma análise integrada do ambiente.

Dentre as espécies vegetais em regiões tropicais, as palmeiras estão entre as espécies de plantas vasculares mais abundantes com grande dispersão mundial. São amplamente distribuídas em áreas bem drenadas e são raras em áreas muito secas ou frias (Begnini, 2008).

A palmeira do gênero Syagrus é endêmica da América do Sul, sendo constituída por 42 espécies e oito híbridos naturais. Ocorre desde o leste da Colômbia até a Guiana Francesa, sul do Uruguai e norte da Argentina. No Brasil é encontrada desde o sul da Bahia, Espírito Santo, Minas Gerais, Goiás, Mato Grosso do Sul até o Rio Grande do Sul, em áreas de Mata Atlântica, mata de pinhais, florestas de galeria e mata semidecídua da bacia do Paraná (Lorenzi et al., 2004;

\footnotetext{
${ }^{2}$ KOVALEVSKY, A.L., 1969, Trudy Buryat Inst. Yestvestvenn. Nauk, № 2, 195 pp .
} 
Begnini, 2008). Em ambiente com condições favoráveis, essa espécie pode atingir até 15 metros de altura, com diâmetro do caule de $35 \mathrm{~cm}$.

A Syagrus romanzoffiana (Chamisso) Glassman é da família Palmae, conhecida popularmente como jerivá, gerivá, coqueiro-gerivá, coqueiro, coco-decachorro, baba-de-boi, coco-de-catarro e coco-de-babão.

Apresenta reprodução sexuada, inflorescência em cacho pendente, ramificado, de até $150 \mathrm{~cm}$ de comprimento, com centenas de ráquilas. Os frutos do tipo drupa são globosos ou ovóides, de cor amarela ou alaranjada, com um fino exocarpo e um mesocarpo fibroso, suculento e adocicado, que envolve uma única semente (Begnini, 2008); e, por se tratar de espécie com longos períodos de frutificação, é uma importante fonte alimentar para os animais frugívoros (Giombini, 2009).

Apresenta, também, grande potencial ornamental, sendo utilizada em projetos paisagístico em jardins públicos e residenciais, como vegetação urbana em áreas marginais a rodovias, estradas e grandes avenidas. 


\subsection{OBJetivos}

Estabelecer parâmetros que possibilitassem uma avaliação integrada do sistema solo-água-planta e possível contaminação por metais pesados. A partir dos resultados, identificar possíveis aplicações em áreas contaminadas por metais pesados.

Averiguar se a palmeira Jerivá (Syagrus romanzoffiana), de larga distribuição geográfica, pode ser empregada como espécie mitigadora da contaminação do solo e da água subterrânea.

Aplicar os coeficientes biogeoquímicos utilizados na prospecção mineral, a fim de, testar sua exatidão ao distinguir aspectos que envolvem a contaminação do solo e da água subterrânea. 


\section{2. ÁreA de Estudo}

A área de estudo está inserida no centro de Lazer Engenheiro Goulart, no Parque Ecológico do Tietê (PET-EG), localizado no Município de São Paulo, entre as coordenadas $23^{\circ} 49^{\prime}$ de latitude Sul e $46^{\circ} 52^{\prime}$ de longitude Oeste. (Figura 2)

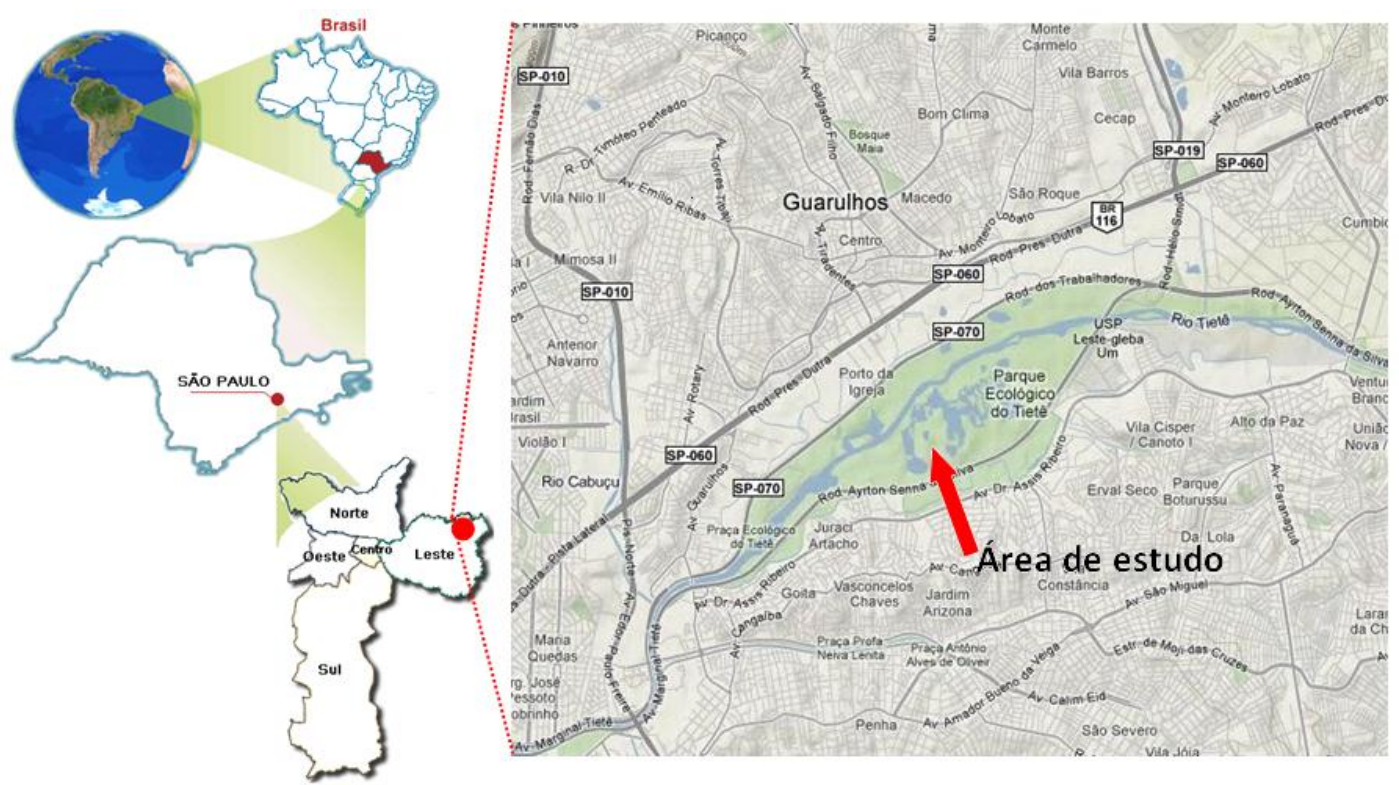

Figura 2 - Localização da área de estudo e áreas adjacentes (Google Earth, 2010).

O Parque Ecológico do Tietê tem acesso pela rodovia Ayrton Senna (anteriormente rodovia dos trabalhadores), no sentido para o Rio de Janeiro, próximo ao quilômetro 17; administrado pelo Governo do Estado de São Paulo através do Departamento de Águas e Energia Elétrica - DAEE, autarquia vinculada à Secretaria Estadual de Recursos Hídricos, Saneamento e Obras.

O projeto de criação do PET iniciou-se em meados de 1976 e tinha como finalidade preservar as planícies de inundação do rio Tietê, naturalmente ocupadas pelas águas durante as cheias do rio, e minimizar os impactos causados pelas enchentes na região metropolitana de São Paulo. Juntamente com as obras de barragens, retificação do canal e desassoreamento do Tietê, o projeto inicial previa $140 \mathrm{~km}$ lineares de área marginal ao rio, sendo que $67,5 \mathrm{~km}$ ficariam a leste (a montante), 18,5 km a oeste (a jusante) da área de estudo e $46 \mathrm{~km}$ destinados a 
avenidas marginais, construídas ao longo dos rios Pinheiros e Tietê, que cruzariam a cidade.

A área prevista para o PET se insere na Área de Proteção Ambiental (APA) da várzea do rio Tietê, que abrange desde os municípios de Salesópolis, Biritiba Mirim, Mogi das Cruzes, Suzano, Poá, Itaquaquecetuba, Guarulhos até o Município de São Paulo e, a partir deste, os municípios de Osasco, Barueri, Carapicuíba e Santana do Parnaíba. Entretanto, o projeto inicial de implantação sofreu modificações e cortes orçamentários que incluíram a devolução de terras já desapropriadas e consecutivamente a diminuição do projeto básico. A inauguração efetiva do PET somente se concretizou em 1982, em uma área total de 76.910.000 $\mathrm{m}^{2}$, com $11.870 .000 \mathrm{~m}^{2}$ destinados a paisagismo e $13.970 .000 \mathrm{~m}^{2}$ de superfície ocupada por áreas alagadas (lagos); o restante da área foi utilizado no sistema viário interno.

Anteriormente à implantação do PET a área era formada por pequenas propriedades rurais (Varnier, 2001). Teramussi (2008) relata que o parque foi construído numa área degradada, formada por grandes cavas originadas pela atividade de extração de areia, que posteriormente tornaram-se lagos. Há registros também de que a região tenha sido utilizada como lixão.

A área de estudo está apontada em vermelho na Figura 3, e esta distante 150 metros a leste do lago principal do PET e 30 metros a oeste do local onde se localizou, no passado, o depósito de lixo. 


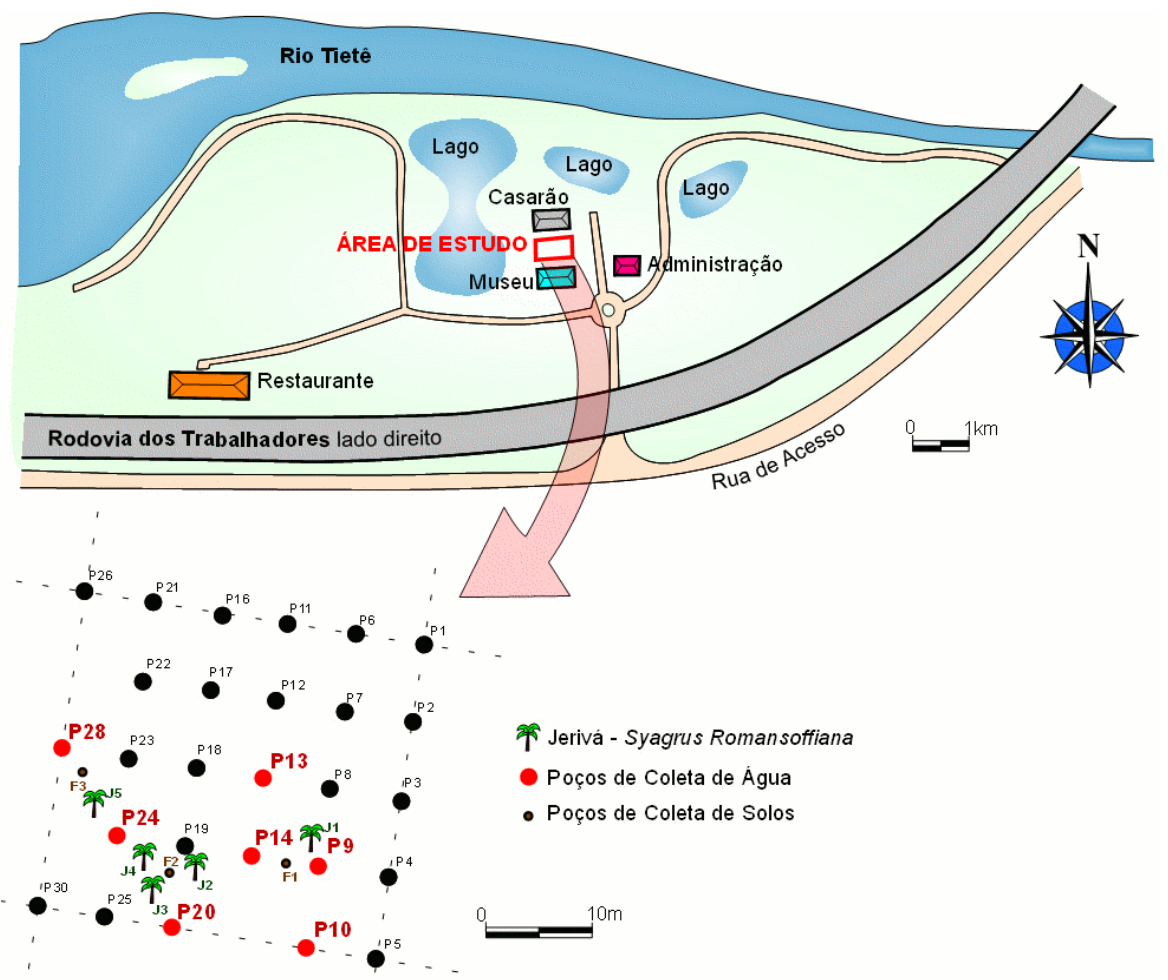

Figura 3 - Esquema do Parque Ecológico do Tietê-PET adaptado de Ross (1991). A Rodovia dos trabalhadores hoje é denominada Ayrton Senna. Destaque para área de estudo adaptado de Mondin (2005) com os poços selecionados, as espécies-tipo Palmeiras Jerivás e os locais de coleta de solo.

A ocupação na área do PET se resume basicamente a dois períodos distintos: Até meados da década de 70, grande parte da área apresentava-se como propriedades rurais onde predominava o cultivo de hortaliças, flores, eucalipto usado como lenha nas olarias da região, e criação de gado, utilizado para amassar o barro. Uma pequena parte da área era destinada a deposição de lixo de forma irregular, aterrado por material de demolição e material retirado das margens/calha do rio. $O$ segundo período, pós 1976, com o projeto de implantação do PET, o objetivo principal foi reintegrar o local com a fauna e a flora da região, auxiliando a recuperação do rio Tietê, tornar o local em uma área de lazer para a região leste da RMSP.

A vegetação natural do PET foi parcialmente suprimida. Atualmente, podem ser observados diferentes estágios sucessionais de flora, que se inserem nos remanescentes vegetais que resistiram ao uso e ocupação até meados da década de 70. Quando da implantação do PET, o levantamento florístico indicava a predominância de reflorestamento de Eucalyptus sp. O número de espécies que 
ocorriam nos remanescentes de matas era relativamente pequeno e sem grande valor econômico, salvo raras árvores de maior porte que foram preservadas no desmatamento parcial (Troppmair et al., 1976).

Para a recomposição vegetal da área, a escolha das espécies baseou-se na concepção inicial de utilizar a flora regional, mata tropical secundária e mata hidrófila, em toda a área do PET. Entretanto, elementos da flora exótica foram também utilizados (Troppmair et al., 1976).

\subsection{Aspectos Fisiográficos}

Segundo relatórios de implantação do PET, a área de estudo compreende uma unidade de relevo e de solos bastante específica dentro do universo fisiográfico do Planalto Paulistano, pois se trata de um fundo de vale totalmente preenchido por sedimentos aluviais e solos hidromórficos recentes, sob a forma clássica de uma calha aluvial meândrica, excepcionalmente contínua (Troppmair et al., 1976). Observando o modelo regional, que abrange a planície de inundação do Tietê, com largura variando entre 300 e $3.200 \mathrm{~m}$, verifica-se que a planície fluvial do rio Tietê mantem-se a mesma desde Biritiba-Mirim, município a leste da RMSP, até Barueri, município da região metropolitana de São Paulo (Figura 4).

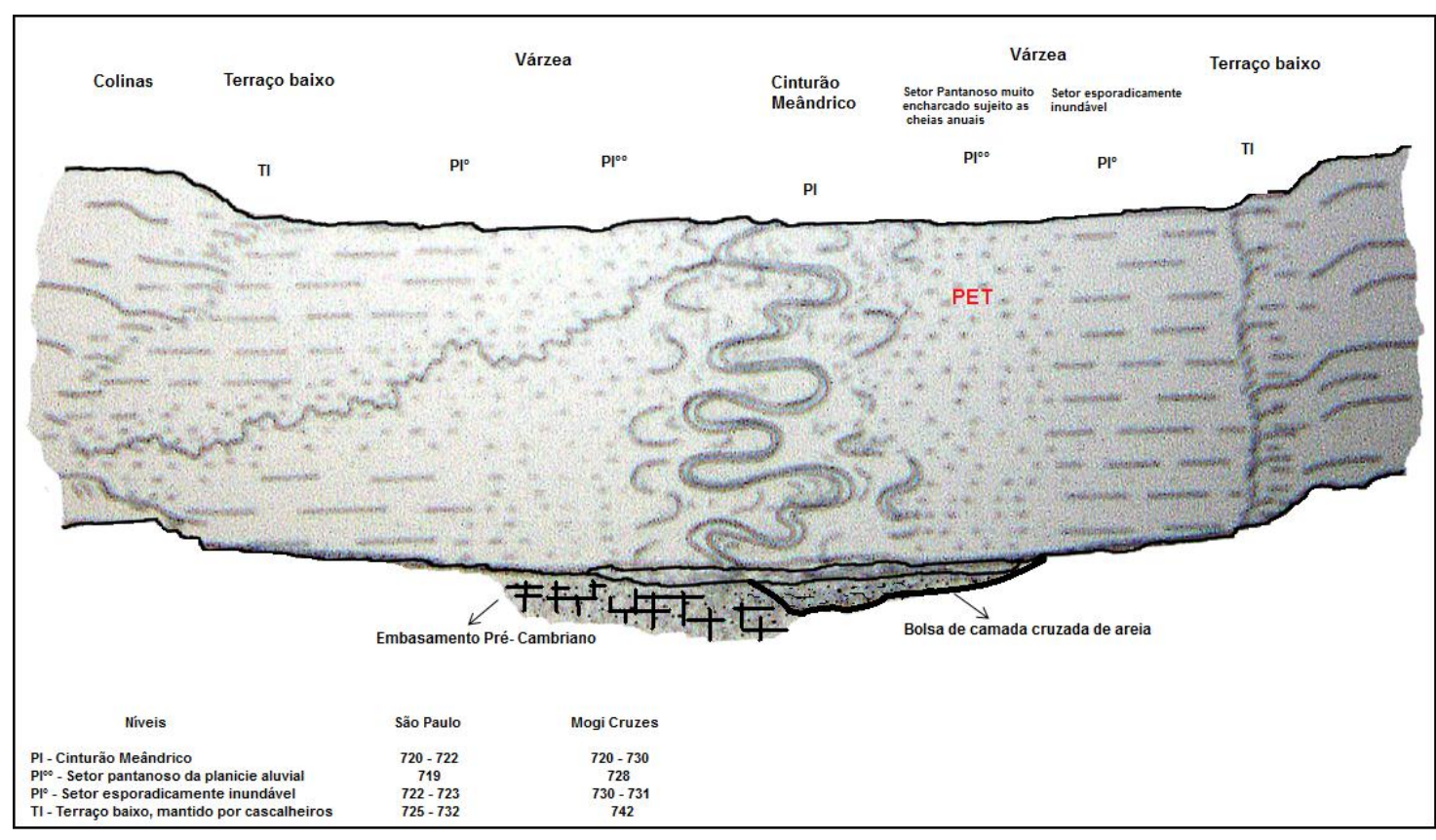

Figura 4 - Planície de inundação do Tietê e os componentes dos aspectos fisiográfico regionais (Troppmair et.al.; 1976). 
Os níveis topográficos na margem esquerda do rio Tietê e a ausência de degraus perceptíveis na margem direita marcam um perfil assimétrico para as vertentes do vale. Subtraída a tendência para escalonamento de níveis, que é um fato de presença mais local e válido, sobretudo, para o sítio da área central da cidade, em ambas as margens do rio existem elevações colinosas de até 90-123 metros, acima do nível de referência representado pelas várzeas, como a área do PET. Tal fato define o conjunto das planícies regionais como uma planície aluvial de compartimento do planalto, embutida em um sistema de colinas. O nível médio das colinas mais elevadas gira em torno de 800-820 metros, enquanto o nível das planícies aluviais, outrora submersíveis do vale do Tietê, em seu principal setor dentro da área metropolitana de São Paulo, é de aproximadamente 720-722 metros (Troppmair et al., 1976).

De acordo com Troppmair et al., (1976), no projeto de implantação do Parque Ecológico do Tietê foram realizados 18 furos de sondagem até a profundidade de 10 metros. A partir deste perfilhamento, observaram-se três camadas de solo: na primeira, um acamamento bastante homogêneo de solo aluvionar argilo-orgânico, eventualmente turfoso, com espessura média igual a 1,5 metros variando de pouco consistente a inconsistente.

A camada subjacente à primeira é constituída por areia com granulometria variável, e reduzido teor de silte e argila, de idade Quaternária. Esse horizonte apresenta-se pouco compacto.

Cerca de 6 metros a partir da superfície, encontram-se os solos resultantes de alteração gnáissica, nos quais predominam uma granulometria silte e areia, e fragmentos angulosos de quartzo e feldspatos (Figura 5).

O solo na área do PET está associado à planície aluvionar do rio Tietê. A carta de solos apresentada por Troppmair et al. (1976) define que os grandes grupos de solos da planície aluvial do rio Tietê são solos aluvionar, hidromorfos, hidromorfos de transição, latossolo vermelho/amarelo-fase rasa (Figura 6). 


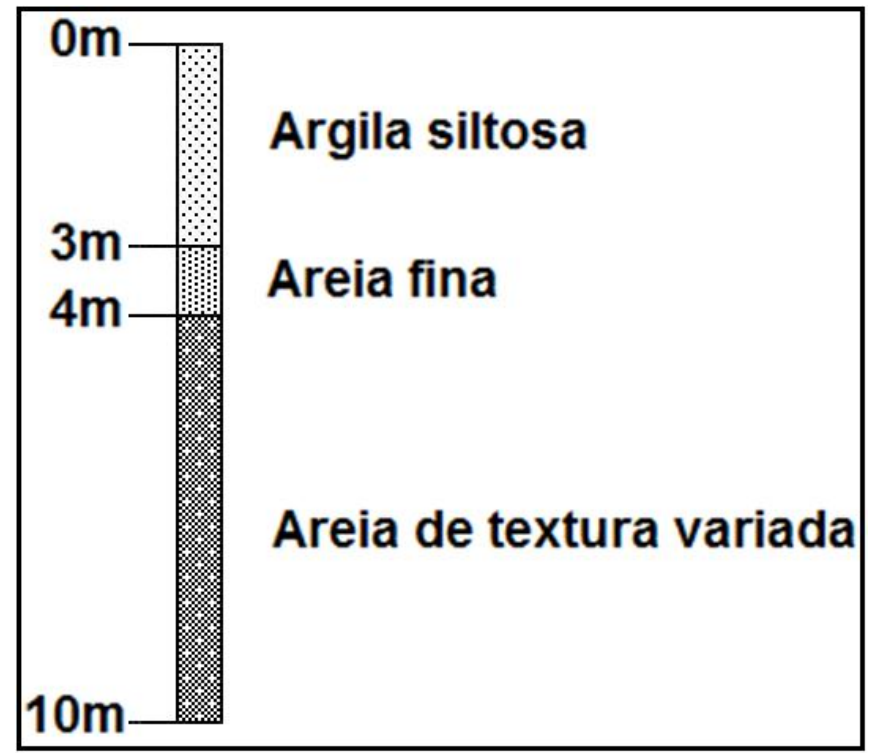

Figura 5 - Perfil de solo na área do PET (Troppmair et al., 1976).

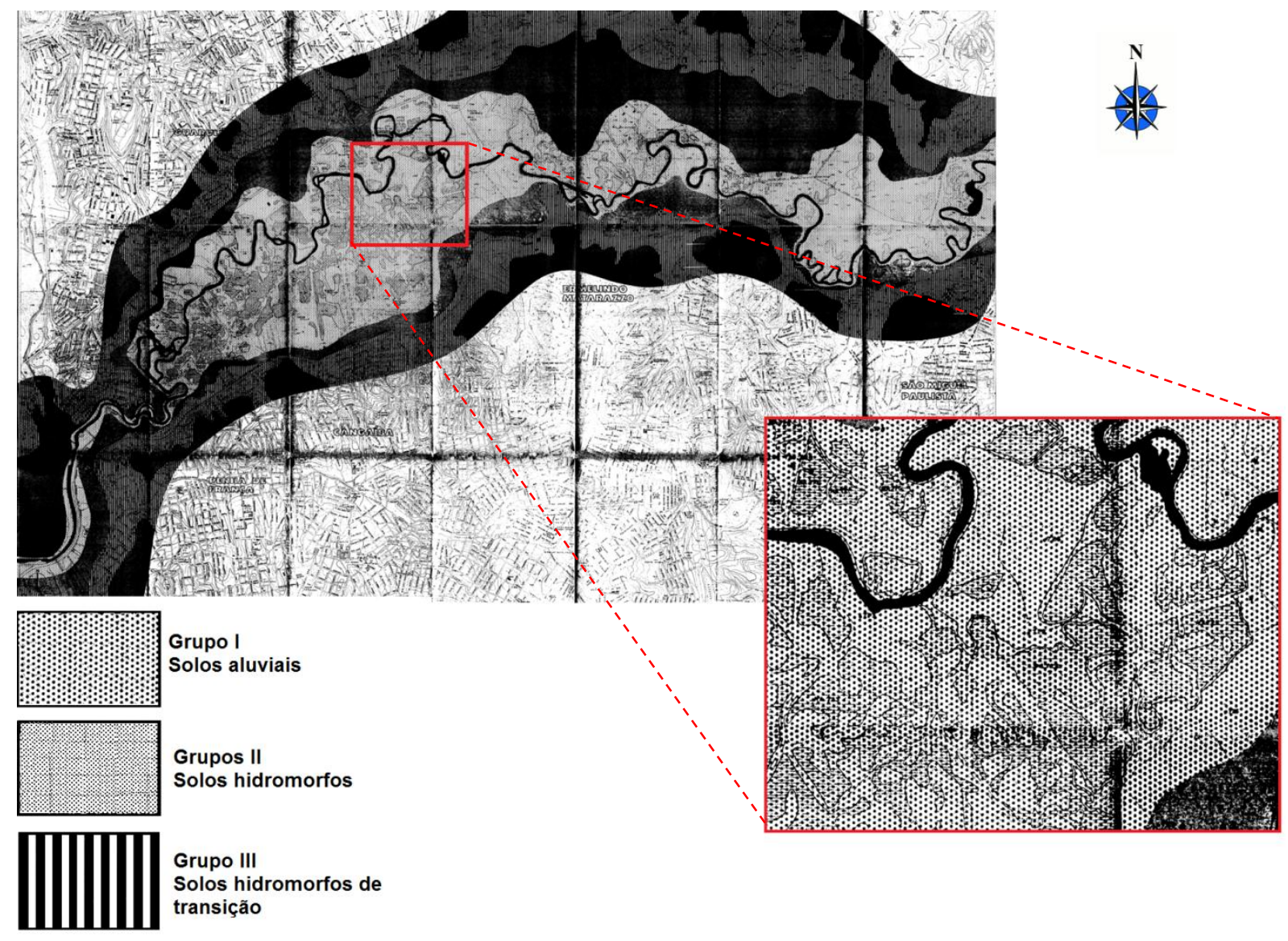

Figura 6 - Carta de solo da planície aluvial do rio Tietê trecho Parque Ecológico do Tietê (Troppmair et al., 1976). 
Mondim (2005) também descreveu os solos/sedimentos da área onde foram implantados os poços de coleta, que foram posteriormente utilizados neste trabalho. O autor observou que a primeira camada de solos/sedimentos, apresenta granulometria areno-argilosa mal selecionada, variável de tamanho argila até areia grossa, e grânulos contendo, por vezes, matéria orgânica. Essa camada tem espessura variável, em média de 0,5 metro. A segunda camada é formada por solos/sedimentos argilo-siltosos, com matéria orgânica. Na parte superior desta camada ocorrem sedimentos mal selecionados (argila à grânulos) gradando para um solos/sedimentos argiloso na base. Com relação aos perfis dos poços (PM 13, PM 14, PM 20, PM28) que são mais próximos dos indivíduos vegetais estudados, os primeiros 0,4 metro contêm solo arenoso argiloso de coloração clara seguido de um horizonte com solo argiloso siltoso com matéria orgânica de coloração preta. O poço PM9 tem nos seus primeiros 0,3 metro solo orgânico, arenoso com areia grossa e grânulos de cor marrom, seguido por um horizonte de solo argiloso de coloração preta, e o PM 24 apresenta em seus primeiros 0,5 metro solo arenoso siltoso de coloração clara, seguido de um horizonte de solo argiloso mal selecionado com matéria orgânica de coloração preta.

O clima na região, segundo a classificação de Strahler (1963), é subtropical úmido, que abrange o Brasil Meridional, porção localizada ao sul do Trópico de Capricórnio, com predominância da massa tropical atlântica, que provocando chuvas fortes. No inverno, é frequente a penetração de frentes polares, dando origem às chuvas frontais. $O$ índice médio anual de pluviosidade é elevado e as chuvas são bem distribuídas durante todo $o$ ano, fazendo com que não exista uma estação seca. $\mathrm{Na}$ classificação de Köppen (1948), a área de estudo é classificada como Cwa clima subtropical ou temperado com chuvas de verão e verões quentes.

Para o período de coleta deste estudo, levantamentos de dados pluviométricos e de temperatura referente, à região estão apresentados na Figura 7. 


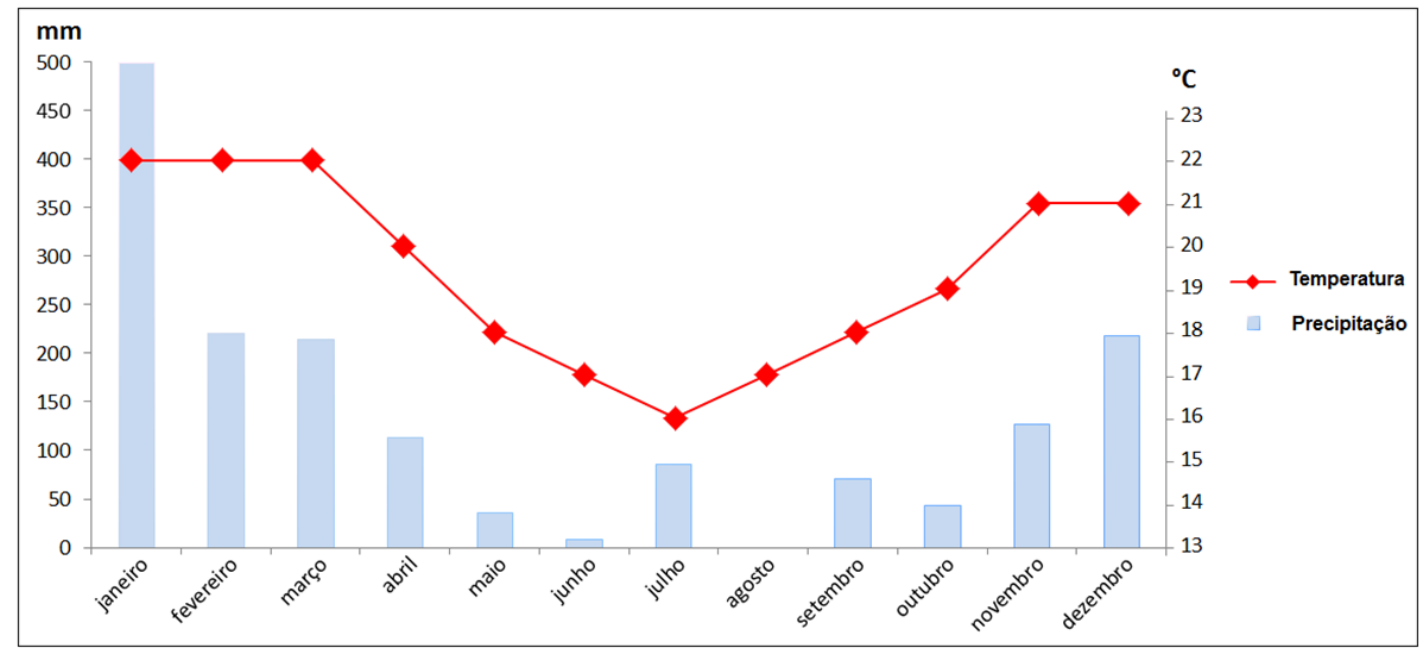

Figura 7 - Dados pluviométricos da subprefeitura da Penha e temperatura média da cidade de São Paulo no ano de 2010 (Prefeitura do munícipio de São Paulo, 2010).

Na Figura 8, é possível compararmos os remanescentes vegetais no ano de 1977 com os de 2007, observa-se o aumento do volume vegetal em 2007, devido ao reflorestamento com introdução de espécies variadas.

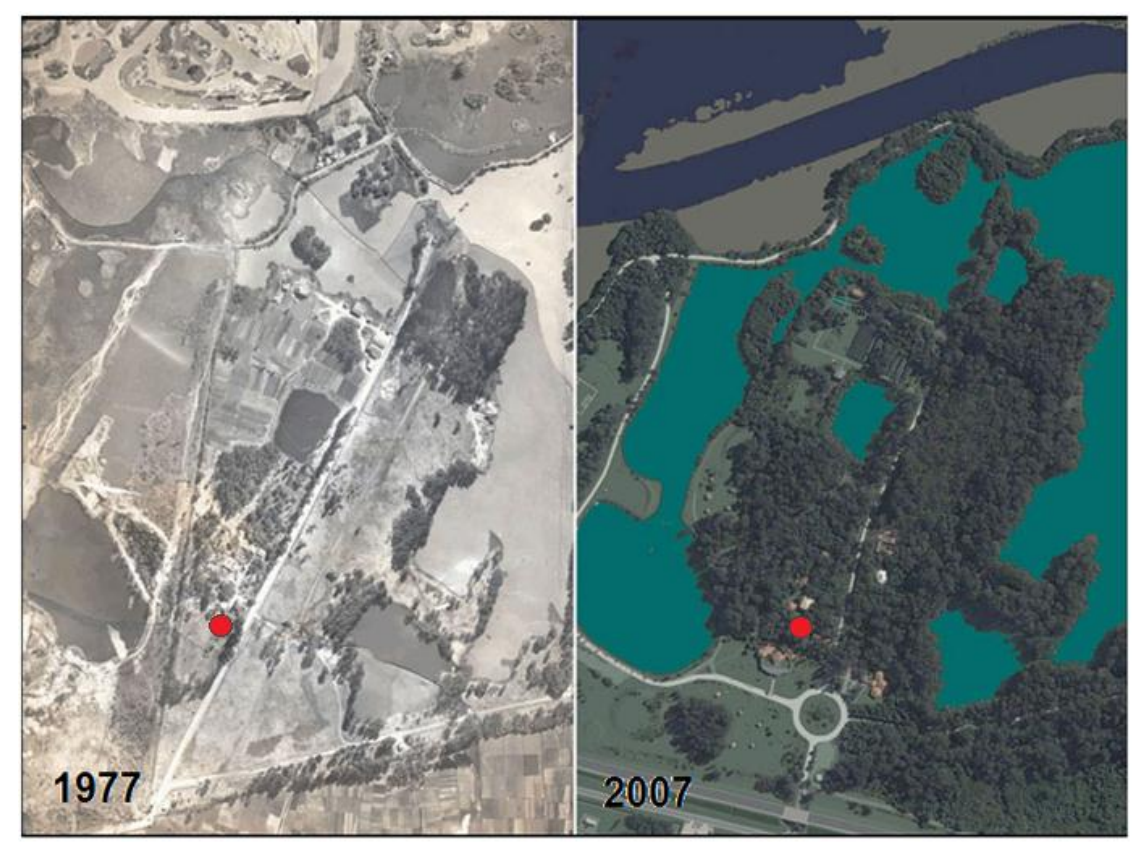

Figura 8 - Parque Ecológico do Tietê - vista aérea nos anos 1977 e 2007, A área em estudo esta apontada em vermelho. (Fonte: www.ecotiete.com.br). 


\subsection{Hidrogeologia Local}

A bacia hidrográfica do Alto Tietê está inserida em dois grandes sistemas aquíferos distintos: o Sistema Aquífero Cristalino, formado por rochas précambrianas fraturadas/alteradas, e o Sistema Aquífero Sedimentar, formado pelos sedimentos das formações presentes na bacia (Ferrari, 2006).

Segundo Varnier (2001), os aquíferos livres e rasos como é o caso do aquífero do PET, ocorrem, com frequência, em planícies aluvionares e apresentam, em geral, zona não saturada de alguns metros e níveis estáticos próximos à superfície. Estes aquíferos apresentam grandes oscilações do nível d'água condicionada aos fenômenos da recarga.

Mondim (2005) conclui que o aquífero da área de estudo é um aquífero livre/raso e que apresenta rápidas respostas frente aos eventos de precipitação, tornando-se bastante dinâmico quanto aos eventos de recarga. Varnier \& Hirata (2000) observaram o mesmo comportamento, indicando nível freático variando de 2,70 m (estação seca) a 1,30 m (estação úmida) da superfície do terreno, heterogêneo quanto à condutividade hidráulica, que varia de $1 \times 10^{-7}$ a $7 \times 10^{-5} \mathrm{~m} / \mathrm{s}$ na profundidade de 3 metros.

O comportamento do aquífero é diferenciado dentro de cada uma das estações observadas (úmida e seca). Durante o período chuvoso, há correlação entre as cargas hidráulicas e as precipitações, formando o fluxo descendente. No período de seca, predomina o fluxo ascendente entre as profundidades de 3 e 6 metros, e não há correlação de cargas hidráulicas frente às precipitações (Mondim 2005).

Ross (1991) pesquisou quatro áreas ao longo dos rios Tietê e Pinheiros na Região Metropolitana de São Paulo (RMSP) e demonstrou que os aquíferos livres não recebem, durante o período de estiagem, água contaminada por infiltração proveniente destes dois rios. Durante o período de chuva, no entanto, quando os níveis dos rios estão elevados, os gradientes hidráulicos tendem a reverter temporariamente o sentido e o aquífero livre recebe recarga do rio por um pequeno período de tempo, mas insignificante para comprometer a qualidade das águas subterrâneas. 
Um elemento interessante, apresentado por Troppmair et al., (1976), é a importância da implantação da vegetação para a proteção mecânica das encostas, e a purificação das águas.

Cabe ressaltar que a espécie escolhida para ser investigada neste estudo não fazia parte da lista de espécies selecionadas para a recomposição da flora no PET. Encontramos citações e listas de espécies vegetais, e dentre as espécies escolhidas, são mencionadas Syagrus coronata, Syagrus oleracea e Syagrus flexuosus, o que não nos permite inferir se a Syagrus romanzoffiana foi introduzida por ação antrópica, ou estava no banco de espécies. 


\section{MATERIAIS E MÉTODOS}

Para o desenvolvimento deste trabalho foram coletadas amostras de água subterrânea em poços de monitoramento preexistentes na área de estudo construídos na pesquisa realizada por Mondim (2005) (Figura 9)

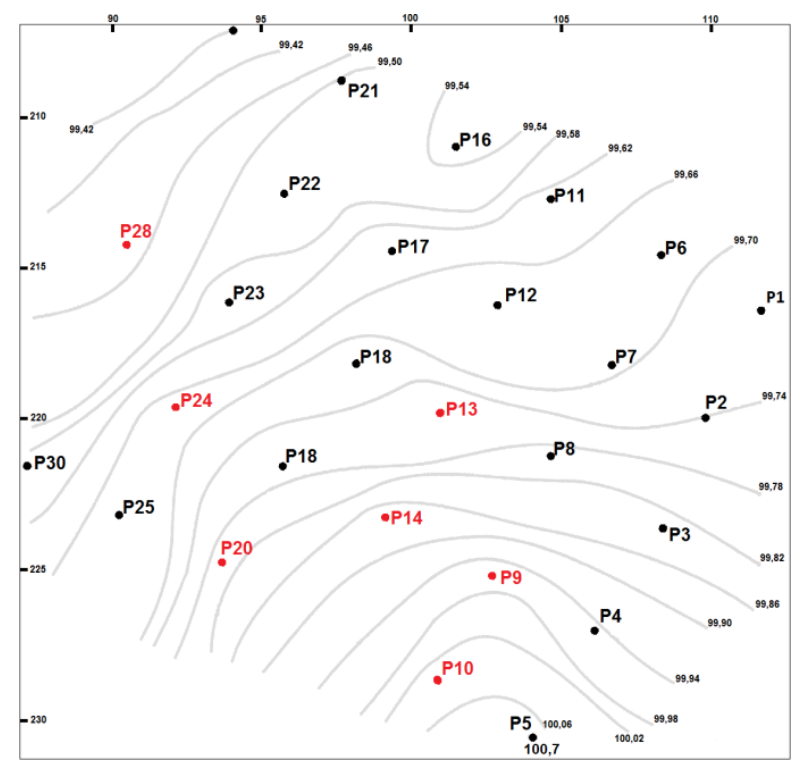

Figura 9 - Mapa topográfico dos poços de água subterrânea (Mondim, 2005). Destacados em vermelho os poços onde foram coletadas as amostras utilizadas no presente estudo

A partir destes poços, identificamos as espécies vegetais arbóreas, adultas, dentre as quais foi selecionada como espécie-tipo para avaliação biogeoquímica a palmeira Jerivá (Syagrus romanzoffiana) essa espécie foi selecionada por ter maior incidência na área de pesquisa (Figura 10).

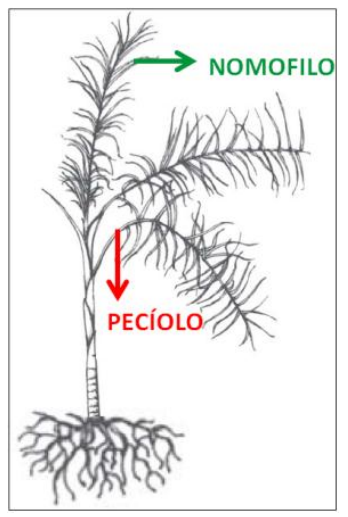

Figura 10 - Esquemática da palmeira Jerivá - Syagrus romanzoffiana, destaque para os órgãos utilizados neste trabalho (adaptado de Bernacci et al., 2007). 
Foram selecionados sete poços buscando-se localizar pontos de amostragem a jusante e a montante dos cinco indivíduos vegetais selecionados, e três pontos de coleta de solo de forma que possibilitasse a representatividade da área (Figura 11).

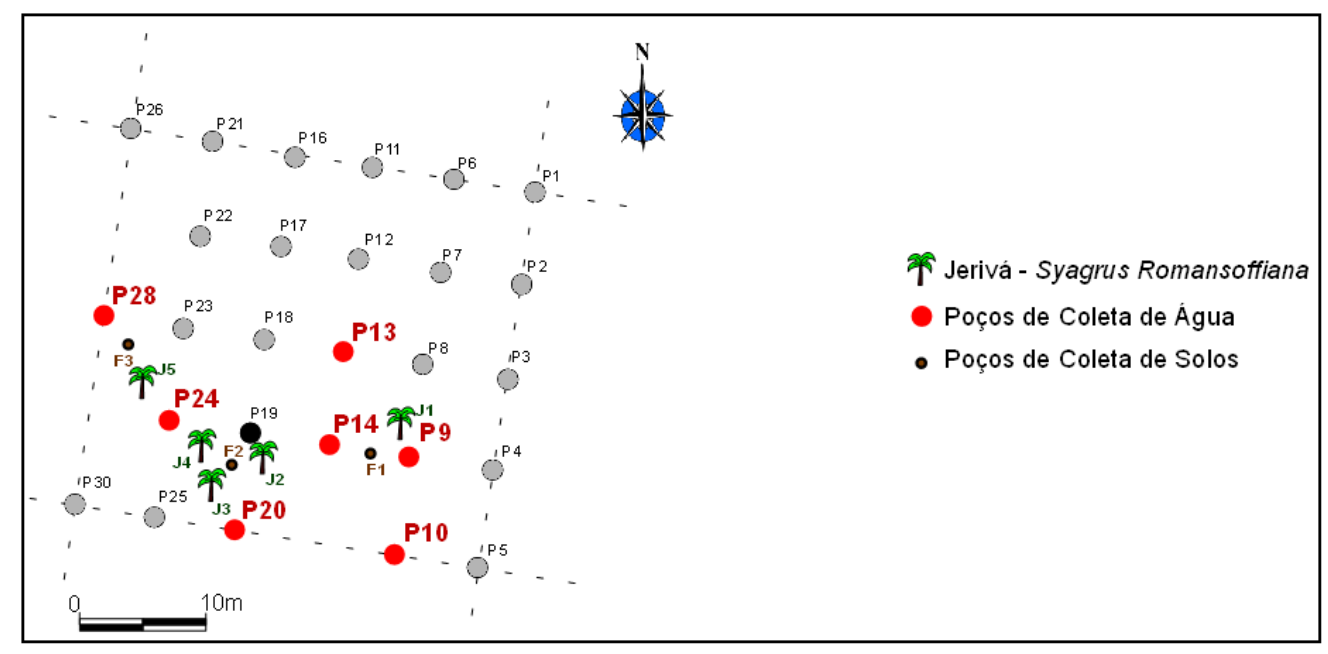

Figura 11 - Esquema da localização das palmeiras Jerivá, dos poços de monitoramento e dos pontos de coleta de solo no PET.

A amostragem do solo foi feita respeitando um limite mínimo de 1,5 metros de distância das espécies-tipo. Tal procedimento foi adotado devido às características morfo-estruturais da Syagrus romanzoffiana, que apresenta raízes pouco profundas, porém extensas. Dessa forma, estabelecemos a profundidade de $60 \mathrm{~cm}$ para coleta do solo.

Para a coleta das amostras, foram definidas duas etapas de campo: uma no mês de junho/2010, na estação seca, e outra em outubro/2010, na estação úmida. Para definirmos os dados de pluviosidade na área, utilizamos as medições realizadas pelo CGE (Centro de Gerência de Emergência) na subprefeitura da Penha, que indicaram um volume acumulado de precipitação para junho/2010 de $8,1 \mathrm{~mm}$ e outubro/2010 de $43,4 \mathrm{~mm}$.

Como padrão de referências, para as espécies-tipo, foram coletadas amostras no Parque Estadual da llha do Cardoso - PEIC, floresta Núcleo Perequê, ecossistema de Mata Atlântica ambiente isento de contaminação de qualquer tipo. 


\subsection{Coleta e preparação das amostras de água subterrânea.}

As características construtivas dos poços implantados são $300 \mathrm{~cm}$ de profundidade, $2,54 \mathrm{~cm}$ de diâmetro e uma coluna d'água média de $100 \mathrm{~cm}$. Tais características indicaram um volume médio de $500 \mathrm{~mL}$. A amostragem de baixa vazão foi o método de amostragem utilizado.

Os poços da área estudada são multi-níveis, com profundidade de 3; 6 e 10 metros. Neste estudo foram selecionados apenas os poços de 3 metros.

A coleta da água subterrânea seguiu o procedimento indicado por Soriano (2005), que investigou os métodos da amostragem, e indicou a baixa vazão como uma metodologia gratificante para áreas que não requerem a remoção de grandes volumes de água, evitando neste caso as consequências indesejadas da purga tradicional.

As amostras de água subterrânea foram coletadas em conformidade com a norma NBR 15495-1 (ANBT, 2007).

A água estagnada foi removida com auxílio de bomba peristáltica Geopump Série II acoplada a célula de fluxo multi-portas e com eletrodo de membrana de vidro conectado ao analisador de campo Digimed Modelo DM-2, que determina potencial hidrogeniônico $(\mathrm{pH})$, potencial de redução/oxidação (Eh), condutividade elétrica (CE) e temperatura $(\mathrm{T})$. Somente após a estabilização desses parâmetros, as amostras foram coletadas.

Para a filtragem in situ, utilizamos bomba de vácuo manual e membrana de 45 micrometros e o volume coletado de $500 \mathrm{~mL}$ foi dividido em dois frascos. Para um dos frascos, a amostra foi acidulada com $72 \mathrm{mg}$ nítrico $\left(\mathrm{HNO}_{3}\right)$ e encaminhada para análise química por ICP OES Espectrometria de Emissão Óptica com Plasma Indutivamente Acoplado, modelo 3410 da ARL no Laboratório de Química do Departamento de Mineralogia e Geotectônica do Instituto de Geociências - USP. Os limites de detecção deste aparelho são: $\mathrm{Ba}>10, \mathrm{Co}>15, \mathrm{Cr}>15, \mathrm{Cu}>15, \mathrm{La}>15, \mathrm{Ni}$ $>15, \mathrm{Sc}>10, \mathrm{Sr}>5, \mathrm{~V}>15, \mathrm{Y}>10, \mathrm{Zn}>10$ e $\mathrm{Zr}>25 \mathrm{ppm}$. O segundo frasco foi acondicionado em recipiente com gelo e, no Laboratório, foi congelado em freezer até uma hora antes da análise dos ânions por cromatografia iônica em equipamento da Metrohm, modelo 761.0020 com os limites de detecção $\mathrm{Br}^{-}=0,15 \mathrm{ppm} ; \mathrm{NO}_{3}{ }^{-}=$ $0,10 \mathrm{ppm} ; \mathrm{NO}_{2}{ }^{-}=0,02 \mathrm{ppm} ; \mathrm{SO}_{4}{ }^{2-}=0,15 \mathrm{ppm} ; \mathrm{F}^{-}=0,02 \mathrm{ppm} ; \mathrm{Cl}^{-}=0,02 \mathrm{ppm}$ e $\mathrm{PO}_{4}{ }^{3-}$ 
= 0,15 ppm, no Laboratório de Hidrogeologia e Hidrogeoquímica do Instituto de Geociências - UNESP Rio Claro.

\subsection{Coleta e preparação das amostras do solo}

$\mathrm{Na}$ coleta do solo, procedemos de forma similar a Andrade (2009), que utilizou plantas em uma área desativada, após 50 anos de atividade em mineração de chumbo e, da mesma forma, as amostras de solo para este estudo foram coletadas numa profundidade entre 10 e $60 \mathrm{~cm}$. O solo foi amostrado para obter conhecimento das características físicas e químicas desse compartimento. Assim uma vez caracterizado na primeira campanha, não se verificou a necessidade de uma segunda coleta.

O solo foi amostrado como amostra deformada em três pontos na área de estudo e um ponto amostrado na área de referência associada à espécie-tipo coletada no PEIC. Os pontos amostrados foram selecionados esquematicamente correlacionando as espécies - tipo. Após a retirada de $10 \mathrm{~cm}$ de serrapilheira, com auxilio de um trado holandês que pode coletar até $20 \mathrm{~cm}$ de material por vez (Figura 12). Os furos foram aprofundados ate $60 \mathrm{~cm}$, sendo separados em dois horizontes (A e B). Esse procedimento foi adotado ao identificarmos em poucos centímetros de profundidade uma descontinuidade entre as espessuras dos horizontes e, curiosamente, o material húmico não estar presente no horizonte superior, integrando a serrapilheira, e sim no horizonte B (Figura 13) como Mondim (2005) também identificou. O furo F3 apresentou resíduos plásticos a $45 \mathrm{~cm}$ (Figura 14), impedindo o avanço com o trado, e devido às condições regentes, para a escolha dos pontos de coleta, não foi possível fazer outro furo. 


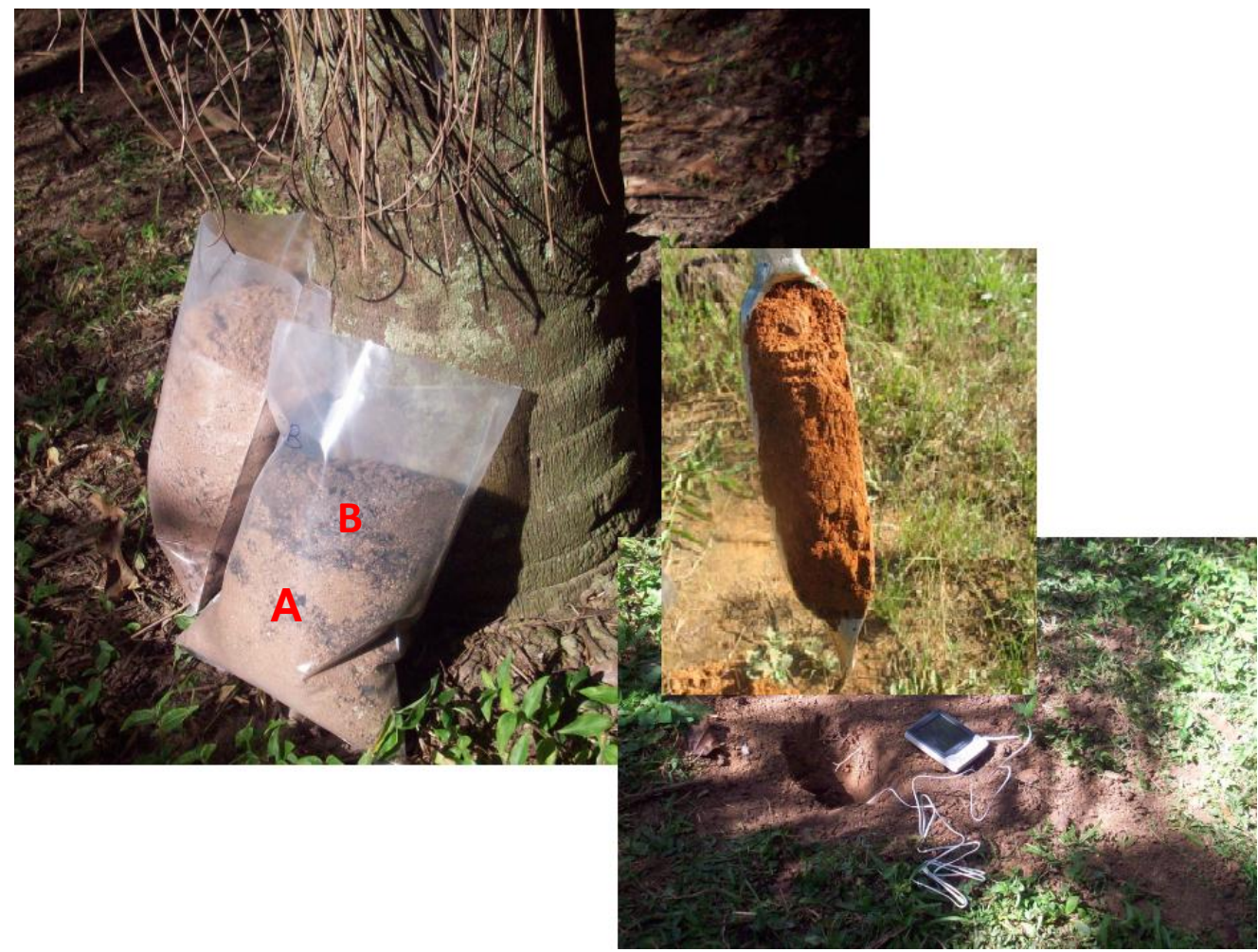

Figura 12 - Foto do procedimento de coleta do solo no PET, destacando os horizontes A e B.

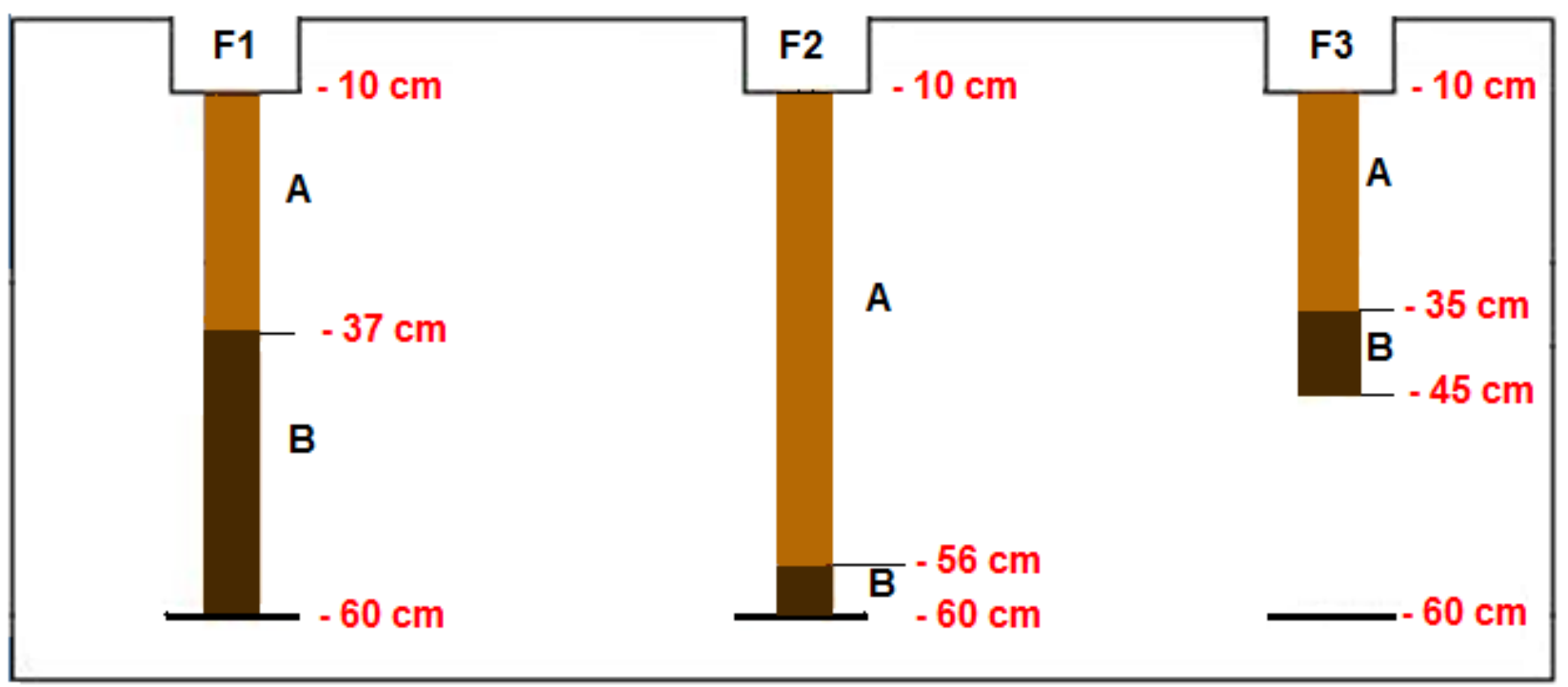

Figura 13 - Perfil do solo, identificando os horizonte A e B e seus respectivos limites. 

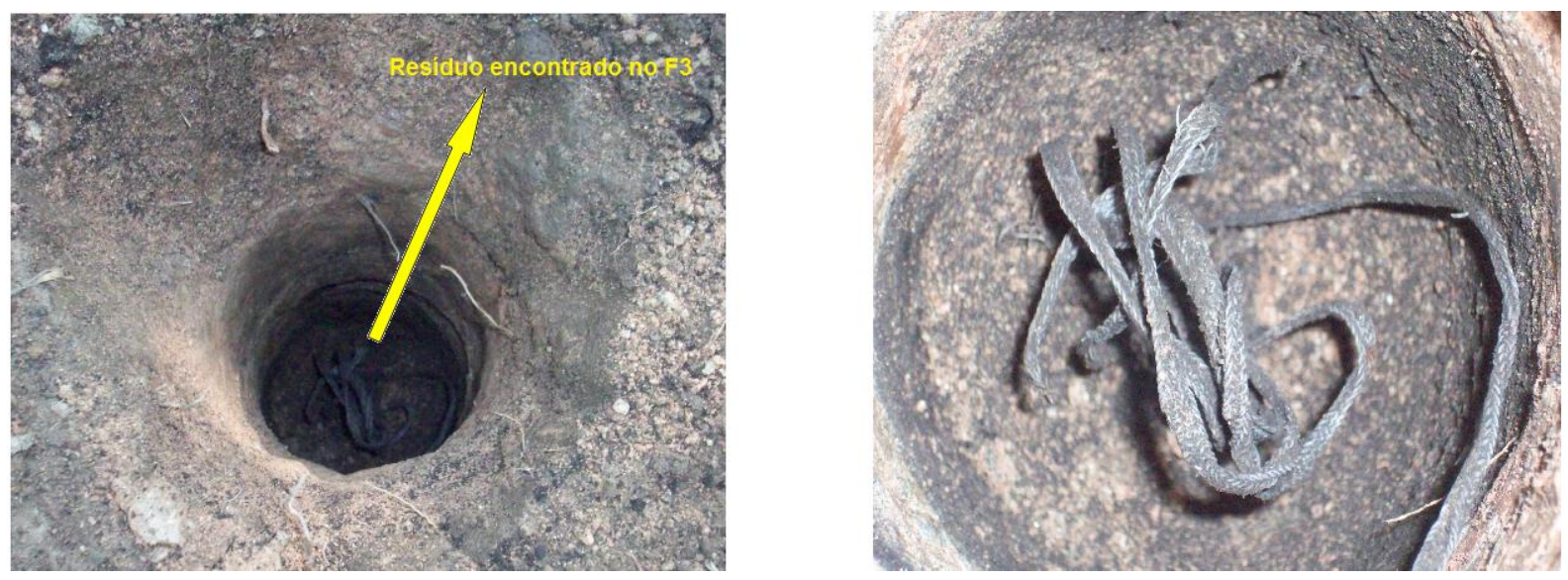

Figura 14 - Foto do furo $3(F 3$,$) indicando resíduo plástico encontrado a 45 \mathrm{~cm}$.

O solo coletado foi disposto à secagem por 48 horas em tabuleiro de madeira, em temperatura ambiente, forrado e coberto com papel toalha proporcionando a isenção de corrente de ar e poeira. Da amostra, bruta foram feitas observações em lupa para análise dos grãos minerais e micro-nodulações (Figura 15).

Após secagem das amostras, realizou-se uma catação dos resíduos de origem antrópica. Em seguida, as amostras foram destorroadas e peneiradas, separando-se a fração menor que $2 \mathrm{~mm}$ adotada para este estudo. As etapas dos ensaios realizados no solo estão esquematizadas no fluxograma (Figura 16).

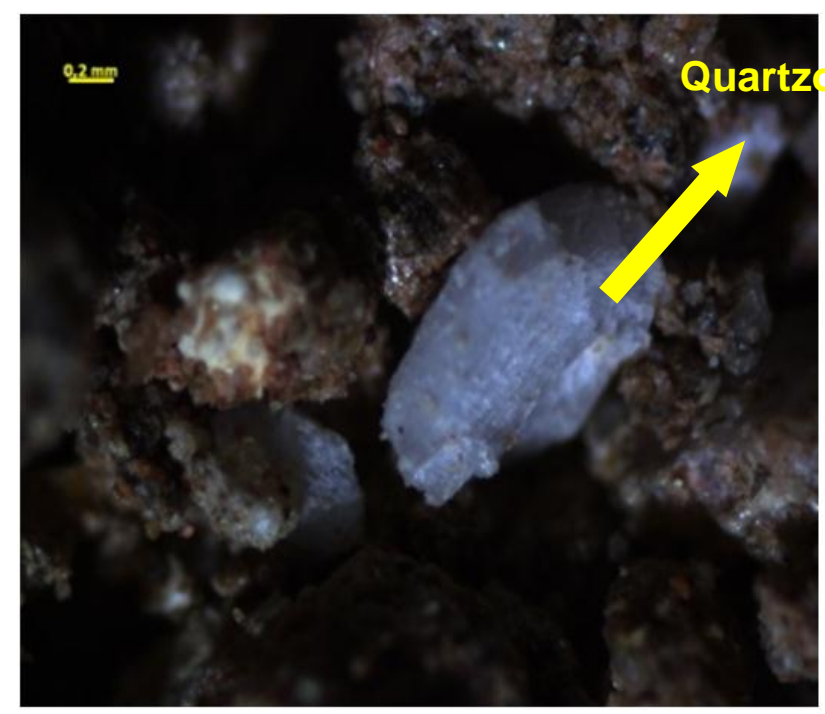

Figura 15 - Fotomicrografia da amostra de solo do PEIC com destaque para grão de Quartzo. 


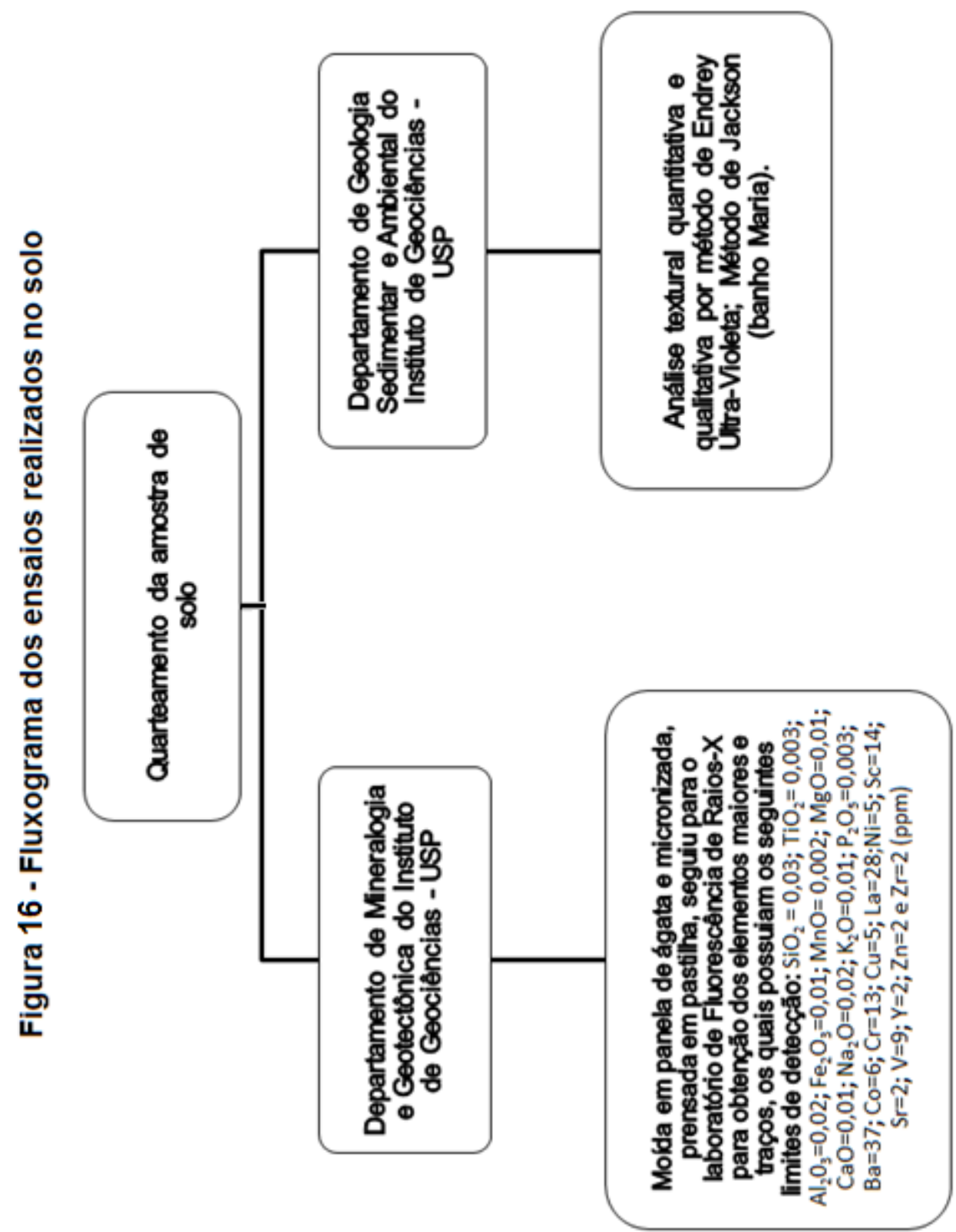




\subsection{Coleta e preparação das amostras da espécie-tipo (Palmeira Jerivá)}

Os indivíduos da espécie-tipo escolhida encontrados na área de estudo podem ser classificados, em termos de estágio ontogenético, como virgens a reprodutores (Bernacci et al., 2008), com estipe aéreo e raízes caulígenas, alguns com presença de estruturas reprodutivas.

A amostragem das espécies-tipo foi realizada com o corte de uma folha adulta (nomofilos + pecíolo) (Figura 17), de cada indivíduo, num total de cinco amostras, denominadas $\mathrm{J} 1, \mathrm{~J} 2, \mathrm{~J} 3, \mathrm{~J} 4$ e J5. Com auxílio de um podão, as folhas foram cortadas na bainha, rente ao estipe. A metodologia utilizada após a coleta das espécies-tipo é uma adaptação daquela sugerida por Lima \& Cunha (2007), que sugere que as amostras das plantas devem ser lavadas com água corrente, sendo a última lavagem feita com água destilada em abundância. Depois as amostras deveriam ser secadas em estufa a uma temperatura de $80-100^{\circ} \mathrm{C}$ por aproximadamente 6 horas, e calcinar em forno mufla até obter cinzas de coloração cinza clara.

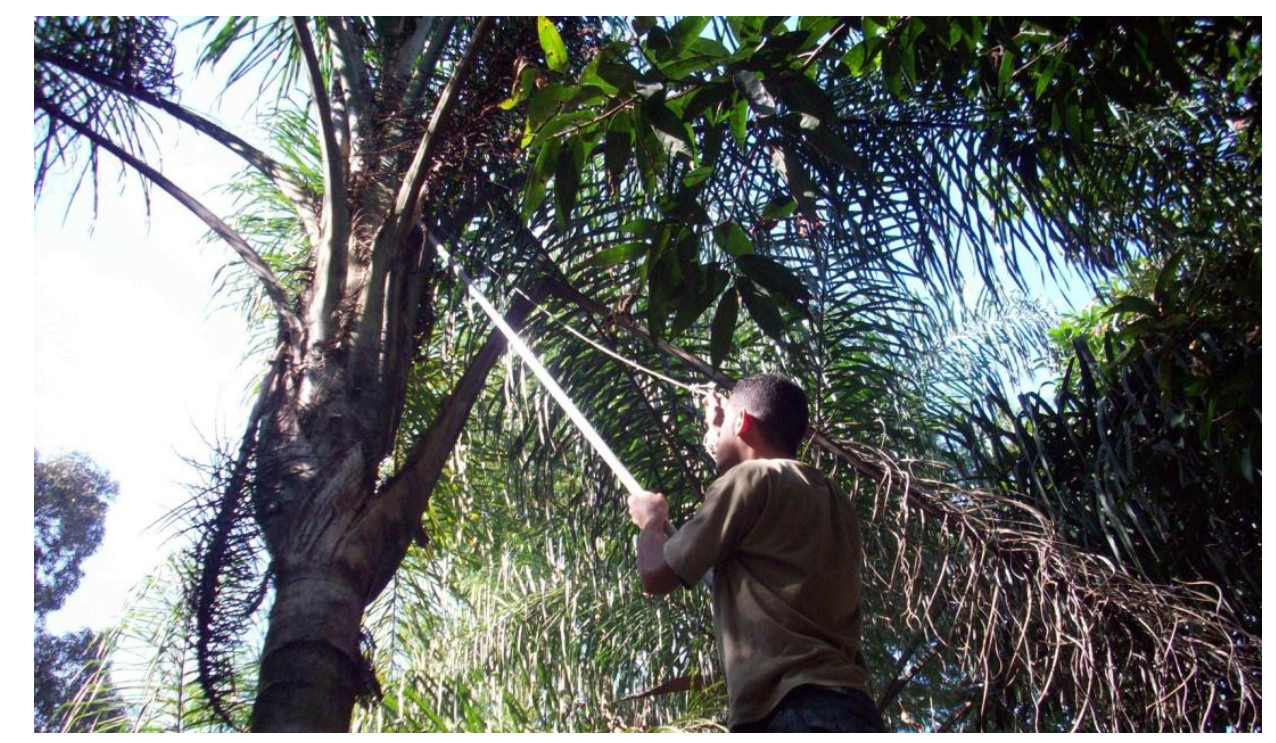

Figura 17 - Foto do procedimento de coleta do nomofilo e do pecíolo, com a poda sendo feita na bainha, rente ao estipe.

A amostra J1 não foi lavada, como as demais, com o objetivo de averiguar a influência dos resíduos de deposição atmosférica.

As folhas foram colocadas para secagem em estufa a temperatura de $80^{\circ} \mathrm{C}$ por 72 horas; após secagem, os nomofilos apresentavam-se apenas desidratados. 
Foram separados pecíolos dos nomofilos, em seguida fragmentados manualmente (mãos isentas de anéis, relógio, pulseiras e protegidas com luvas látex). O pecíolo, mais resistente, não possibilitou a fragmentação com as mãos. Foi necessário recorrer ao auxílio de uma faca de aço inoxidável. Assim, devidamente separados os órgãos constituintes da folha, cada amostra de palmeira-jerivá produziu dois conjuntos para análise: $P J_{n}=$ pecíolo indivíduo $n ; J_{n}=$ nomofilo do indivíduo $n$.

Sabendo de um provável risco de incêndio na mufla e um grande volume inicial de amostra, por não serem de extrema importância a este estudo os elementos mais voláteis, optou-se por processo de carbonização das amostras, em cadinho de porcelana, em uma temperatura branda no bico de Bunsen.

Após a calcinação, as amostras foram levadas ao forno mufla à temperatura de $700^{\circ} \mathrm{C}$ por 15 minutos e após a $1000^{\circ} \mathrm{C}$, até a estabilização da temperatura, por aproximadamente 45 minutos. As cinzas obtidas nesta operação foram moídas em almofariz de ágata e homogeneizadas para análise. Não houve necessidade de quarteamento dessas amostras, pois todo o material obtido foi utilizado.

Para uma análise comparativa quanto à absorção de metais pelas Palmeiras Jerivá encontradas na área de estudo, coletou-se uma folha adulta, da mesma espécie-tipo no mesmo estádio ontogenético, em um ambiente considerado isento de metais ou outros contaminantes produzidos por ação antrópica. Assim, foi realizada coleta da espécie tipo padrão, individuo J6 na área de floresta do Parque Estadual da llha do Cardoso - PEIC; o mesmo procedimento de tratamento das amostras coletadas no PET foi adotado para a espécie-tipo padrão.

Para a segunda etapa de campo, a partir dos resultados analíticos obtidos com a primeira amostragem das espécies-tipo, foram realizadas algumas alterações de amostragem: somente nomofilos jovens (observado o tamanho das folhas, grossura dos pecíolos) foram coletados. Consideramos neste procedimento identificar se o tempo de exposição apresenta correlação com o teor de metais assimilados.

Cabe ressaltar que quando das primeiras coletas de palmeira Jerivá realizadas no PET, os indivíduos coletados começaram a apresentar início de putrefação menos de 24 horas após a coleta; enquanto o indivíduo-padrão amostrado em ambiente isento de ação antrópica, na Mata Atlântica, após 48 horas em secagem ao ambiente, ainda não apresentava qualquer sinal de degradação, 
somente apresentando as folhas murchas. Outra característica diferencial entre as espécies-tipo coletadas no PET e ambiente padrão foi que os pecíolos da amostra em ambiente isento de ação antrópica e poluição os pecíolo apresentaram menor resistência ao corte, sendo possível a realização desse procedimento manualmente.

\subsection{Tratamento estatístico dos dados}

Os procedimentos adotados para o tratamento estatístico dos dados obtidos pelas análises geoquímicas foram baseados, em parte, naqueles sugeridos por (Imbernon 1993) Primeiramente, os dados foram analisados de maneira exploratória, com a utilização de planilhas Excel, buscando reconhecer tendências entre os materiais coletados.

Os dados foram recalculados a partir da exclusão do valor da perda ao fogo (PF). Esse procedimento parte da premissa que as interpretações consideraram o material biológico (folhas e pecíolos) seco e calcinado (cinzas). Portanto, não poderiam ser considerados os elementos voláteis perdidos no procedimento de queima.

Algumas variáveis apresentaram resultados abaixo do limite de detecção da técnica empregada (LD). Para solução do problema, os valores foram substituídos pela metade do LD, conforme sugere Larizzatti (2002).

Os sumários estatísticos foram calculados por grupo de amostras (média, mediana, desvio padrão, valores máximo e mínimo) e diagramas de distribuição (box-whisker plots).

Foram utilizados métodos multivariados para os conjuntos de amostras. Tais métodos operam sobre todas as variáveis avaliadas ou mensuradas de um levantamento amostral. Permitem reduzir um conjunto de 10, 20, 30 ou mais variáveis a 3, 4, 5 (ou mais) dimensões ou fatores, sem perder a capacidade explicativa, resumindo a informação abundante que se possui.

Assim, alguns conjuntos de amostras foram tratados pelo método estatístico de análise de clusters, uma técnica exploratória de análise multivariada que permite a agregação de variáveis em grupos homogêneos consoantes ao seu grau de semelhança. Também foi utilizada a análise fatorial como método multivariado de análise das interdependências. Os fatores são entidades (constructos) hipotéticas não diretamente observáveis, que se inferem ou se constroem a partir do 
agrupamento das variáveis. Não existe uma solução única para a análise fatorial de um conjunto de dados, mas apenas dois princípios básicos que se deve ter em conta: o Princípio da Parcimônia, que explica as correlações entre as variáveis observadas, utilizando o menor número de fatores possível; e a Interpretabilidade, para que os fatores tenham um significado no contexto estudado, guardando em si mesmos uma coerência lógica.

A análise fatorial exploratória foi aplicada para buscar dimensões subjacentes, e saber o que é mais importante ou mais significativo do conjunto de variáveis que consideramos neste trabalho. Como não é necessário que as variáveis tenham uma distribuição normal, optamos pela Análise Fatorial Equamax, que ajusta da melhor forma, minimizando o número de fatores de variáveis em cada fator.

Para a aplicação das opções estatísticas descritas foi utilizado o software Statistica (StatSoft, 2007). Considerando a dependência espacial dos elementos químicos no solo (Vetorazzi \& Ferraz, 2000; Carvalho et al. 2003), para a espacialização dos parâmetros analisados foi utilizado o software Surfer (Golden, 2002), interpolando-se os valores por krigagem simples, na opção default do programa. 


\section{REsUltados E Discussão}

\subsection{Amostras de Solo}

Os resultados analíticos obtidos para as amostras de solo estão presente na Tabela 3 do Anexo, os elementos maiores foram recalculados em função da perda ao fogo (PF), e esse resultado esta presente na Tabela 4 do Anexo.

A partir do conjunto de dados foram calculados sumários estatísticos (Tabela 5 do Anexo). O gráfico do tipo box \& whisker plot para os elementos maiores e elementos menores do solo está representado nas Figuras $18 \boldsymbol{a}$ e $\boldsymbol{b}$.

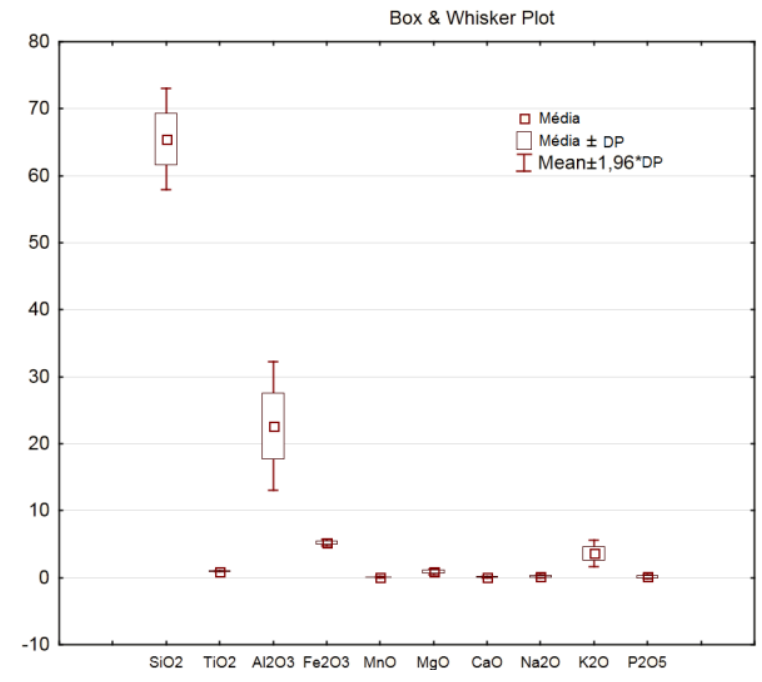

(a)

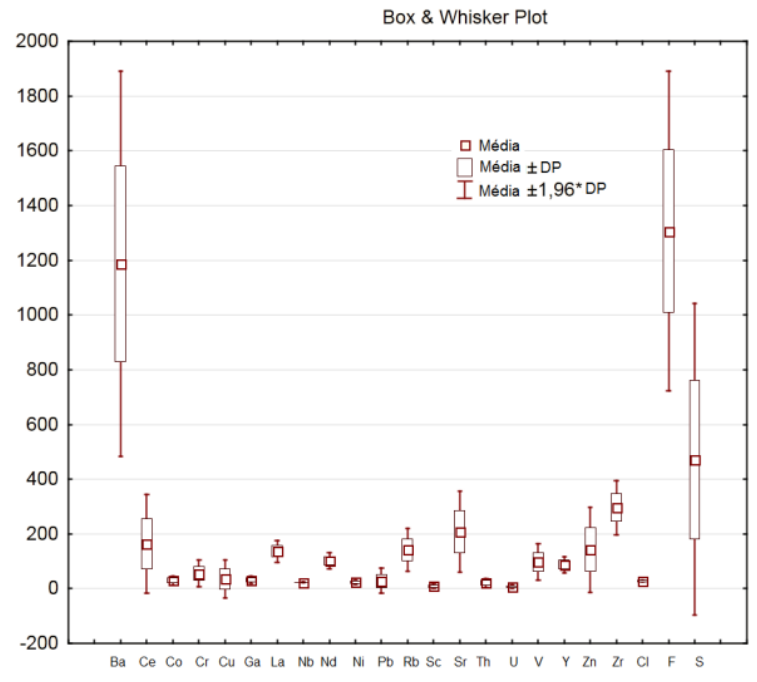

(b)

Figura 18 - Box-whisker plots para elementos maiores (a) e elementos menores $(\boldsymbol{b})$ em amostras do solo coletadas no PET.

Alguns elementos apresentam desvio padrão com valores superiores a unidade. Desvios-padrão relativos mais elevados significam uma menor homogeneidade do elemento no material. No conjunto das amostras, F1B apresenta os teores mais elevados de $\mathrm{Al}_{2} \mathrm{O}_{3}$ e $\mathrm{K}_{2} \mathrm{O}$ e o mais baixo em $\mathrm{SiO}_{2}$, evidenciando a heterogeneidade do solo.

Os solos do PET e do ambiente referência foram submetidos à análise granulométrica pelo método de Robson (pipetagem), e os dados estão contidos na Tabela 1 (abaixo), e plotados em diagrama de Shepard (Figura 19).

Tabela 1 - Análise granulométrica das amostras de solo do PET e de ambiente referência não antropizado (F4) 


\begin{tabular}{|cccccccc|}
\hline & F1A & F1B & F2A & F2B & F3A & F3B & F4 \\
Argila & 9,05 & 27,43 & 16,05 & 28,18 & 13,01 & 32,33 & 1,35 \\
Silte & 40,80 & 36,30 & 38,01 & 27,64 & 39,12 & 22,93 & 2,40 \\
Areia & 41,85 & 18,65 & 33,47 & 36,68 & 43,32 & 32,27 & 95,20 \\
\hline
\end{tabular}

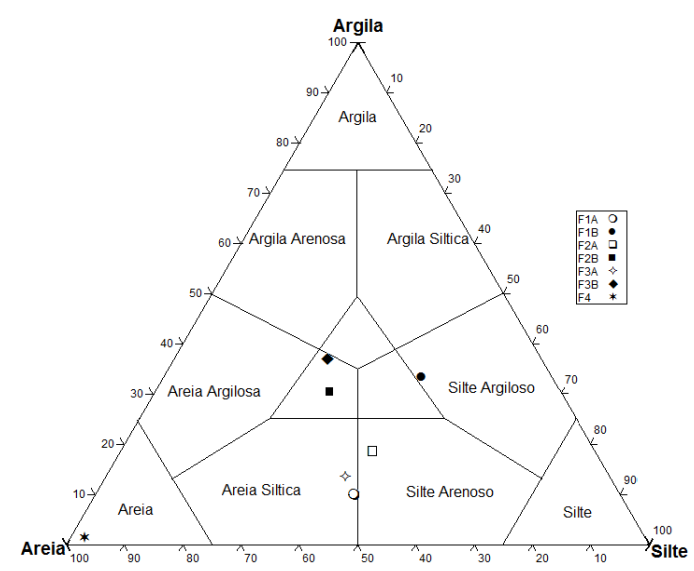

Figura 19 - Classificação textural das amostras de solo segundo Diagrama de Shepard, (1954).

As amostras referentes ao horizonte $B$ se diferenciam daquelas do horizonte A na proporção areia-silte-argila. Dentre as amostras coletadas no PET, a amostra F1B foi a que apresentou proporção areia-silte-argila mais diferenciada.

Enquanto nas demais amostras o teor de areia encontra-se entre $32-43 \%$, na amostra F1B tem-se 18,65\%. Da mesma forma, para os teores de silte+argila, a amostra F1B apresenta o valor mais elevado, em relação às demais amostras. Isto explica os desvios padrões significantes na amostra F1B para silício, alumínio e potássio, como apontado anteriormente.

A amostra de solo F4 (referência) é mais arenosa, e também possui o teor de silício mais alto e baixo teores de ferro, alumínio e potássio. De fato, o ambiente no qual foi coletada a amostra F4 está localizado próximo de restinga e dunas, sendo abundante em areia e pobre em argilominerais e óxi-hidróxidos de ferro.

$\mathrm{O}$ Ba e $\mathrm{F}$ apresentam desvio padrão relativo elevado em todas amostras.

Para o conjunto coletado no PET, as amostras do horizonte B nos furos F1 e F3 apresentam teores mais elevados em relação ao horizonte $A$ para os elementos $\mathrm{Ce}, \mathrm{Cr}, \mathrm{Cu}, \mathrm{Ga}, \mathrm{Th}, \mathrm{U}, \mathrm{V}$ e S, além de teores menores para os elementos Ba, Co, La, $\mathrm{Rb}, \mathrm{Sr}, \mathrm{Y}, \mathrm{Zr}$ e F. Comportamento inverso é observado no furo F2 no mesmo horizonte. 
Para análise dos resultados dos elementos menores, utilizou-se outra técnica visando o estudo das relações composicionais entre as amostras de solo, que consistiu na análise de cluster no modo-Q (Figura 20).

A aplicação desta técnica teve como finalidade o agrupamento das amostras geoquimicamente similares; quanto mais próxima da origem a ligação é efetuada, melhor é a correlação entre as amostras.

$\mathrm{A}$ análise de cluster mostrou, de forma muito clara, a indiferença do $\mathrm{Ba}$ e $\mathrm{F}$ em relação aos demais elementos menores de todo o conjunto. Alguns elementos formaram clusters coerentes entre si, como $\mathrm{Cu}-\mathrm{Pb}$, Co-Ga-Nb-Ni-Th-Cl, Sc-U, e Rb$\mathrm{V}$-Y-Nd-La. Os elementos $\mathrm{Ce}, \mathrm{Sr}, \mathrm{Zn}, \mathrm{Zr}$ e $\mathrm{S}$ (em ordem decrescente) apresentam similaridade fraca com os grupos de cluster formados.

Observa-se que os resultados obtidos apresentaram o mesmo padrão de cluster tanto para o conjunto de dados que incluíam a amostra de solo referência (amostra F4), como para o conjunto de dados do qual tal amostra foi subtraída.

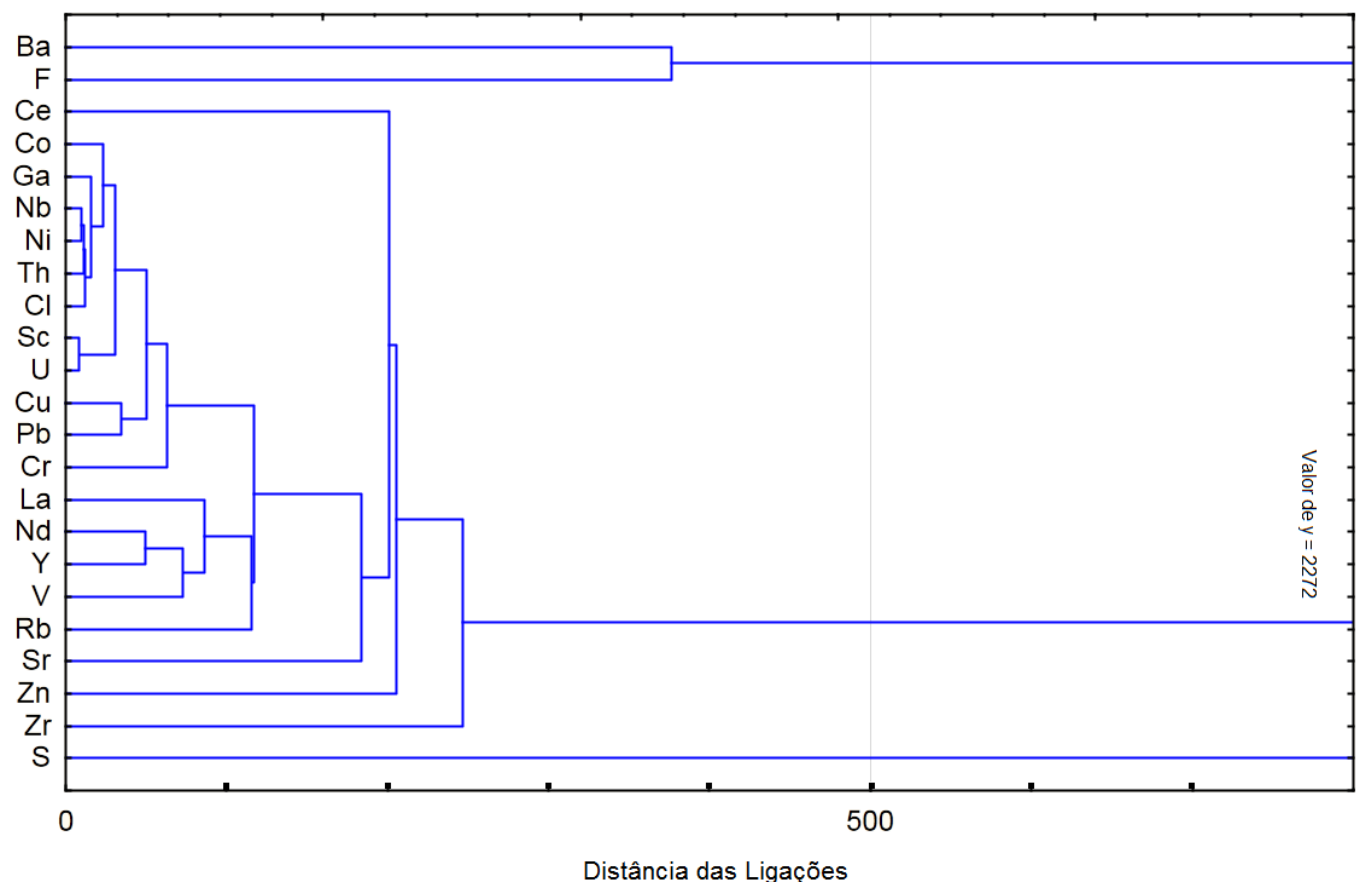

Figura 20 - Análise de cluster no modo-Q, considerando 23 elementos menores e traços e mostrando relações entre as amostras analisadas.

Para ampliar a análise dos elementos menores e traços, utilizou-se a análise fatorial com rotação de dois fatores a interpretação das relações entre as variáveis, 
buscando identificar grupos de elementos de comportamento semelhante no conjunto de amostras.

Como as variáveis não são totalmente independentes, pois algumas guardam entre si altos valores de correlação, é possível construir um "novo espaço" cujos eixos (fatores) serão combinações lineares das variáveis originais. Os coeficientes das variáveis para essas combinações lineares são os loadings (carregamentos) e as coordenadas das amostras nesse espaço são os factor scores (pontuação dos fatores) (Imbernon, 1993).

A partir desse processo, foram calculados os valores próprios para cada fator, que indicam a porcentagem de sua variância total explicada pelo modelo de $\boldsymbol{n}$ fatores. A retenção de um número $\boldsymbol{k}$ limitado de fatores $(k<n)$ nos possibilitou compreender o comportamento dos elementos menores e traços.

A rotação dos eixos em dois fatores permitiu essa análise; e para esse procedimento, não foram inseridos os dados da amostra F4, pois incluindo essa amostra os resultados apresentaram discrepâncias.

Para a execução da análise fatorial, o número total de amostras consideradas foi de 6, cada qual com 23 variáveis, que formaram uma matriz de 6 por 23 .

As técnicas de análise fatorial para dados geoquímicos são mais comumente aplicadas à prospecção mineral, mas neste trabalho foram utilizadas para analisar como os metais se relacionam no solo. A Tabela 2 indica os loadings e as comunalidades estimadas para cada variável em cada um dos fatores rotacionados, e os valores próprios, comunalidades para os dois fatores rotacionados. 
Tabela 2 - Loadings e comunalidades estimadas para cada variável em cada um dos fatores rotacionados (rotação Equamax) para o solo:

\begin{tabular}{|c|c|c|c|c|c|c|c|}
\hline \multirow[b]{2}{*}{ Variável } & \multicolumn{2}{|c|}{ Loadings } & \multicolumn{2}{|c|}{ Comunalidades } & \multicolumn{3}{|c|}{ Valores próprios e Comunalidades } \\
\hline & Fator 1 & Fator 2 & Fator 1 & Fator 2 & & Fator 1 & Fator 2 \\
\hline $\mathrm{Ba}$ & $-0,95959$ & 0,271371 & 0,920813 & 0,994455 & \multirow{2}{*}{$\begin{array}{l}\text { Valores } \\
\text { Próprios }\end{array}$} & \multirow{2}{*}{14,89329} & \multirow{2}{*}{5,57759} \\
\hline $\mathrm{Ce}$ & 0,97388 & 0,089235 & 0,948441 & 0,956404 & & & \\
\hline Co & $-0,69317$ & 0,616126 & 0,480480 & 0,860091 & \multirow{2}{*}{$\begin{array}{c}\text { \% Variância } \\
\text { Total }\end{array}$} & \multirow{2}{*}{64,75343} & \multirow{2}{*}{24,25038} \\
\hline $\mathrm{Cr}$ & 0,72208 & $-0,624559$ & 0,521404 & 0,911478 & & & \\
\hline $\mathrm{Cu}$ & 0,32277 & $-0,911756$ & 0,104181 & 0,935481 & \multirow{3}{*}{$\begin{array}{c}\begin{array}{c}\text { Valores } \\
\text { próprios } \\
\text { Cumulativo }\end{array} \\
\%\end{array}$} & \multirow[b]{2}{*}{14,89329} & \multirow[b]{2}{*}{20,47088} \\
\hline $\mathrm{Ga}$ & 0,96813 & 0,223570 & 0,937278 & 0,987262 & & & \\
\hline La & 0,51401 & 0,725702 & 0,264207 & 0,790851 & & \multirow[b]{2}{*}{64,75343} & \multirow[b]{2}{*}{89,00381} \\
\hline $\mathrm{Nb}$ & $-0,23732$ & $-0,235926$ & 0,056319 & 0,111980 & Cumulativo & & \\
\hline Nd & 0,18201 & 0,804774 & 0,033129 & 0,680791 & & & \\
\hline $\mathrm{Ni}$ & 0,95316 & $-0,281053$ & 0,908509 & 0,987499 & & & \\
\hline $\mathbf{P b}$ & 0,17213 & $-0,938476$ & 0,029627 & 0,910364 & & & \\
\hline $\mathbf{R b}$ & $-0,96645$ & 0,204083 & 0,934019 & 0,975669 & & & \\
\hline Sc & 0,94455 & 0,324965 & 0,892171 & 0,997774 & & & \\
\hline $\mathrm{Sr}$ & $-0,96200$ & 0,186988 & 0,925435 & 0,960400 & & & \\
\hline Th & 0,99257 & $-0,008355$ & 0,985201 & 0,985271 & & & \\
\hline U & 0,85080 & 0,487070 & 0,723869 & 0,961106 & & & \\
\hline V & 0,98510 & 0,159210 & 0,970430 & 0,995778 & & & \\
\hline $\mathrm{Y}$ & $-0,66900$ & 0,583139 & 0,447567 & 0,787618 & & & \\
\hline Zn & 0,08396 & $-0,957697$ & 0,007049 & 0,924232 & & & \\
\hline $\mathrm{Zr}$ & $-0,86122$ & $-0,204288$ & 0,741693 & 0,783427 & & & \\
\hline $\mathrm{Cl}$ & 0,99677 & $-0,073724$ & 0,993558 & 0,998993 & & & \\
\hline$F$ & $-0,99723$ & 0,028619 & 0,994462 & 0,995281 & & & \\
\hline $\mathbf{S}$ & 0,98018 & $-0,133873$ & 0,960749 & 0,978671 & & & \\
\hline
\end{tabular}

Os dois fatores rotacionados suportam $89 \%$ da variância total, indicando que o modelo escolhido é consistente. A Figura 21 é a representação gráfica dos dados obtidos.

Consideraram-se para a interpretação quatro grupos formados, em função do quadrante ocupado no gráfico. 


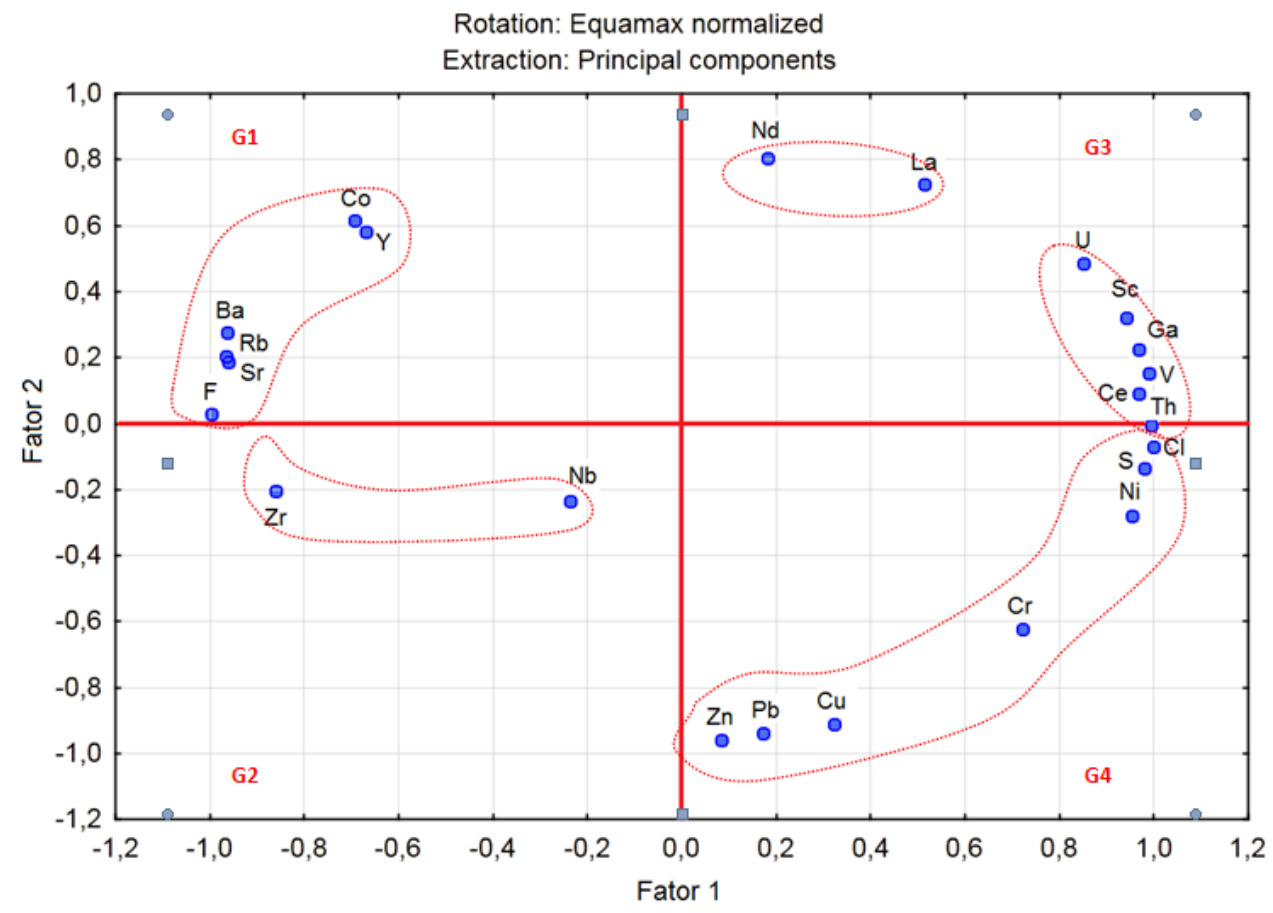

Figura 21 - Representação gráfica da análise para componentes principais dois fatores rotacionados para o solo.

- Grupo 1 (G1): distingue Co-Y-Ba-Sr-Rb-F com altos loadings negativos para 0 Fator 1; para o Fator 2, loadings positivos próximo de zero para Ba-Sr-Rb-F e valores altos para Co-Y;

- Grupo 2 (G2): os elementos Zr e Nb apresentam, respectivamente, alto e baixo loadings negativos para o Fator 1 e baixos loadings negativos para o Fator 2;

- Grupo 3 (G3): formado por dois subgrupos, Nd-La com baixos loadings positivos para o Fator 1 e altos loadings positivos no Fator 2; e o subgrupo U, Sc, Ga, V, Ce e Th com altos loadings positivos para o Fator 1 e baixos loadings positivos para o Fator 2 ;

- Grupo 4 (G4): formado pelos elementos $\mathrm{Zn}, \mathrm{Pb}, \mathrm{Cu}, \mathrm{Cr}, \mathrm{Ni}, \mathrm{Cl}, \mathrm{S}$ apresenta loadings positivos variando de baixo $(\mathrm{Zn}, \mathrm{Pb}, \mathrm{Cu})$ a alto $(\mathrm{Cr}, \mathrm{Ni}, \mathrm{S}, \mathrm{Cl})$ para o Fator 2.

Assim, o Fator 1 parece opor $\mathrm{Ba}$ e $\mathrm{Zr}$, presentes no solo (G1 e G2), em relação à assinatura geoquímica marcada por alguns ETR presentes no (G3). Salientam-se os metais pesados $\mathrm{Zn}, \mathrm{Pb}, \mathrm{Cu}$, Cr (G4) agrupados e em oposição aos demais elementos menores e traços, que provavelmente foram introduzidos no solo por ação antrópica. 
Os teores de Ba e F são elevados no solo. Embora o F seja um elemento com uma porcentagem baixa na crosta terrestre; está presente na composição de várias rochas, plantas e nos mamíferos, fazendo parte também de processos antrópicos de produção, processos esses observados no histórico de uso e ocupação na área incidente ao PET. A presença de Ba pode estar relacionada aos resíduos de construção civil, os quais foram encontrados (alto teor de areia e fragmentos de material cerâmico), na camada superior do solo (horizonte A), a Tabela 2 do Anexo traz os valores para qualidade do solo.

\subsection{Amostras de Água}

A água subterrânea foi captada dos poços de monitoramento implantados por Mondim (2005), nas duas estações principais. Ainda in situ, fizeram-se leituras dos parâmetros físico-químicos, $\mathrm{pH}$, Eh, condutividade elétrica (CE) e temperatura; posteriormente, analisaram-se cátions e ânions. Os resultados das duas campanhas encontram-se na Tabela 1 do Anexo.

A condutividade elétrica e a temperatura nas duas campanhas de coleta foram plotadas em gráfico (Figura 22). O tratamento dos resultados obtidos para as amostras de água consistiu, inicialmente, na correlação entre os dados químicos e os parâmetros $\mathrm{pH}$ e Eh. Elementos que se apresentaram acima do limite de detecção foram plotados nos diagramas correspondentes aos micronutrientes (Figura 23 a, b, c, d), e macronutrientes (Figura 24 a, b, c, d, e).
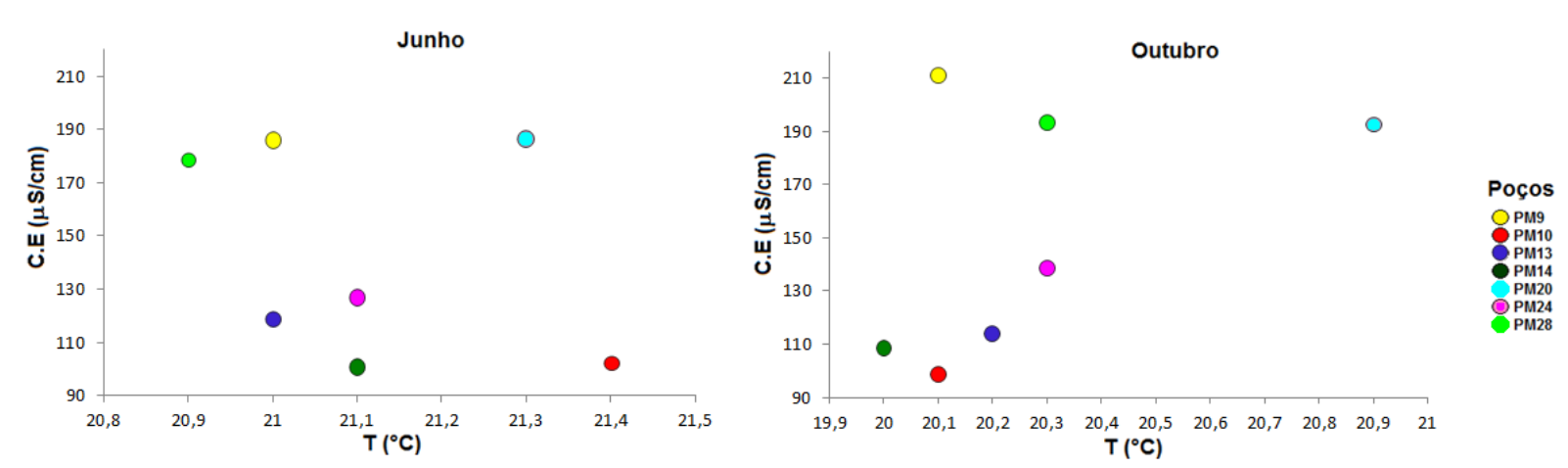

Figura 22 - Gráfico C.E. vs. T dos meses de Junho e Outubro 
A condutividade elétrica nas duas campanhas não mostrou estar sob influência da temperatura. Poços com a mesma temperatura (PM9 e PM13 em junho e PM9 e PM10 em outubro) apresentaram grande diferença de condutividade elétrica, o que indica, nesse caso específico, que a dissolução dos íons está relacionada com a oferta de água nas estações, pois em outubro quando houve maior volume de precipitação, ocorreu um aumento na condutividade.

Valores baixos de $\mathrm{pH}$ correspondem a maior concentração de íons $\mathrm{H}^{+}$livres em solução; conforme o pH aumenta, esta concentração diminui.

Quanto mais ácida for a solução, maior será a competição entre os íons $\mathrm{H}^{+}$, o que dificulta a dissolução destes. Com o aumento do $\mathrm{pH}$, ocorre uma maior concentração de complexos nos quais as moléculas de água são substituídas por outros ligantes inorgânicos, como $\mathrm{OH}^{-}$. Estas estruturas, por serem maiores ou menos solúveis, dificultam o processo de troca iônica (Jimenez et al., 2004).

Os micronutrientes apresentaram o mesmo comportamento de solubilidade nas duas campanhas; o baixo valor de $\mathrm{pH}$ e o Eh alto contribuíram para a ausência de oxigênio dissolvido, possibilitando que o ferro e o manganês presentes na água estejam na forma solúvel $\mathrm{Fe}^{2+}$ e $\mathrm{Mn}^{2+}$. Não podemos afirmar qual a origem desses elementos na água, mas podemos levantar algumas hipóteses:

a) ambos foram introduzidos naturalmente a partir do intemperismo do substrato rochoso, liberados na água subterrânea por processos de lixiviação do solo;

b) ambos por ação antrópica, gerados por atividade humana de uso e ocupação descritos no histórico pré-parque.

Com o pH relativamente baixo, os íons $\mathrm{Na}^{+}$e $\mathrm{Cl}^{-}$foram detectados em baixa concentração. Salienta-se que alta concentração desses íons é mais comum em águas mais alcalinas.

Da mesma forma, os macronutrientes $\mathrm{K}_{2} \mathrm{O}, \mathrm{CaO}$ e $\mathrm{MgO}$ e os micronutrientes apresentaram o mesmo comportamento de solubilidade em água.

A presença do íon $\mathrm{SO}_{4}{ }^{2-}$ foi identificada em todos os poços. Como exceção, apenas o poço PM14, na amostragem realizada na estação seca, apresentou valores próximos à linha de transição ambiental de especiação deste composto, entre a forma redutora e a forma aquosa solúvel. 
O poço PM14 apresentou os menores valor de Eh e pH, também diferenciou o comportamento do Nitrogênio, que se apresentou na forma mais redutora. Os poços PM24 (Junho) e PM10/PM28 (Outubro) se posicionaram próximos à linha de transição ambiental entre o ambiente redutor e a forma aquosa disponível do $\mathrm{NO}_{3}$.

As coletas sazonais indicaram que no mês de junho (estação seca) o aquífero apresentou condições mais redutoras em relação ao mês de outubro (estação chuvosa); em ambas as campanhas, não foram observadas concentrações acima dos valores de referência a prevenção da saúde humana. 
a)

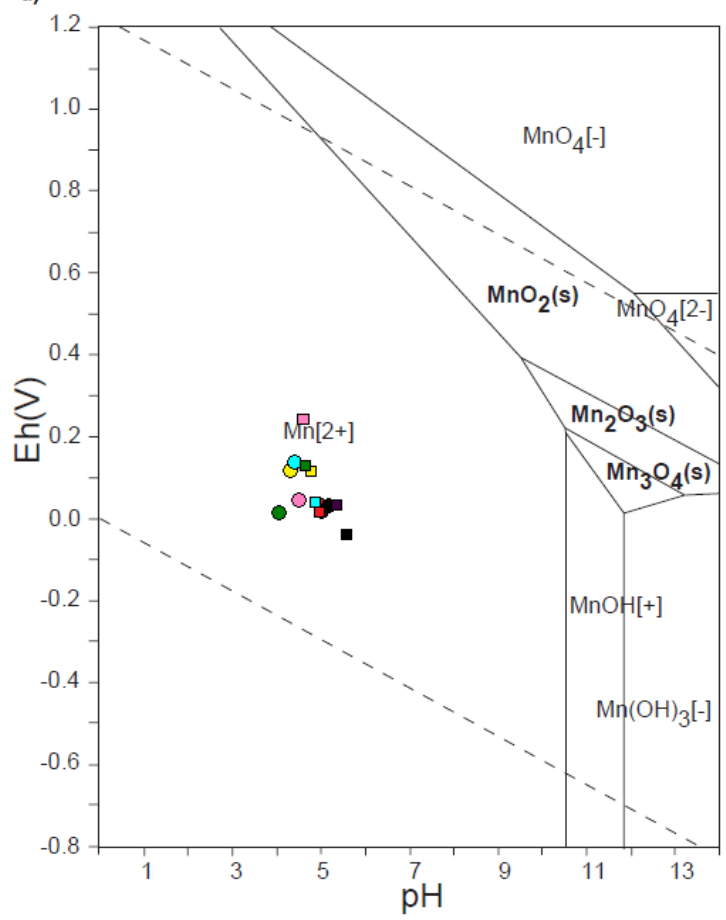

d)

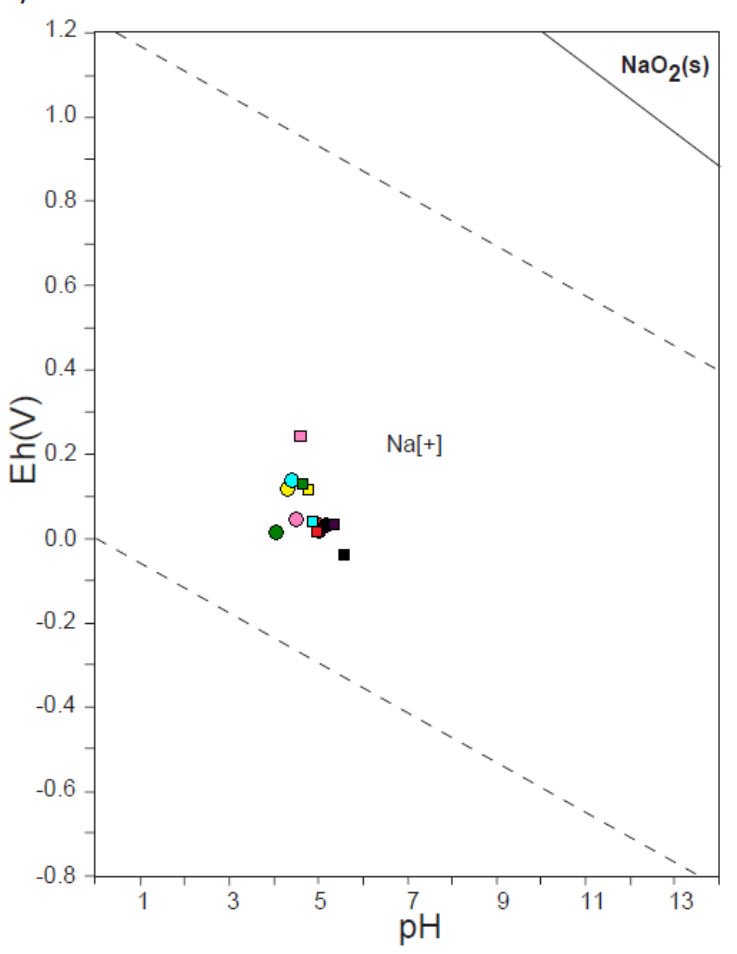

b)

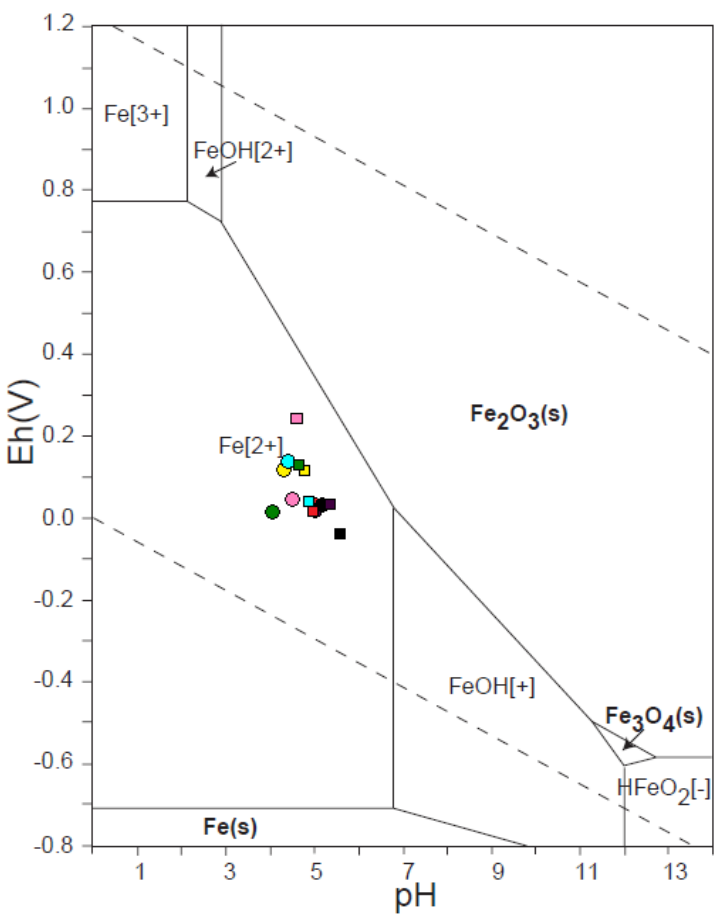

e)

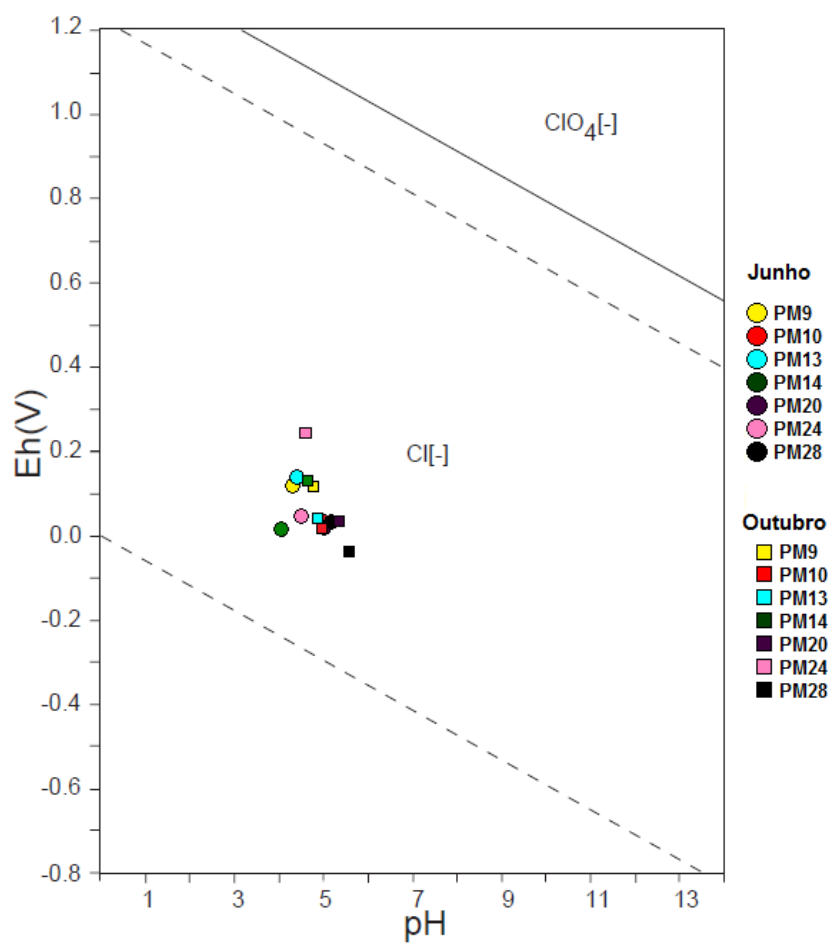

Figura 23 - a, b, d, e - Diagrama $\mathrm{pH}=\mathrm{f}(\mathrm{Eh})$ dos micronutrientes $\mathrm{Na}, \mathrm{Mn}, \mathrm{Fe}$ e $\mathrm{Cl}$ a $25^{\circ} \mathrm{C}$ e 1 atm, com projeção dos valores de água subterrânea dos poços (PM9, PM10, PM14, PM20, PM24 e PM28) (Takeno, 2005 e Broonkins, 1988). 

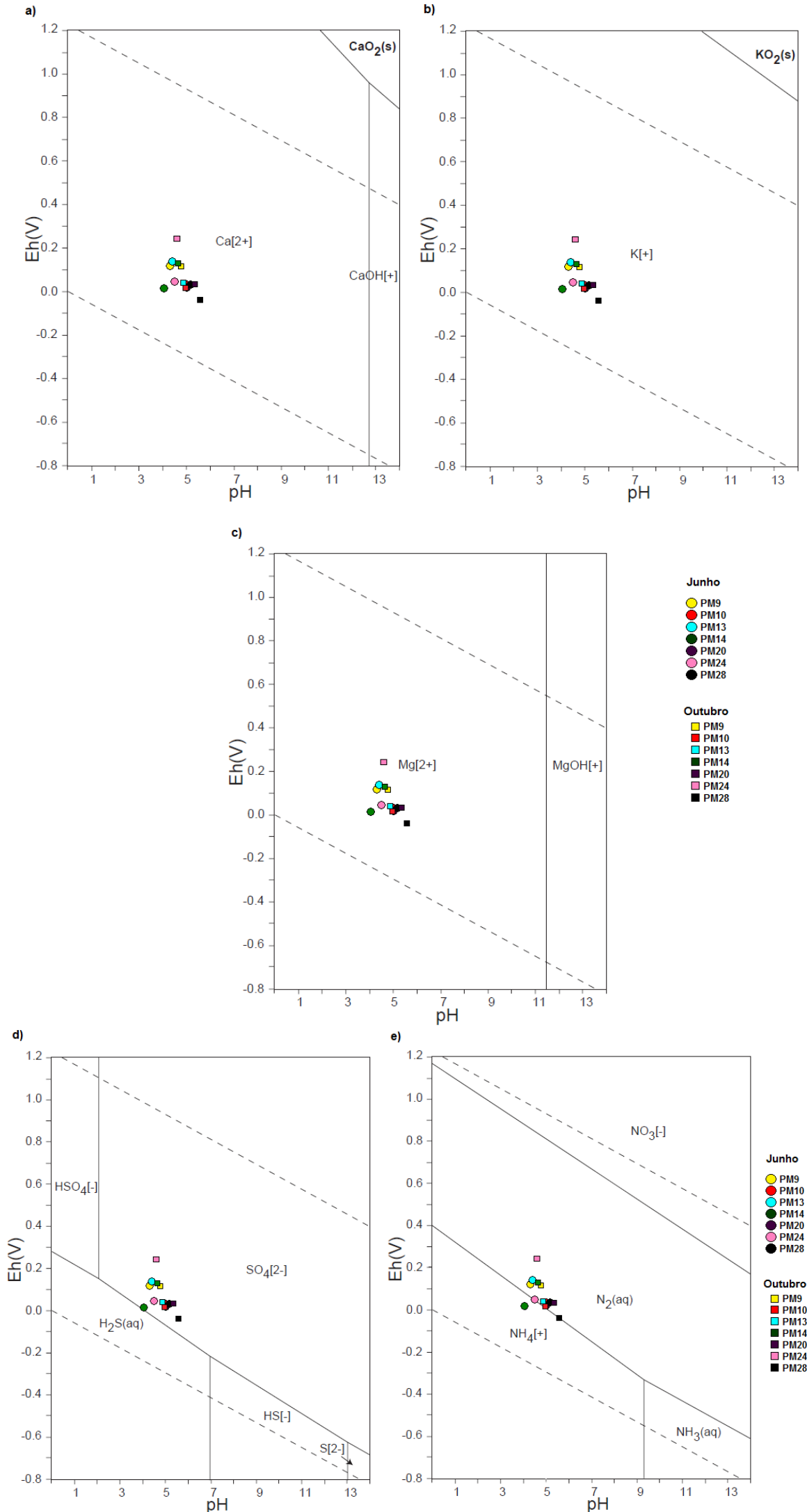

Figura 24 - a, b, c, d, e, $f$ - Diagrama $\mathrm{pH}=\mathrm{f}(\mathrm{Eh})$ dos macronutrientes $\mathrm{N}, \mathrm{K}, \mathrm{Ca}, \mathrm{Mg}$ e $\mathrm{S}$ a $25^{\circ} \mathrm{C}$ e $1 \mathrm{~atm}, \mathrm{com}$ projeção dos valores de água subterrânea dos poços (PM9, PM10, PM14, PM20, PM24 e PM28) (Takeno, 2005 e Broonkins, 1988). 
A interpolação das dados por Krigagem foi realizada com a utilização do software Surfer. As curvas de isovalores gerados permite a visualização do comportamento dos elementos estudados, dentro do aquífero. Para os poços PM 9, PM 20, PM 24, PM 28, os elementos $\mathrm{Ca}, \mathrm{K}, \mathrm{Na}$ e Mg apresentaram acúmulo de concentração a jusante da área de estudo em ambas as campanhas (Figura $25 \mathrm{~d}$; e; f). Também permitem uma comparação entre os parâmetros físico-químicos, $\mathrm{pH}$ e Eh. Observando as curvas de isovalores desses parâmetros (Figura 25 a; b), verificamos que os poços com elevado valor de Eh (vermelho) são os que apresentam menor valor de $\mathrm{pH}$.

$\mathrm{Mn}, \mathrm{Fe}, \mathrm{Na}, \mathrm{Cl}$ e $\mathrm{Mg}$ apresentaram maior condutividade elétrica associados a maiores teores dos elementos, o que indica uma tendência oxidante (Figura 25 b; e; f).

As curvas dos isovalores dos íons $\mathrm{K}, \mathrm{Ca}, \mathrm{Mg}, \mathrm{Na}$ e $\mathrm{Mn}$ apresentou correlação positiva com a condutividade elétrica, o que é esperado, pois esse parâmetro é diretamente proporcional à quantidade de íons dissolvidos na água. Comportamento anômalo foi observado para nitrato, cloreto e sulfato, (Figura $25 \mathrm{c}$; f), pois observouse comportamento antagônico à condutividade elétrica para as duas campanhas, com exceção do cloreto no poço PM 9 em ambas as amostragens (Figura 25 f).

O nitrato apresentou comportamento diferenciado: os poços com concentrações mais baixas em junho apresentaram maior concentração em outubro.

Varnier (2001) estudou a contaminação do aquífero livre do PET, por nitrato oriundo de fossas sépticas, incluindo a área em estudo. Em sua pesquisa, a autora observou íons maiores, $\mathrm{CaO}, \mathrm{MgO}, \mathrm{Fe}_{2} \mathrm{O}_{3}, \mathrm{Na}, \mathrm{K}_{2} \mathrm{O}, \mathrm{SO}_{4}{ }^{2-}$, a série nitrogenada e os parâmetros físico-químicos, e concluiu que havia contaminação da água subterrânea pelo sistema "in situ" de saneamento básico, com valores superiores àqueles permitidos pela legislação. Porém, em poucos metros, essa pluma contaminante era dispersa e não era mais possível sua identificação.

Os poços que apresentaram pH maior ( $\mathrm{PM} \mathrm{9,} \mathrm{PM} 20, \mathrm{PM} 28$ ) tiveram concentração de $\mathrm{SO}_{4}{ }^{2-}$, com exceção do PM 28. 


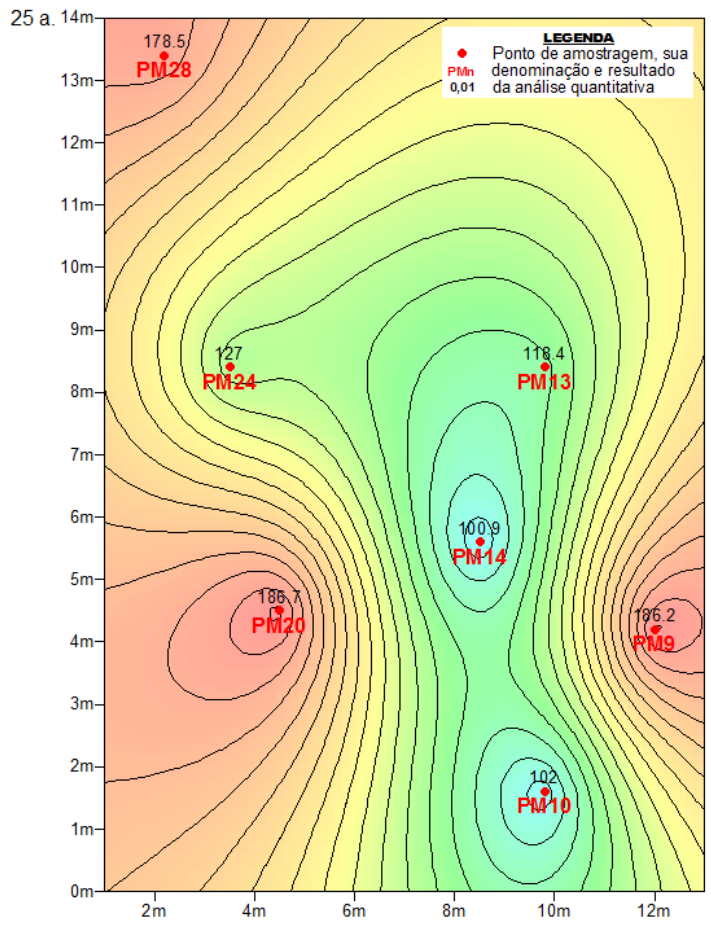

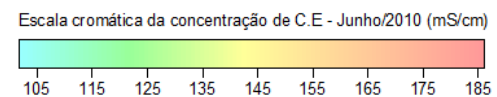

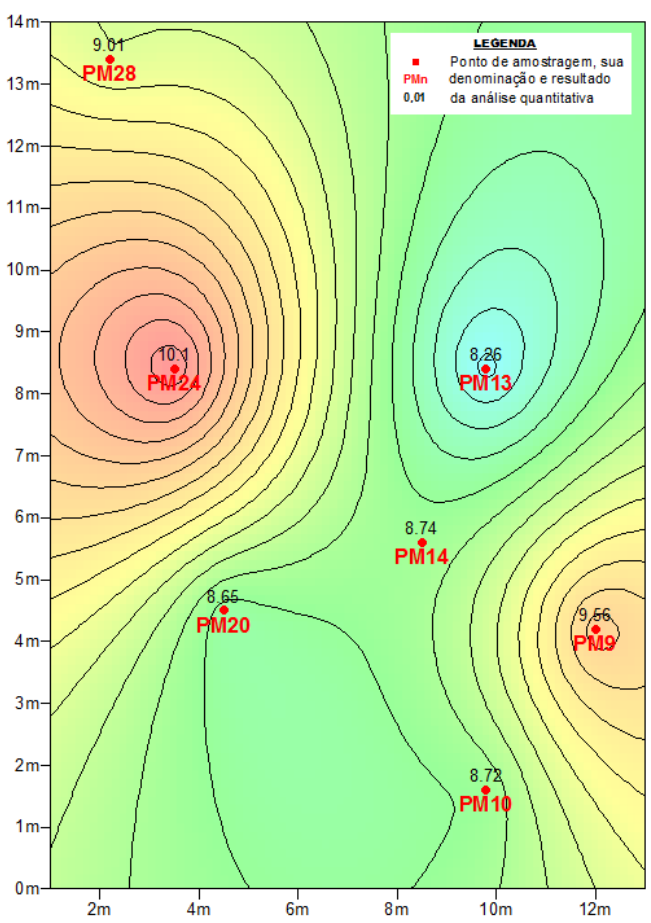

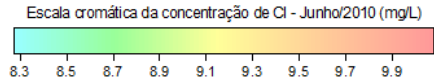

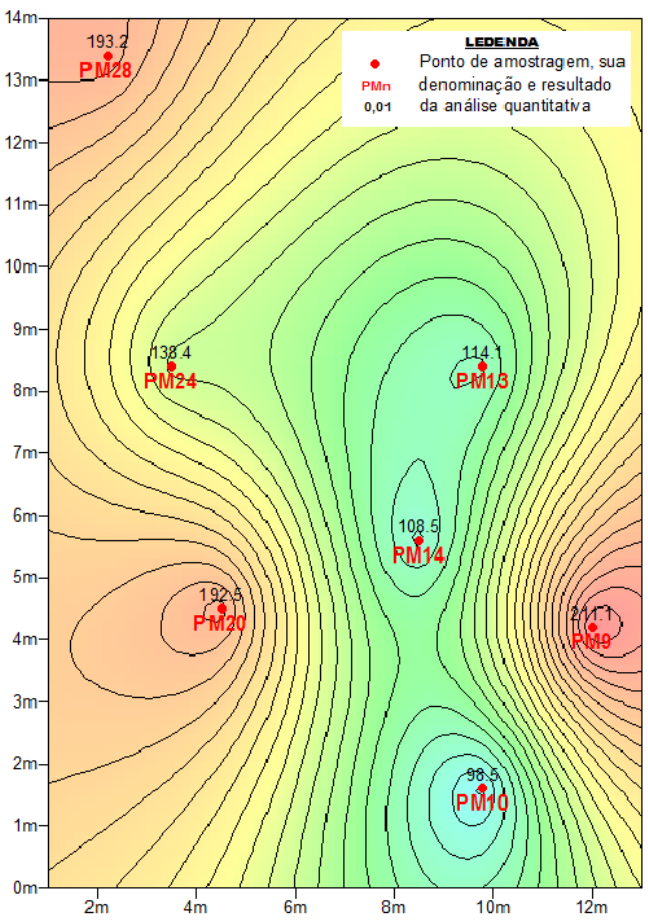

Escala cromática da concentração de C.E - Outubro/2010 (mS/cm) \begin{tabular}{|cccccccc|}
\hline & & & & & & & \\
100 & 115 & 130 & 145 & 160 & 175 & 190 & 205
\end{tabular}

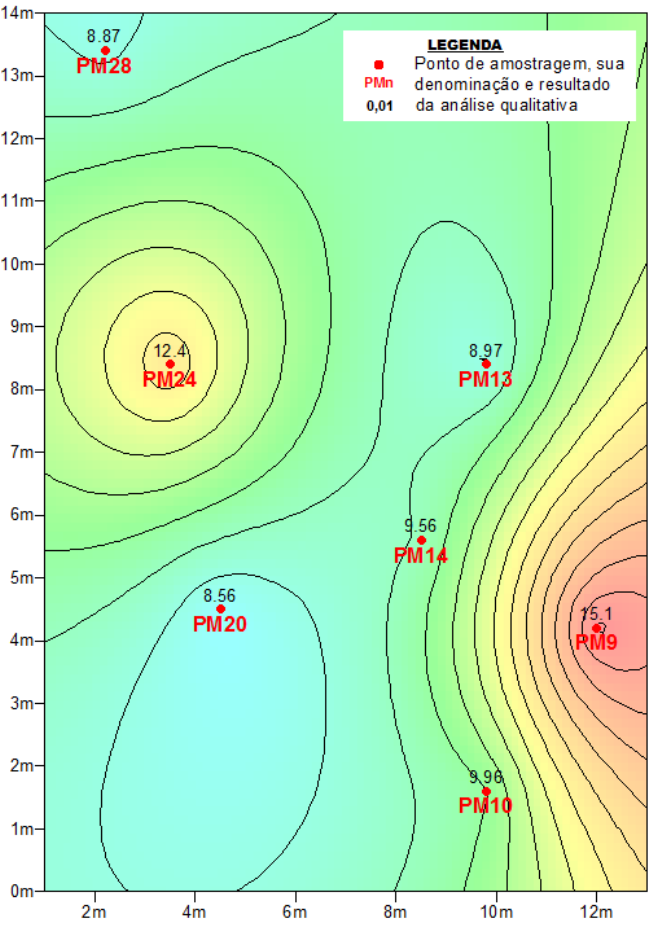

Escala cromática da concentração de $\mathrm{Cl}$ - Outubro/2010 (mg/)

$\begin{array}{lllllllllllll}9.5 & 10 & 10.5 & 11 & 11.5 & 12 & 12.5 & 13 & 13.5 & 14 & 14.5 & 15\end{array}$

Figura 25 a - Curvas de isovalores para C.E e Cl- (junho e outubro). 

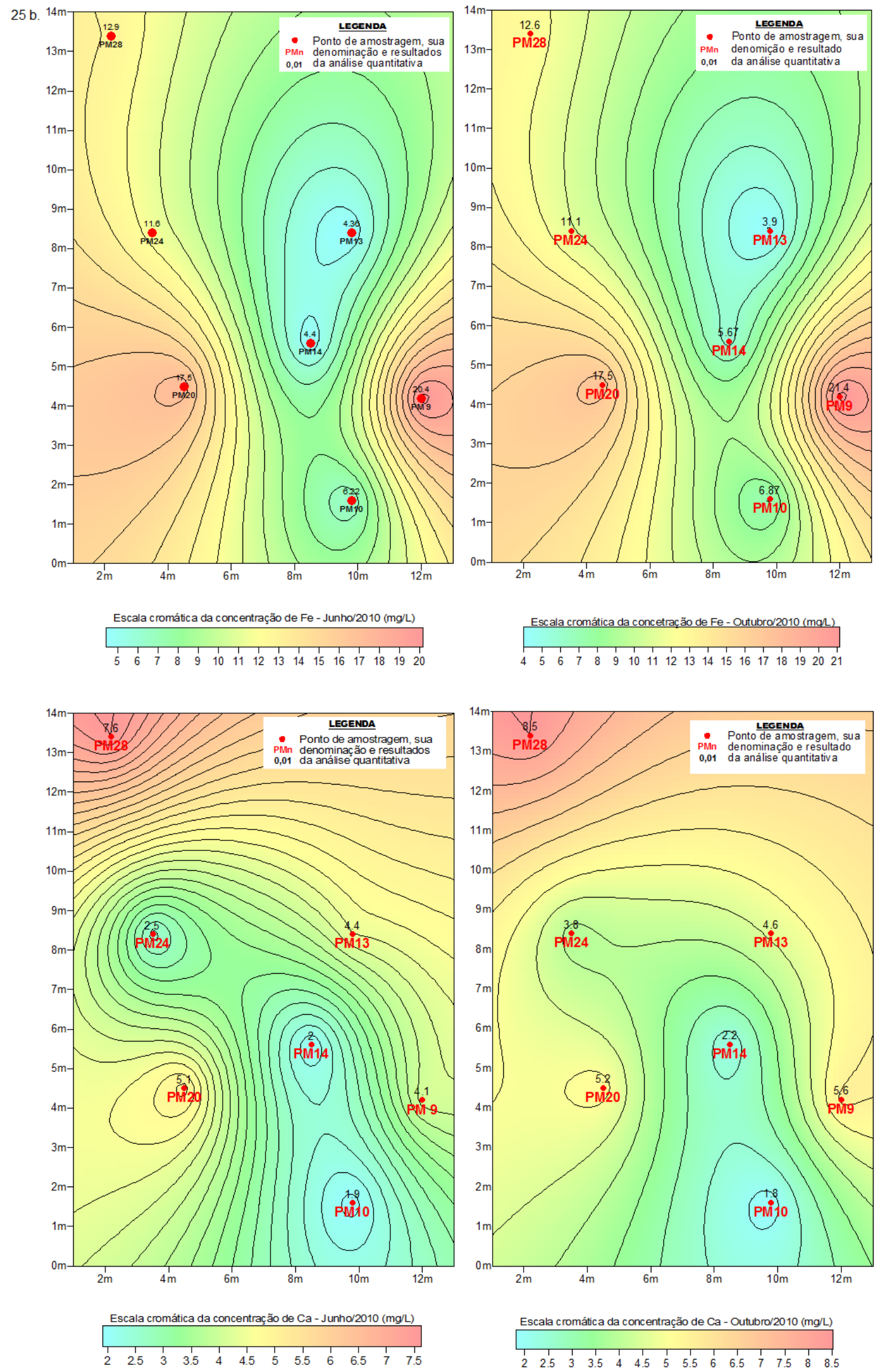

Figura 25 b - Curvas de isovalores para Fe e Ca (junho e outubro). 

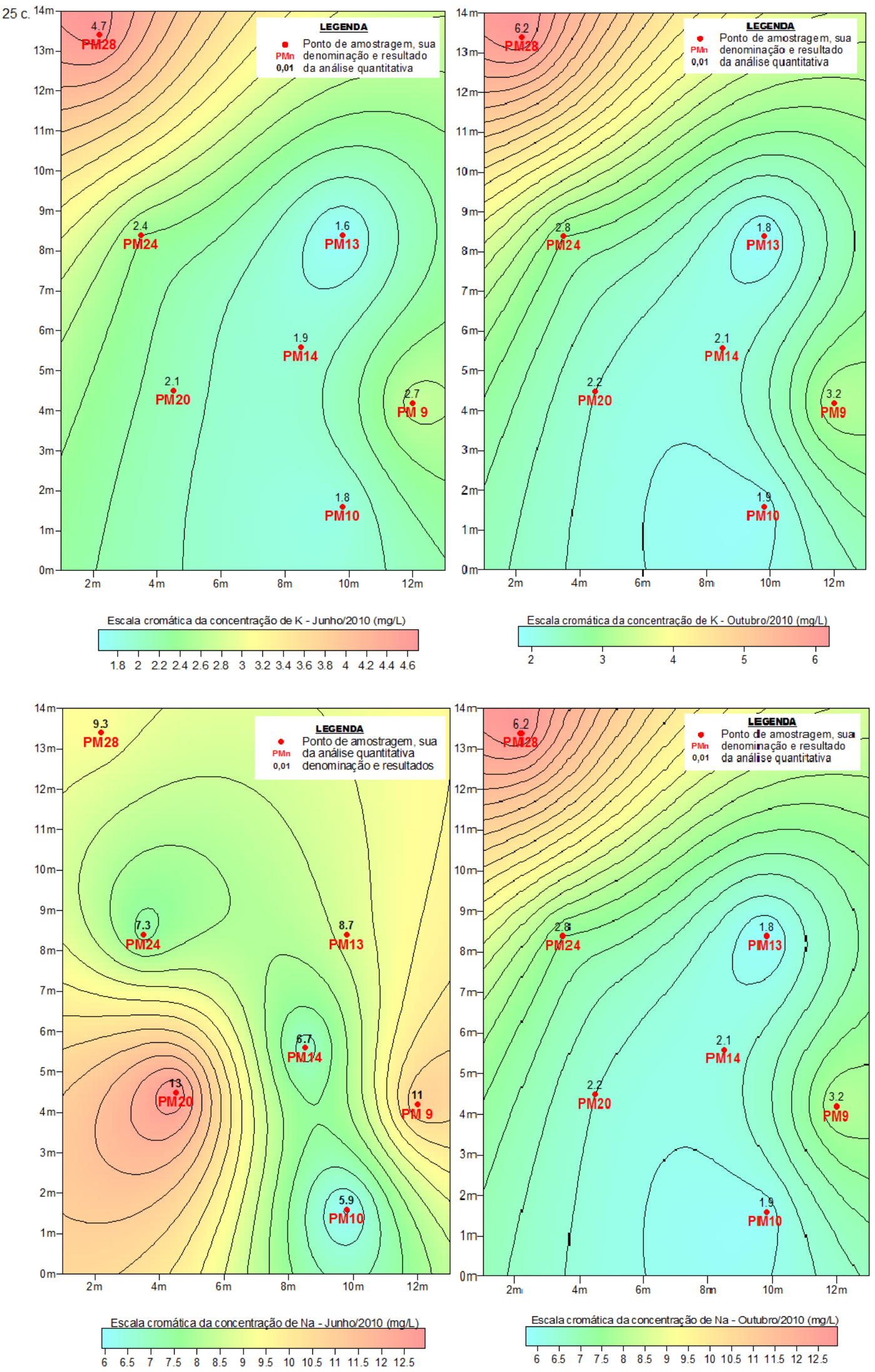

Figura $25 \mathrm{c}$ - Curvas de isovalores para $\mathrm{K}$ e $\mathrm{Na}$ (junho e outubro). 

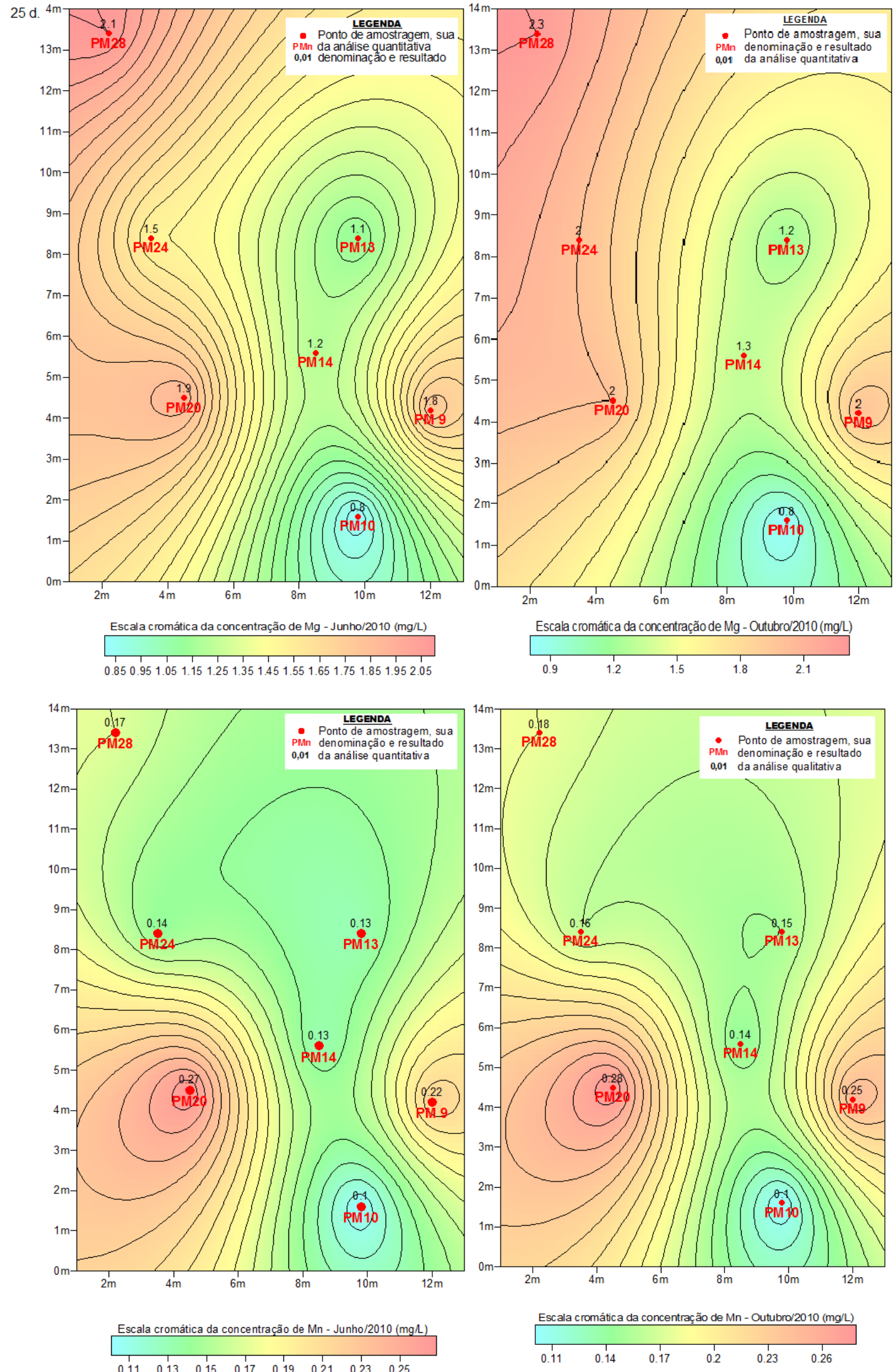

Figura $25 \mathrm{~d}$ - Curvas de isovalores para Mg e Mn (junho e outubro). 

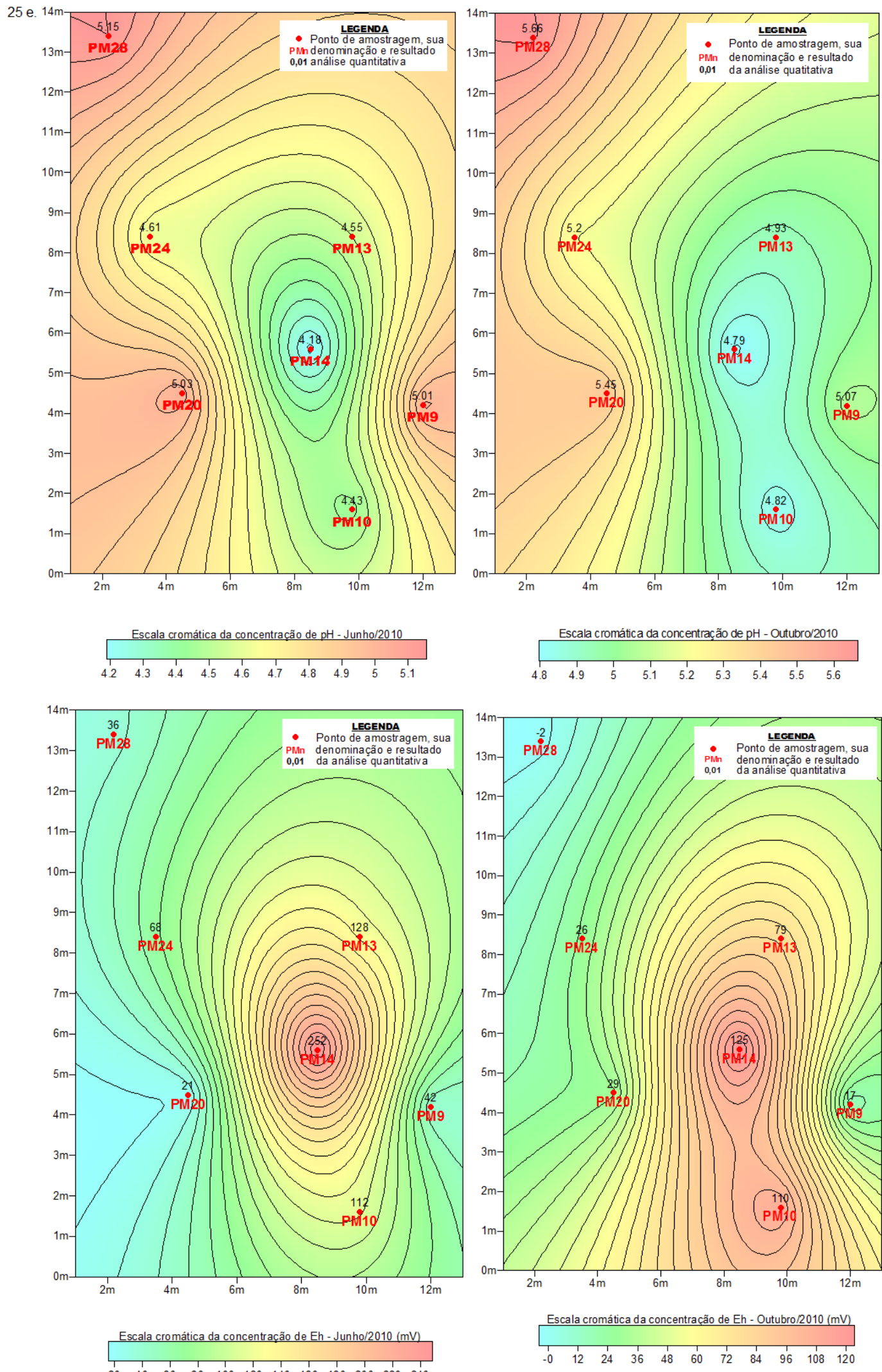

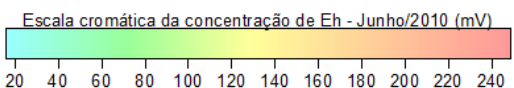

$\begin{array}{lllllllllll}-0 & 12 & 24 & 36 & 48 & 60 & 72 & 84 & 96 & 108 & 120\end{array}$

Figura 25 e - Curvas de isovalores para pH e Eh (junho e outubro). 

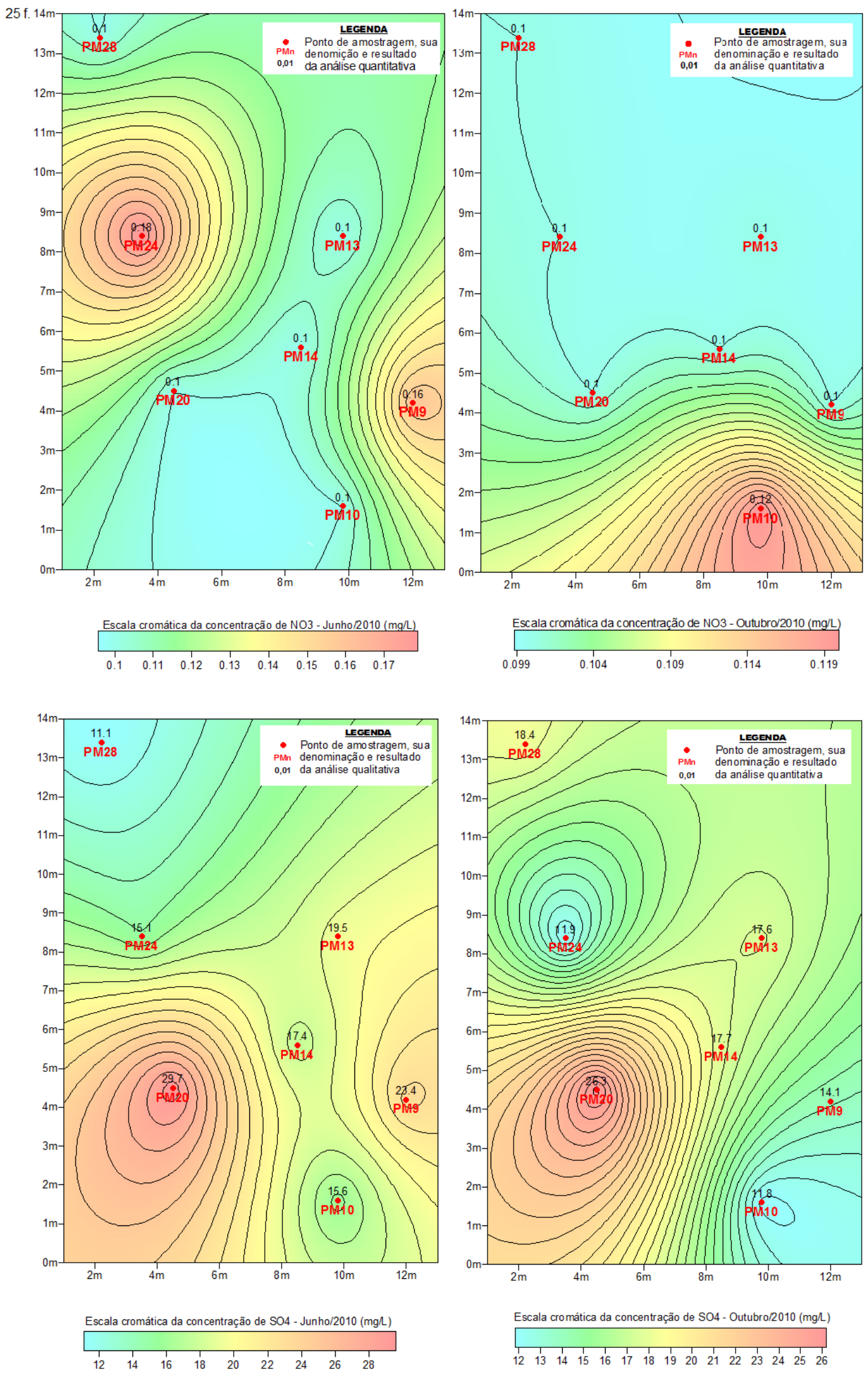

Figura $25 \mathrm{f}$ - Curvas de isovalores para $\mathrm{NO}_{3}{ }^{-}$e $\mathrm{SO}_{4}{ }^{2-}$ (junho e outubro). 
A partir dos dados químicos obtidos da água foram calculados os sumários estatísticos apresentados na Tabela 6 do Anexo. O gráfico do tipo box \& whisker plot para os parâmetros físico-químicos das amostras de água nas duas campanhas de amostragem está representado na figura 26 ( $\boldsymbol{a}$ e $\boldsymbol{b}$ ).

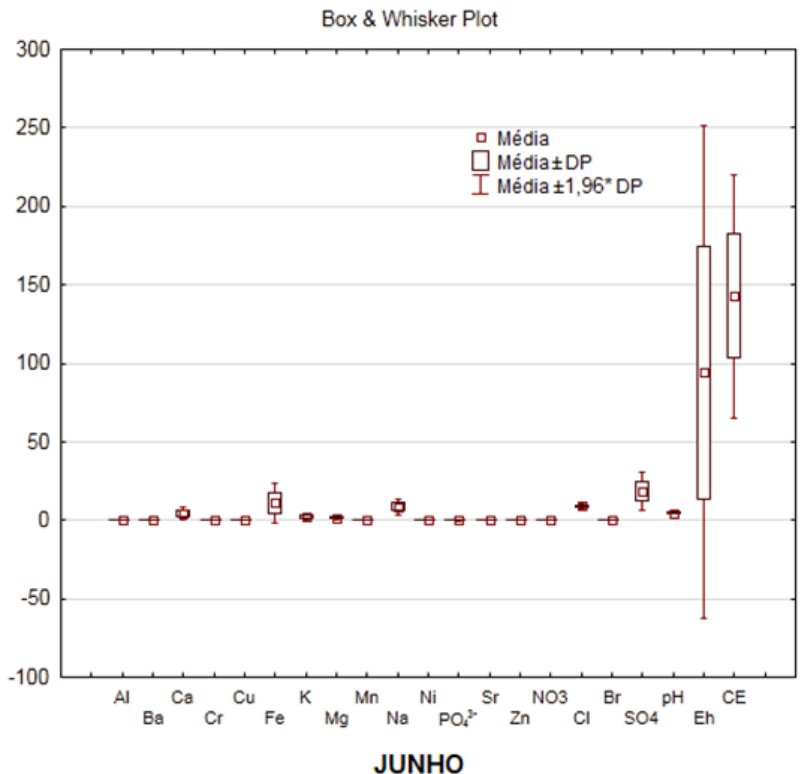

(a)

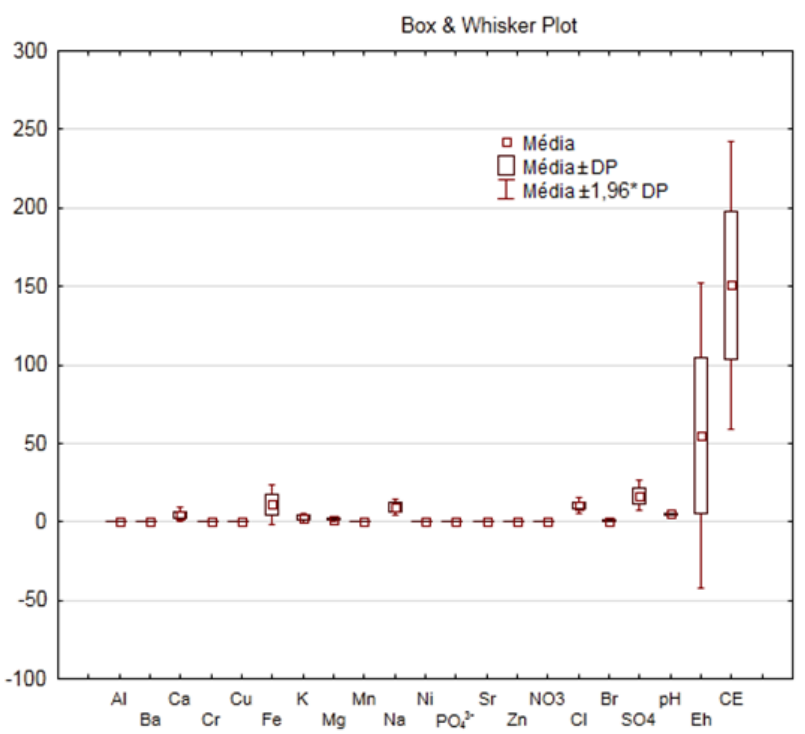

OUTUBRO

(b)

Figura 26 - Box-whisker plots para os cátions, ânions e parâmetros físico-químicos da água subterrânea nos poços de monitoramento do PET para os meses de junho (a) e outubro (b).

O tratamento estatístico dos resultados das amostras de água consistiu, inicialmente, na correlação entre os dados químicos e os parâmetros pH, Eh e CE. Os dados foram plotados na forma de matriz de correlações (Figura 27). Os parâmetros com valores abaixo do LD ( $\mathrm{Cr}$, Cu e Ni) estão apontados em quadros verdes na matriz, mas não apresentaram correlações.

Para as coletas de junho e outubro, dentre os cátions, constatou-se que $\mathrm{Al}, \mathrm{Ni}$ e $\mathrm{Zn}$ têm correlações positivas entre si. com o Al. Em outubro o $\mathrm{Ni}$ apresentou dentro do limite de detecção diferente do $\mathrm{Al}_{2} \mathrm{O}_{3}$ e $\mathrm{Zn}$; esse grupo de elementos tem correlação positiva com os ânions $\mathrm{NO}_{3}, \mathrm{Cl}^{-}, \mathrm{Br}^{-}$com Eh; e negativa com $\mathrm{SO}_{4}{ }^{2-}, \mathrm{PO}_{4}{ }^{2}$, $\mathrm{pH}, \mathrm{CE}$. 
Os íons $\mathrm{Ba}, \mathrm{Fe}_{2} \mathrm{O}_{3}, \mathrm{MgO}, \mathrm{MnO}$ e $\mathrm{Na}$ apresentam comportamento similar, e inverso ao apresentado pelo $\mathrm{Al}_{2} \mathrm{O}_{3} \cdot \mathrm{K}_{2} \mathrm{O}$ e $\mathrm{CaO}$ têm comportamento tal como o último grupo.

Dentre os parâmetros físico químicos, o pH apresenta correlações positivas com praticamente todos os cátions exceto $\mathrm{Al}, \mathrm{Ni}$ e $\mathrm{Zn}$, com todos os ânions, com CE negativa com Eh. A CE tem comportamento idêntico ao do pH. A elevação da CE está associada ao aumento das concentrações de sais dissolvidos, representados, principalmente, pelo aumento de concentração de $\mathrm{PO}_{4}{ }^{-2}, \mathrm{SO}_{4}{ }^{-2} ; \mathrm{Cl}^{-}, \mathrm{Ca}, \mathrm{Na}, \mathrm{Mg} . \mathrm{O}$ Eh, apresenta correlação positiva com $\mathrm{NO}_{3}^{-}, \mathrm{Cl}^{-}$e $\mathrm{Br}^{-}$e negativa com $\mathrm{SO}_{4}^{-2}$ e $\mathrm{PO}_{4}^{-2}$.

Para as coletas de outubro o $\mathrm{Al}$ e $\circ \mathrm{Zn}$ apresentaram comportamento semelhante ao observado para a coleta de junho. Os demais cátions, $\mathrm{Ba}, \mathrm{Ca}, \mathrm{Fe}, \mathrm{K}$, $\mathrm{Mg}, \mathrm{Mn}$ e $\mathrm{Na}$ apresentam todos comportamento idêntico, correlação positiva entre si, e negativa com o $\mathrm{Zn}$ e Al. Os parâmetros físico-químicos o ânion $\mathrm{NO}_{3}{ }^{-}$têm correlação positiva com Zn e Al e esses são adverso com pH e C.E. 


\section{JUNHO}

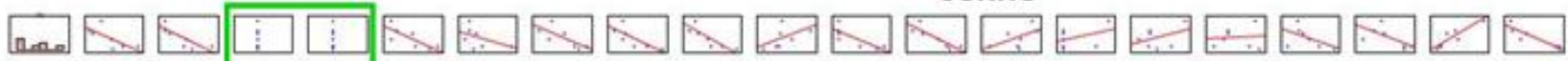
A and

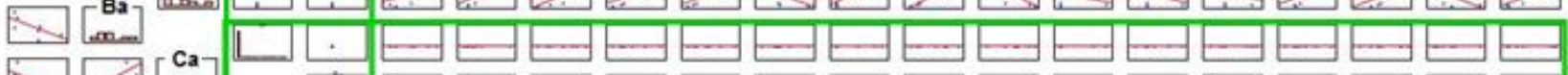

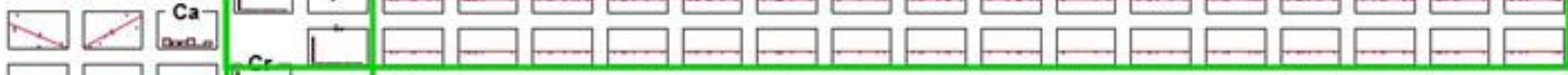

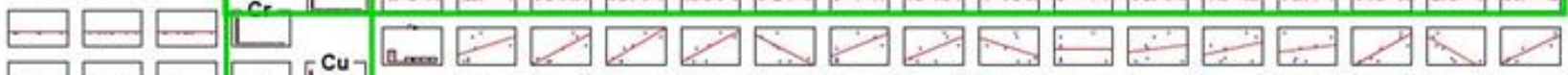

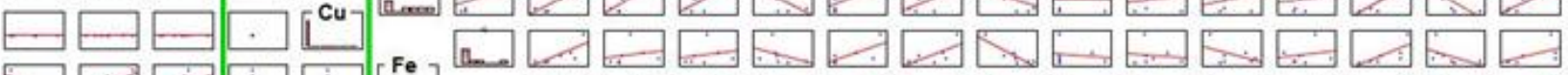

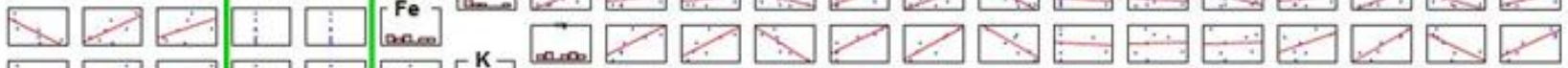
EDQ

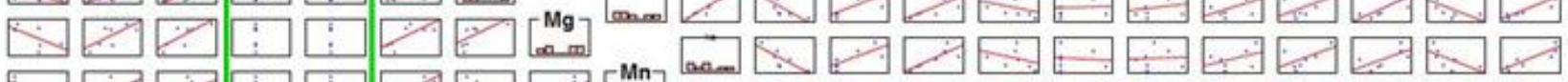

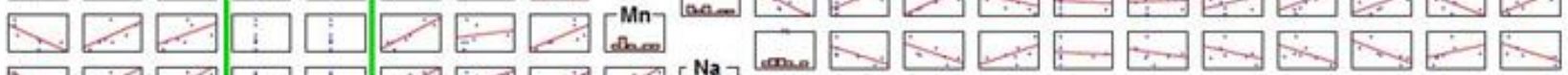

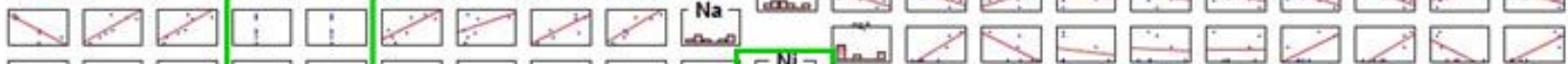
E曰E

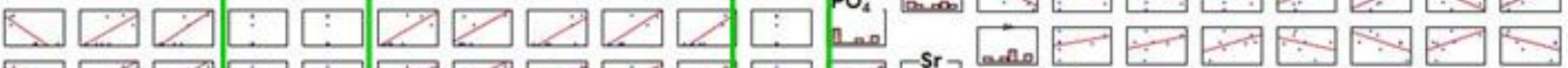

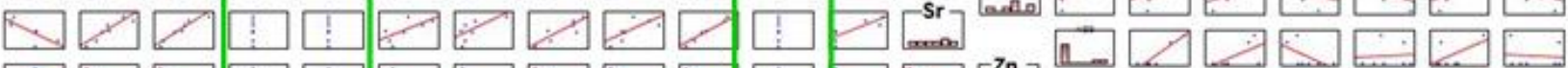

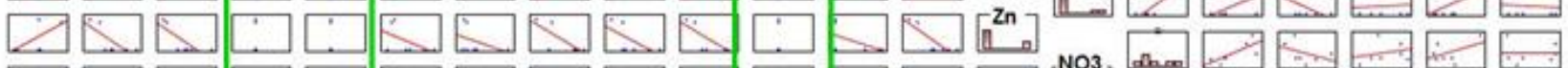

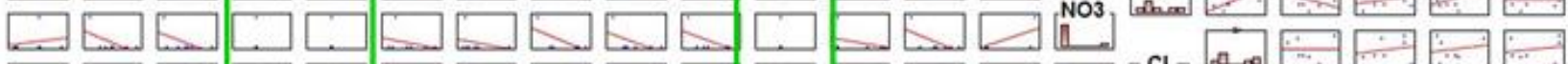

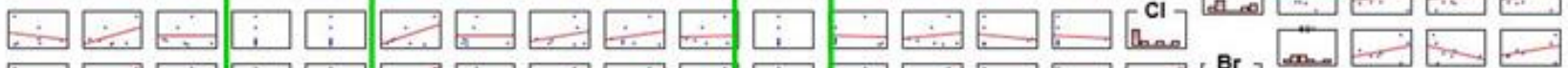

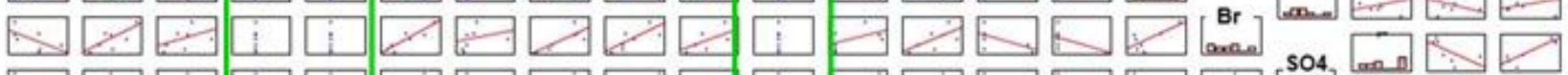

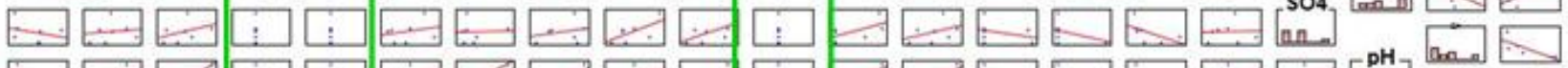

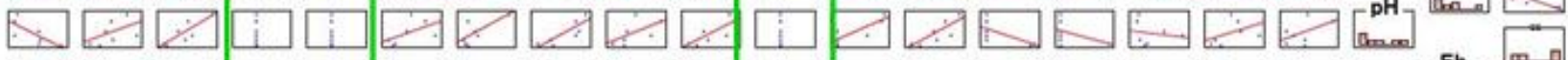

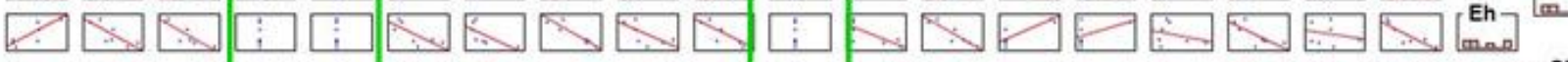

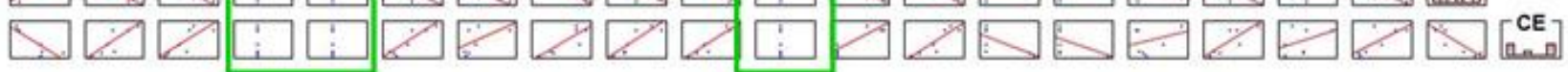

\section{OUTUBRO}

Figura 27 - Matriz de correlações entre os dados analisados para cátions e ânions e parâmetros pH, Eh e CE. Coletas de Junho e Outubro. 
A Tabela 3 indica os loadings e as comunalidades estimadas para cada variável em cada um dos fatores rotacionados, e os valores próprios e comunalidades para os dois fatores rotacionados. Os fatores rotacionados suportam $72 \%$ da variância total, o que nos indicou que o modelo escolhido é consistente.

Tabela 3 - Loadings e Comunalidades estimadas para cada variável em cada um dos fatores rotacionados (rotação Equamax) para água:

\begin{tabular}{|c|c|c|c|c|c|c|c|}
\hline \multirow[b]{2}{*}{ Variável } & \multicolumn{2}{|c|}{ Loadings } & \multicolumn{2}{|c|}{ Comunalidades } & \multicolumn{3}{|c|}{ Valores próprios e Comunalidades } \\
\hline & Fator 1 & Fator 2 & Fator 1 & Fator 2 & & Fator 1 & Fator 2 \\
\hline Al & $-0,90154$ & 0,069689 & 0,812768 & 0,817624 & \multirow{2}{*}{$\begin{array}{l}\text { Valores } \\
\text { Próprios }\end{array}$} & \multirow{2}{*}{11,09671} & \multirow{2}{*}{2,73802} \\
\hline $\mathrm{Ba}$ & 0,79348 & $-0,061951$ & 0,629618 & 0,633456 & & & \\
\hline $\mathrm{Ca}$ & 0,88978 & 0,051053 & 0,791707 & 0,794313 & \multirow{2}{*}{$\begin{array}{c}\text { \% Variância } \\
\text { Total }\end{array}$} & \multirow{2}{*}{58,40373} & \multirow{2}{*}{14,41061} \\
\hline $\mathrm{Fe}$ & 0,79946 & $-0,024012$ & 0,639138 & 0,639714 & & & \\
\hline K & 0,66152 & $-0,065079$ & 0,437615 & 0,441850 & \multirow{2}{*}{$\begin{array}{c}\text { Valores } \\
\text { próprios } \\
\text { Cumulativo }\end{array}$} & \multirow{2}{*}{11,09671} & \multirow{2}{*}{13,83472} \\
\hline $\mathbf{M g}$ & 0,90750 & $-0,100427$ & 0,823549 & 0,833635 & & & \\
\hline Mn & 0,84054 & 0,014910 & 0,706513 & 0,706735 & \multirow{2}{*}{$\begin{array}{c}\% \\
\text { Cumulativo }\end{array}$} & \multirow{2}{*}{58,40373} & \multirow{2}{*}{72,81434} \\
\hline $\mathrm{Na}$ & 0,92321 & 0,097057 & 0,852320 & 0,861740 & & & \\
\hline $\mathrm{Ni}$ & $-0,36836$ & 0,793167 & 0,135691 & 0,764804 & & & \\
\hline $\mathrm{PO}_{4}{ }^{3-}$ & 0,90730 & 0,000007 & 0,823201 & 0,823201 & & & \\
\hline $\mathrm{Sr}$ & 0,95202 & $-0,003766$ & 0,906343 & 0,906357 & & & \\
\hline $\mathrm{Zn}$ & $-0,72477$ & 0,395963 & 0,525295 & 0,682082 & & & \\
\hline NO3 & $-0,22949$ & 0,780094 & 0,052666 & 0,661212 & & & \\
\hline $\mathrm{Cl}$ & 0,13809 & $-0,698153$ & 0,019069 & 0,506488 & & & \\
\hline $\mathrm{Br}$ & 0,40477 & $-0,845707$ & 0,163838 & 0,879058 & & & \\
\hline $\mathrm{SO}_{4}$ & 0,47122 & 0,475163 & 0,222053 & 0,447833 & & & \\
\hline pH & $-0,90154$ & 0,069689 & 0,643124 & 0,780115 & & & \\
\hline Eh & 0,79348 & $-0,061951$ & 0,679499 & 0,722974 & & & \\
\hline CE & 0,88978 & 0,051053 & 0,931504 & 0,931533 & & & \\
\hline
\end{tabular}

A Figura 28 é a representação gráfica dos dados obtidos. Os comportamentos observados refletem aqueles identificados na matriz de correlações. Os cátions $\mathrm{Al}_{2} \mathrm{O}_{3}, \mathrm{Zn}$, Ni e o ânion $\mathrm{NO}_{3}^{-}$estão associados ao Eh, opondo-se aos demais parâmetros estudados. 


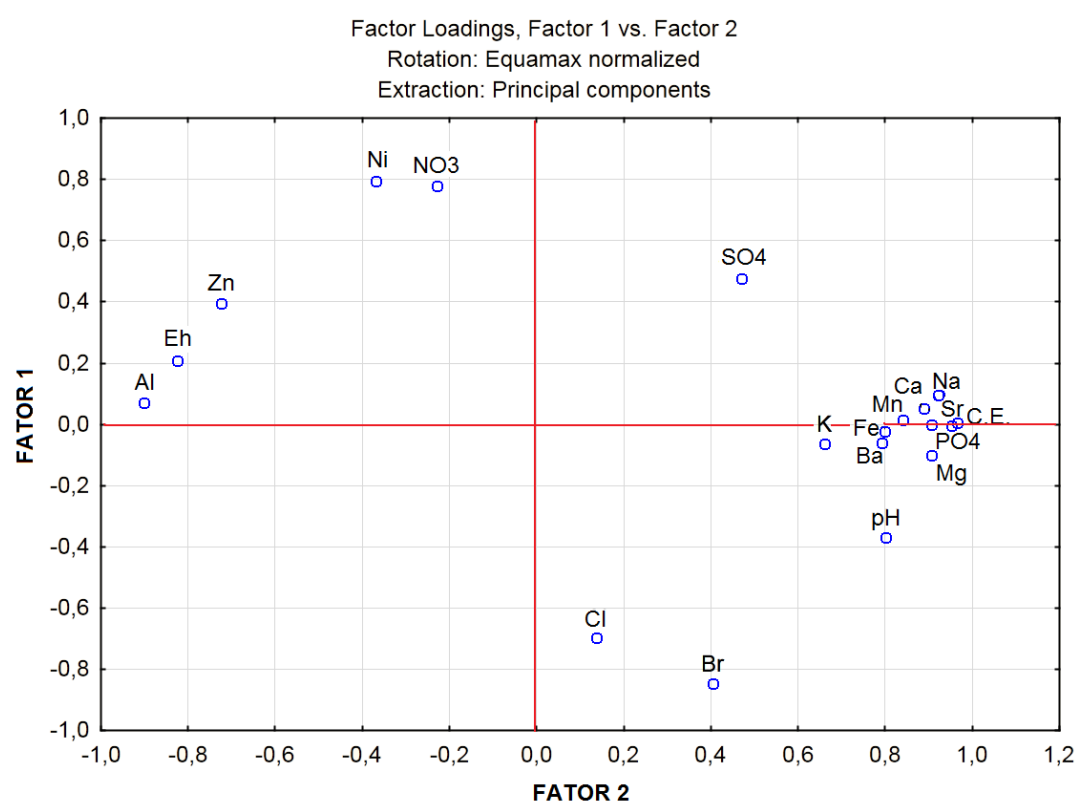

Figura 28 - Representação gráfica da análise para componentes principais para dois fatores rotacionados

\subsection{Amostras de Jerivá}

Para verificarmos a relação entre os elementos analisados nos órgãos da folha (nomofilo e pecíolo) e comparar com os períodos de coleta, foi efetuada uma análise por componentes principais entre os dados químicos nas duas campanhas (Figuras 29 e 30).

Optamos por agrupar os elementos em função da necessidade dos mesmos à planta. Assim, estabelecemos os seguintes grupos:

Grupo 1 - Macronutirentes: cálcio, magnésio, potássio e fósforo $(\mathrm{CaO}, \mathrm{MgO}$, $\left.\mathrm{K}_{2} \mathrm{O}, \mathrm{P}_{2} \mathrm{O}_{5}\right)$;

Grupo 2 - Micronutrientes (ou oligoelementos): dos principais oligoelementos, foram considerados aqueles dosados pelas técnicas utilizadas, ferro, manganês, cobre, zinco $\left(\mathrm{Fe}_{2} \mathrm{O}_{3}, \mathrm{MnO}, \mathrm{Cu}, \mathrm{Zn}\right)$;

Grupo 3 - Grupo dos elementos benéficos: silício, sódio, níquel e cobalto $\left(\mathrm{SiO}_{2}, \mathrm{Na}_{2} \mathrm{O}, \mathrm{Ni}, \mathrm{Co}\right)$;

Grupo 4 - Elementos presentes no solo e água: tais elementos foram dosados nos nomofilos e pecíolos, identificados no solo, na água subterrânea ou em 
ambos os compartimentos. Assim os elementos deste grupo são titânio, alumínio, bário, cromo, lantânio, escândio, estrôncio, vanádio, ítrio e zircônio.

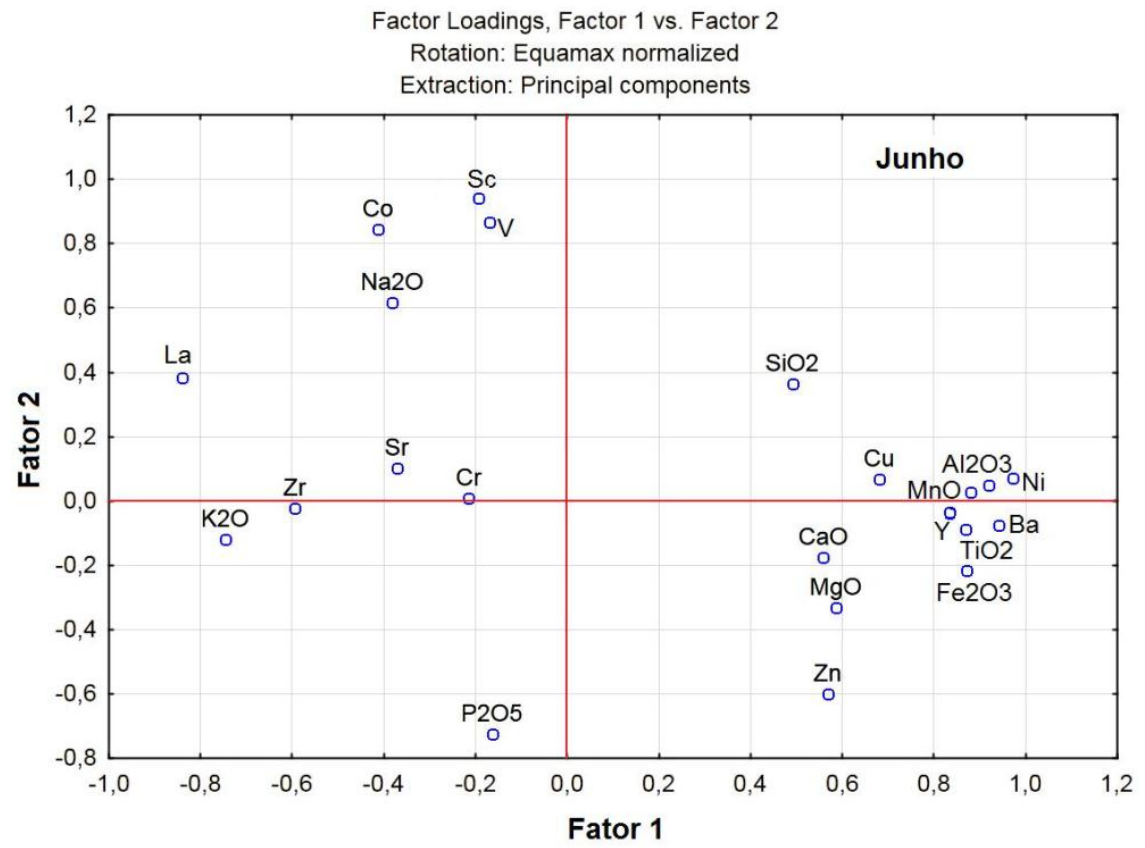

Figura 29 - Análise dos componentes principais dos elementos maiores e traços na espécie tipo para o mês de Junho.

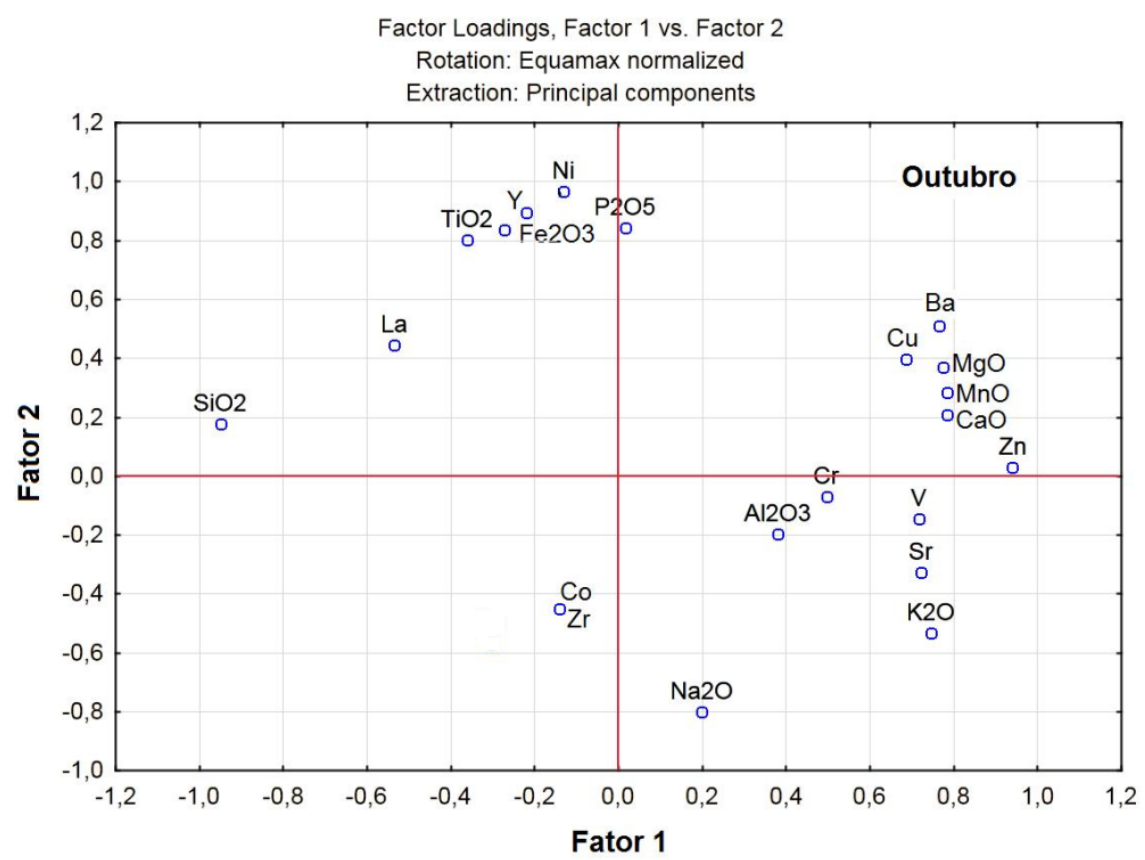

Figura 30 - Análise dos componentes principais dos elementos maiores e traços na espécie tipo para o mês de Outubro.

Verificou-se, para os elementos maiores, que, tanto em junho quanto em outubro, o potássio e o fósforo apresentam diferentes comportamento e são 
antagônicos a $\mathrm{MgO}$ e $\mathrm{CaO}$. A absorção de $\mathrm{CaO}$ e $\mathrm{MgO}$ pela planta ocorre de maneira similar, por interceptação radicular e fluxo de massa, o que explicaria o comportamento constante observado para esses elementos.

O fósforo tem sua absorção controlada pelo $\mathrm{pH}$ da solução de solo, e quanto menor for o pH maior será a sua absorção. De fato, ao observarmos os dados de pH da água Figura 25, identificou-se que no mês de junho o pH era mais baixo do que no mês de outubro, assim como os teores de $\mathrm{P}$ nos nomofilos e pecíolos foram mais elevados em junho do que em outubro.

O potássio é absorvido, principalmente, durante o estágio de crescimento vegetativo. A alta taxa de absorção do potássio pressupõe que existe uma forte competição, com a absorção de outros cátions, e as taxas de absorção deles são especialmente aumentadas, quando a absorção de potássio é baixa (Grimme, 1974). Na coleta de nomofilo e pecíolos em outubro optou-se pela retirada de folhas mais jovens em relação a primeira amostragem em junho. Outro aspecto da absorção de potássio é ter a sua retenção nas células das plantas competitivamente afetada por $\mathrm{H}^{+}, \mathrm{Ca}^{2+}, \mathrm{Mg}^{2+}$ e $\mathrm{Na}^{+}$(Elzam \& Hodges, 1967).

Dentre os oligoelementos, o $\mathrm{Fe}$ se contrapõe ao $\mathrm{Cu}, \mathrm{Zn}$ e $\mathrm{MnO}$. A absorção do Fe parece ocorrer por processo ativo e existem evidências de que este elemento inibe fortemente a absorção do zinco e vice-versa (Bowen, 1969). O Fe precisa ser reduzido antes de entrar nas células da planta (Chaney et al., 1972), e não é facilmente transportado nos tecidos. Por isso deficiências ocorrem em órgãos jovens das plantas. Tanto a absorção quanto o transporte deste elemento em plantas são fortemente afetados por $\mathrm{pH}$ e concentração de macronutrientes como cálcio e fosforo.

A interação entre zinco e fósforo tem sido bastante estudada e é bem conhecido o fato de que altos teores de $\mathrm{P}$ induzem a deficiência de zinco. Tal fato pode ser observado nos nomofilos e pecíolos: quando se tem alto teor de fosforo, o zinco está em concentrações mais baixa.

Em todos os trabalhos sobre absorção e distribuição de Mn nas plantas têm sido encontradas evidências de que sua absorção é controlada metabolicamente, aparentemente de uma forma similar ao que ocorre para outros íons como Mg e Ca. 
Isto explicaria em ambos os períodos de coleta a correlação positiva do $\mathrm{Mn}$ com $\mathrm{Ca}$ e Mg.

No meio natural, esses elementos precisam estar presente na forma iônica ou como quelato. De acordo com Romheld \& Marschner (1983), os quelatos de $\mathrm{Fe}^{3+}$ são reduzidos muito mais rapidamente do que o $\mathrm{FeCl}_{3}$. $\mathrm{A}$ velocidade de redução do ferro é maior em $\mathrm{pH}$ mais baixo.

Os elementos dos grupos 3 e 4 não apresentam correlações justificáveis, com comportamentos diversos nas duas amostragens, excetuando-se ítrio, que está correlacionado a Ti e Fe tanto em junho quanto em outubro.

Para uma análise biogeoquímica os resultados foram calculados os coeficientes de absorção biológica (CAB), coeficiente acropetal (CA) e o coeficiente de absorção temporal (CAT) (Tabela 7 e 8 do Anexo). Os resultados dos coeficientes de absorção estão apresentados nas Tabelas 9, 10 e 11 do Anexo.

O CAB foi calculado de acordo com a posição da palmeira jerivá em relação ao ponto de coleta de solo. Assim, cada indivíduo $\mathrm{J}_{\mathrm{n}}$, foi relacionado com a amostra de solo mais próxima $\left(F_{m}\right)$, considerando cada horizonte $\left(F_{m A}\right.$ e $\left.F_{m B}\right)$.

As análises de cada coeficiente estão resumidas nas Tabelas 5 e 6 a seguir. 
Tabela 4 - Interpretação do Coeficiente de Absorção Biológica (CAB).

\begin{tabular}{|c|c|}
\hline Grupo & Comportamento do CAB \\
\hline $\begin{array}{c}\text { Grupo } 1 \\
\mathrm{CaO}, \mathrm{MgO}, \mathrm{K}_{2} \mathrm{O}, \mathrm{P}_{2} \mathrm{O}_{5}\end{array}$ & $\begin{array}{l}\text { O CAB para os elementos deste grupo apresenta valores sempre acima da unidade, em ambos os horizontes } \\
\text { do solo ( } \mathrm{A} \text { e } \mathrm{B} \text { ) considerados para o cálculo deste coeficiente. Comparativamente, os pecíolos apresentam } \\
\text { valores menores do que os nomofilos. } \mathrm{CaO} \text { e } \mathrm{P}_{2} \mathrm{O}_{5} \text { destacam-se com os valores mais elevados, tanto nos } \\
\text { nomofilos, como nos pecíolos. } \\
\text { Em geral, entre os dois períodos de coleta, o } \mathrm{MgO} \text { e o } \mathrm{CaO} \text { não apresentam variaçães significativas; o } \mathrm{P}_{2} \mathrm{O}_{5} \text {, } \\
\text { no entanto, tem CAB reduzido de forma significativa. O MgO apresenta um aumento discreto, enquanto o } \mathrm{K}_{2} \mathrm{O} \\
\text { tem uma diminuição em relação ao horizonte } \mathrm{A} \text { e um aumento em relação ao horizonte B. }\end{array}$ \\
\hline $\begin{array}{c}\text { Grupo } 2 \\
\mathrm{Fe}_{2} \mathrm{O}_{3}, \mathrm{MnO}, \mathrm{Cu}, \mathrm{Zn}\end{array}$ & $\begin{array}{l}\mathrm{Zn} \text {, MnO e Cu apresentam } \mathrm{CAB} \text { acima da unidade nas folhas em ambos os períodos de coleta nos dois } \\
\text { horizontes. Esses elementos apresentam } \mathrm{CAB} \text { maior na folha em relação ao pecíolo. Para o } \mathrm{Zn} \text {, porém, o CAB } \\
\text { tem valores abaixo da unidade nos pecíolos, com diminuição no teor desse elemento de junho para outubro no } \\
\text { nomofilo, e o inverso ocorre nos pecíolos. Para } \mathrm{MnO} \text { e } \mathrm{Cu} \text {, o } \mathrm{CAB} \text { tem um aumento entre junho e outubro, em } \\
\text { ambos os horizontes tanto nos nomofilos quanto nos pecíolos. O } \mathrm{Fe}_{2} \mathrm{O}_{3} \text { se diferencia neste grupo por } \\
\text { apresentar CAB abaixo da unidade, tanto na primeira quanto na segunda coleta. }\end{array}$ \\
\hline $\begin{array}{c}\text { Grupo } 3 \\
\mathrm{SiO}_{2}, \mathrm{Na}_{2} \mathrm{O}, \mathrm{Ni}, \mathrm{Co}\end{array}$ & $\begin{array}{l}\text { O CAB para } \mathrm{SiO}_{2}, \mathrm{Na}_{2} \mathrm{O}, \mathrm{Ni} \text { e } \mathrm{Co} \text { apresenta comportamento alternativo. } \mathrm{SiO}_{2} \text { varia dentro da unidade, com } \\
\text { discreto aumento entre a coleta de junho e outubro. Co tem CAB abaixo da unidade, e entre as duas coletas } \\
\text { para o nomofilo e pecíolo há discreta diminuição. Ni apresenta pouca variação nos períodos de coleta, com } \\
\text { CAB maior nos nomofilos do que nos pecíolos. }\end{array}$ \\
\hline $\begin{array}{l}\text { Grupo } 4 \\
\mathrm{TiO}_{2}, \mathrm{Al}_{2} \mathrm{O}_{3}, \mathrm{Ba}, \mathrm{Cr}, \mathrm{La}, \mathrm{Sc}, \mathrm{Sr} \\
\text { V, Y, Zr. }\end{array}$ & $\begin{array}{l}\text { O CAB obtido para os elementos deste grupo estão muito próximo à unidade. } \mathrm{TiO}_{2}, \mathrm{Al}_{2} \mathrm{O}_{3}, \mathrm{La}, \mathrm{Sr}, \mathrm{Ba}, \mathrm{V} \text { e } \mathrm{Zr} \\
\text { não apresentam grandes variações entre os períodos de coleta e entre os horizontes de solo. } \mathrm{Sc} \text { e Y } \\
\text { apresentam CAB acima da unidade, variando muito pouco nos nomofilos entre os períodos de coleta e } \\
\text { horizonte, porém, o CAB tem variação significativa nos pecíolos entre os períodos de coleta. }\end{array}$ \\
\hline
\end{tabular}


Tabela 5 - Interpretação dos Coeficientes, Absorção Temporal (CAT) e Coeficiente Acropetal (CA).

\begin{tabular}{|c|c|}
\hline Grupo & Comportamento do CAT \\
\hline $\begin{array}{c}\text { Grupo } 1 \\
\mathrm{CaO}, \mathrm{MgO}, \mathrm{K}_{2} \mathrm{O}, \mathrm{P}_{2} \mathrm{O}_{5}\end{array}$ & $\begin{array}{l}\text { O CAT para os elementos desse grupo apresenta-se maior no nomofilo do que no pecíolo, sendo } \\
\text { exceção a J5, que apresenta comportamento inverso. }\end{array}$ \\
\hline $\begin{array}{c}\text { Grupo } 2 \\
\mathrm{Fe}_{2} \mathrm{O}_{3}, \mathrm{MnO}, \mathrm{Cu}, \mathrm{Zn}\end{array}$ & O CAT neste grupo de elementos tem comportamento similar aos elementos do Grupo 1. \\
\hline $\begin{array}{c}\text { Grupo } 3 \\
\mathrm{SiO}_{2}, \mathrm{Na}_{2} \mathrm{O}, \mathrm{Ni}, \mathrm{Co}\end{array}$ & $\begin{array}{l}\text { O CAT para o } \mathrm{SiO}_{2} \text { e } \mathrm{Na}_{2} \mathrm{O} \text { mostra que esses elementos apresentam-se em maior proporção na } \\
\text { nomofilo do que no pecíolo. No entanto, } \mathrm{Co} \text { e Ni têm comportamento inverso. }\end{array}$ \\
\hline $\begin{array}{c}\text { Grupo } 4 \\
\mathrm{TiO}_{2}, \mathrm{Al}_{2} \mathrm{O}_{3}, \mathrm{Ba}, \mathrm{Cr}, \mathrm{La}, \mathrm{Sc}, \mathrm{Sr} \\
\text { V, Y, Zr. }\end{array}$ & $\begin{array}{l}\text { O CAT nesse grupo não mostrou seguir um padrão de fixação no "pecíolo ou nomofilo", variando entre } \\
\text { as estações. }\end{array}$ \\
\hline Grupo & Comportamento do CA \\
\hline $\begin{array}{c}\text { Grupo } 1 \\
\mathrm{CaO}, \mathrm{MgO}, \mathrm{K}_{2} \mathrm{O}, \mathrm{P}_{2} \mathrm{O}_{5}\end{array}$ & $\begin{array}{l}\text { O CA para } \mathrm{CaO}, \mathrm{K}_{2} \mathrm{O} \text { e } \mathrm{MgO} \text { não apresenta variação nas estações estudadas, sendo mais elevados no } \\
\text { nomofilo. O } \mathrm{P}_{2} \mathrm{O}_{5} \text { teve variação entre as campanhas apenas para } \mathrm{J} 2 \mathrm{e} J 3 \text {. }\end{array}$ \\
\hline $\begin{array}{c}\text { Grupo } 2 \\
\mathrm{Fe}_{2} \mathrm{O}_{3}, \mathrm{MnO}, \mathrm{Cu}, \mathrm{Zn}\end{array}$ & $\begin{array}{l}\text { A CA para } \mathrm{MnO} \mathrm{Fe}_{2} \mathrm{O}_{3} \text { e } \mathrm{Cu} \text { aumentou entre junho e outubro, no nomofilo e no pecíolo. O Zn diminuiu } \\
\text { para todas as espécies vegetais menos na } \mathrm{J} 2 \text {. }\end{array}$ \\
\hline $\begin{array}{c}\text { Grupo } 3 \\
\mathrm{SiO}_{2}, \mathrm{Na}_{2} \mathrm{O}, \mathrm{Ni}, \mathrm{Co}\end{array}$ & $\begin{array}{l}\text { O CA de } \mathrm{SiO}_{2} \text {, } \mathrm{Co} \text { e } \mathrm{Na}_{2} \mathrm{O} \text { aumentou em outubro tanto para os pecíolos quanto para os nomofilos; } \\
\text { sendo o } \mathrm{Co} \text { maior no pecíolo e o Ni maior no nomofilo diminuindo em outubro em relação a junho. }\end{array}$ \\
\hline $\begin{array}{c}\text { Grupo } 4 \\
\mathrm{TiO}_{2}, \mathrm{Al}_{2} \mathrm{O}_{3}, \mathrm{Ba}, \mathrm{Cr}, \mathrm{La}, \mathrm{Sc}, \mathrm{Sr} \\
\mathrm{V}, \mathrm{Y}, \mathrm{Zr}\end{array}$ & $\begin{array}{l}\mathrm{O} C \mathrm{CA} \text { de } \mathrm{Al}_{2} \mathrm{O}_{3} \text { e } \mathrm{TiO}_{2} \text { é maior no pecíolo, porém diminuindo no nomofilo entre as campanhas. Para Ba, } \\
\mathrm{Cr}, \mathrm{La} \text {, Sc, } \mathrm{Sr} \text {, } \mathrm{V}, \mathrm{Y} \text { e } \mathrm{Zr} \text { tem comportamento variável em função da amostra; porém, em geral, } \mathrm{Ba} \text { e Y } \\
\text { têm CA maior no nomofilo, enquanto La, Sr, } \mathrm{V} \text { e Zr têm maior concentração no pecíolo. }\end{array}$ \\
\hline
\end{tabular}


Os dados obtidos para o CAT foram plotados em gráficos, facilitando a visualização da variação temporal do coeficiente em função da espécie-tipo (Figura $31)$.

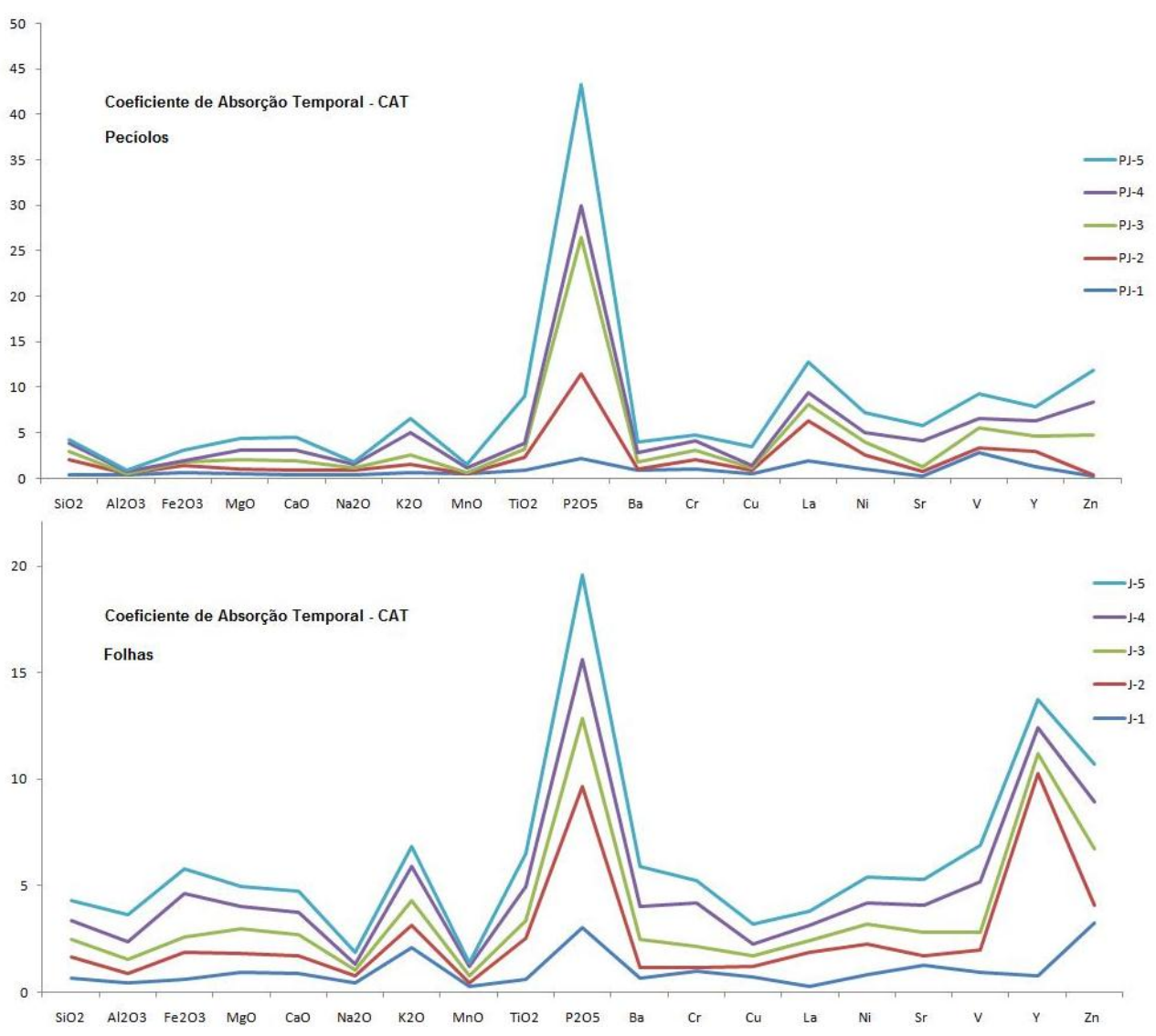

Figura 31 - Gráficos do coeficiente temporal para os nomofilos e pecíolos.

O que podemos verificar é que a jerivá $\mathrm{J} 5$ tem maior absorção de todos os elementos analisados e a $\mathrm{J} 1$ os menores. Cabe ressaltar, que a palmeira J1 não sofreu lavagem para ser encaminhada para análise e tal procedimento não indicou influência de contaminantes atmosféricos provenientes da rodovia Ayrton Senna, distante do local aproximadamente 50 metros.

O CAB da palmeira J5 foi correlacionado com o furo para coleta de solo F3. Neste furo, aos $45 \mathrm{~cm}$ (correspondente ao horizonte B), encontramos um volume significativo de resíduos sólidos, que nos impossibilitou de continuarmos a coleta. Assim, podemos inferir que a palmeira Jerivá nesse estudo não sofreu influência da 
atmosfera e que a oferta de elementos do solo e o principal aporte de nutrição para a jerivá.

O CA foi plotado em gráficos para os meses de junho e outubro tanto para o nomofilo quanto para o pecíolo (Figura 32).

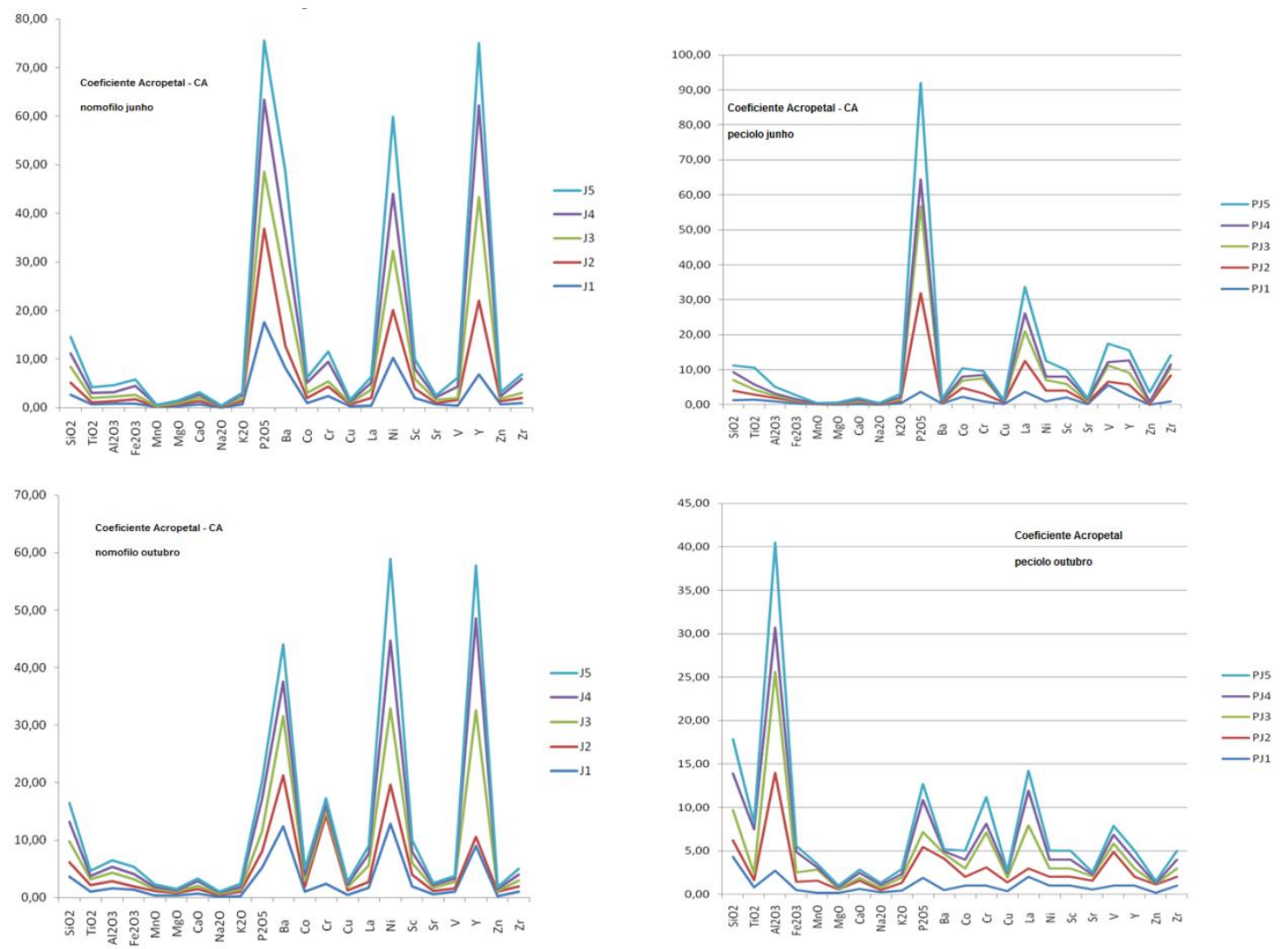

Figura 32 - Gráficos Coeficiente Acropetal do nomofilo e pecíolo para os meses de junho e outubro

O CA nos monofilos não apresentaram comportamento diferenciado entre os dois períodos de coleta, observando-se um mesmo padrão de absorção. Embora na segunda campanha de coleta tenhamos optado por indivíduos mais jovens, esse procedimento não alterou o comportamento de absorção desse coeficiente.

Os pecíolos tiveram uma variação na absorção desse coeficiente, sendo que os indivíduos relacionados ao mês de junho apresentaram maior concentração de elementos, indicando que o tempo de exposição é um fator importante no que se refere a bioassimilação. 


\section{CONCLUSÃo}

A utilização dos coeficientes tem grande significância na interpretação para prospecção biogeoquímica. De fato, enquanto a magnitude de cada parâmetro tem pequena significância para a prospecção mineral de campo, é a variância do mesmo que pode ter um efeito adverso no método biogeoquímico (Brooks, 2000).

Os parâmetros biogeoquímicos aplicados neste trabalho foram adotados como forma de explorar as possibilidades de sua utilização em avaliações ambientais de áreas com histórico de uso e ocupação que envolve deposição de resíduos contaminantes. A comparação entre o coeficiente biogeoquímico das plantas e os dados geoquímicos obtidos para solo e água estabelecemos uma correlação de controle e monitoramento, de etapas que fazem parte do complexo processo de fitorremediação.

A espécie-tipo considerada, a palmeira jerivá (Syagrus romanzoffiana) não tem, na literatura científica, estudo específico sobre o tema. Por apresentar fácil adaptação em ambiente tropical, servir de espécie atrativa para readaptação de fauna, e ter ampla utilização em projetos de paisagismo, torna-se uma espécie que identificamos com potencial para aplicação no estudo presente.

Quando realizamos levantamentos de referências bibliográficas sobre o tema buscamos na literatura estudos que indicassem elementos da flora que pudessem nortear o trabalho. As referências, além de escassas, apresentam somente correlação com áreas de mineração. Os estudos focados na fitorremediação de áreas ainda são incipientes e não se aprofundaram em levantar espécies da flora brasileira com esse potencial.

Plantas hiperacumuladoras de metais têm foco atualmente em diversos estudos e alguns autores, como Brooks (2000), destacam a importância de um herbário, na forma de um índex de espécies, para prover informações importantes sobre as espécies; como sua distribuição espacial no âmbito mundial, substratos relacionados e características de bioassimilação. Assim, além de informações sobre a taxonomia vegetal, seriam identificadas também espécies hiperacumuladoras para cada e metal e situação específica, tal como proposto para o níquel e espécies de 
plantas que se adaptaram a ambientes de alta concentração desse metal (Brooks, 1983; 2000).

Os coeficientes de absorção biológica (CAB) para os elementos essenciais da planta ou macronutriente $(\mathrm{Ca}, \mathrm{Mg}, \mathrm{K}, \mathrm{P})$ e para os micronutriente ou oligoelementos $(\mathrm{Fe}, \mathrm{Mn}, \mathrm{Cu}, \mathrm{Zn}$ ) resultaram em coeficientes com valores acima da unidade.

Os valores de $C A B$ podem variar em magnitude entre $0,0001-10$, mas podem ocorrer valores acima deste intervalo. Plantas hiperacumuladoras de $\mathrm{Ni}$ são descritas na literatura por Brooks 1983 com valores de BAC igual a 25 (Brooks, 1983; 2000) e de Se cerca de 130 descrito por Cannon (1964) apud (Brooks, 1983; $\left.2000^{3}\right)$.

Utilizamos a Classificação de Perel'man, de 1966 (Brooks, 1983) para indicar a absorção do CAB dos elementos dosados e a sequência indicada mostra os elementos com absorção intermediária (verde), absorção fraca (vermelho) e muito fraca (azul):

\section{$\mathrm{Zn}>\mathrm{P}>\mathrm{Mn}>\mathrm{Ca}>\mathrm{Sr}>\mathrm{Cu}>\mathrm{K}>\mathrm{Ba}>\mathrm{Mg}>\mathrm{Ni}>\mathrm{Co}>\mathrm{Fe}>\mathrm{Na}>\mathrm{ETR}>\mathrm{Cr}>\mathrm{Si}>\mathrm{V}>\mathrm{Ti}>\mathrm{Al}$}

Notou-se que há uma variação do $\mathrm{CAB}$ entre as dosagens realizadas no nomofilo e o pecíolo. Para os macro e micronutrientes, que apresentam absorção intermediária a fraca.

$\mathrm{O} \mathrm{Mg}$ e Ca não variaram entre os dois períodos de coleta, mas o $\mathrm{P}$ teve um decréscimo acentuado em Outubro. A mobilidade do fósforo é baixa em todo o tipo de condições: oxidação, redução, em ambientes ácido, neutro e alcalino. No entanto, o íon fosfato é muito móvel (Reimann \& Caritat, 1998), o que explicaria o decréscimo de $\mathrm{P}$ devido a uma maior precipitação em Outubro (estação chuvosa).

Os elementos $\mathrm{Fe}, \mathrm{Mn}$, Cu e $\mathrm{Zn}$ tiveram comportamento variável neste grupo, com CAB mais elevado nas folhas em relação aos pecíolos. Entre os períodos de coleta, o $\mathrm{Zn}$ tem diminuição do $\mathrm{CAB}$ nas folhas e aumento nos pecíolos; o $\mathrm{Mn}$ e $\mathrm{Cu}$ têm aumento desses coeficientes entre os dois períodos de coleta, tanto em folhas quanto pecíolos. A mobilidade do zinco é elevada sob condições de oxidação em meio ácido, e muito baixa em ambiente neutro a alcalino e redutor. A água coletada no mês de Junho (estação seca) apresentou condições mais redutoras em relação à

\footnotetext{
${ }^{3}$ Cannon, H.L., 1964, V.S. Geol. Surv. Bull., 1176, 127pp.
} 
coleta de Outubro (estação chuvosa), o que explicaria o comportamento do CAB para o Zn.

O solo não homogêneo na área explicaria porque alguns jerivás concentram mais $\mathrm{Zn}$ e outras não, pois, formas solúveis de zinco são prontamente absorvidas, e encontra-se na literatura uma correlação linear entre absorção pelas plantas e concentração do nutriente no substrato (Brooks, 2000).

Para o Fe o $\mathrm{CAB}$ apresentou valores abaixo da unidade e é possível correlacionar esse comportamento à mobilidade do ferro, muito baixa sob condições de oxidação, e baixa em ambiente ácido, neutro a alcalino e redutor. Para ocorrer a absorção do Fe pela planta, o metal deveria estar disponível nas soluções do solo, e a disponibilidade do Fe nos solos depende do $\mathrm{pH}$, do teor em fosfatos e do teor de outros metais (Reimann \& Caritat, 1998).

Deve-se considerar, também, que Fe tem como principais barreiras geoquímicas a oxidação e o aumento de $\mathrm{pH}$, que preferencialmente promovem a precipitação do metal sob a forma de óxidos, hidróxidos ou oxihidróxidos de ferro (Reimann \& Caritat, 1998).

Existe uma relação entre o $\mathrm{CAB}$ e $\mathrm{o}$ fato do elemento ser ou não um elemento essencial à nutrição da planta. Timperley et al.1970 (Brooks, 2000) concluíram que, em geral, as plantas não apresentam um CAB constante para elementos essenciais, tais como cobre e zinco. Em contraste, elementos não essenciais tendem a produzir valores relativamente constantes de $\mathrm{CAB}$ em determinadas espécies.

Os elementos benéficos (grupo 3 ) e os elementos que podem ser associados ao solo ou à descarte pretérito de resíduos na área, mostraram comportamento variável para o CAB. Ressaltamos, que para os elementos do grupo 4 , uma maior absorção nos pecíolos em relação as folhas entre os períodos de coleta podem ser indicativos de comportamento padrão, porém, necessitaríamos estabelecer outros períodos de coleta para verificar tal comportamento.

O coeficiente temporal (CAT) e o coeficiente acropetal (CA) tem grande significância para a prospecção biogeoquímica, pois indicam a escolha correta do tipo de amostra biológica.

Para o CAT devemos considerar se as variações ocorrem entre períodos longos ou curtos. Em períodos de coleta de curto tempo, consideramos uma 
acumulação gradual ou uma diminuição na concentração do elemento nas folhas. Essa variação ocorre, em geral, em períodos que variam entre 6 meses a um ano. De fato, em função do tempo de coleta, devemos focar a amostragem em determinados órgãos da planta, pois o metabolismo vegetal varia em função do órgão coletado para amostragem (Brooks, 1993; 2000).

O CAT será um indicador mais eficiente se tivermos claramente definidos quais órgãos da planta terão uma melhor absorção do elemento.

Uma observação interessante nos resultados obtidos para esse coeficiente é a interação entre $\mathrm{Zn}$ e $\mathrm{P}$, pois, é muito conhecido o fato de que altos teores de fósforo induzem a deficiência de zinco. Esse comportamento geoquímico explicaria o CAT do jerivá J5, que apresenta os menores valores para $\mathrm{Zn}$ e os maiores para $\mathrm{P}$, em ambos os períodos de coleta, tanto em folhas quanto pecíolos. Essa planta foi correlacionada a amostra de solo do furo F3, no qual a presença abundante de resíduos antrópicos.

O Coeficiente Acropetal (CA) pode variar ou manter-se constante Brooks (2000) utilizou esse coeficiente em vários campos de estudo e verificou que se mantinha relativamente constante. $\mathrm{O}$ autor sugere que esse comportamento é em função do estudo que realizou, por só utilizar plantas não decíduas, ou seja, plantas que apresentam folhagem em todas as estações, ao invés de optar por plantas que perdem suas folhas sazonalmente.

De fato, é recomendado que sejam utilizadas folhas que tenham pelo menos entre 2 a 3 anos de idades, o que nos remete a optar por espécies perenes.

A absorção de certos elementos traços pelos órgãos de uma planta depende da estrutura e função fisiológica de suas células. Kovalevsky em 1969 (Brooks, 2000) discute o CA e enfatiza que folhas não devem nunca ser utilizadas em prospecção biogeoquímica, porque um limite de absorção é facilmente atingido para um dado elemento. $\mathrm{O}$ autor recomenda utilizarmos galhos que tenham idade mínima de 2 a 3 anos.

Os resultados que obtivemos em nossas coletas refletem a escolha do órgão da planta para o estabelecimento desse coeficiente, pois, as folhas apresentaram comportamento constante no tempo, enquanto os pecíolos indicaram uma variação. 
Apesar da área de estudo, ter um histórico de uso e ocupação por atividades que normalmente impõem certo grau de degradação, parece que não houve influência destas atividades, mesmo se encontrando material de origem antrópica em subsuperfície (furo F3), não se evidenciou influência na água. Do ponto de vista ambiental sendo então uma área poluída e não contaminada.

Identificamos que a sazonalidade é um fator importante no levantamento de dados químicos, que afetam todos os componentes estudados (solo, água, planta). Dentre os coeficientes da prospecção biogeoquímica aplicados neste trabalho, um intervalo mais amplo de amostragem permitiria, possivelmente, estabelecer de forma mais evidentes a relação planta/água.

Por força do tempo imposto à execução da dissertação, ficamos restritos a duas amostragens em período de um ano. O que, concluímos período mínimo para estabelecer as relações iniciais. 


\section{REFERÊNCIAS BIBLIOGRÁFICAS}

AGUIAR, M. R. M. P.; NOVAES, A. C.; GUARINO, A. W. S. 2002. Remoção de metais pesados de efluentes industriais por aluminossilicatos. Química Nova, São Paulo, v. 25, n. 6B, p. 1145-1154.

ANDRADE, M. G.; MELO, V. F.; GABARDO, J.; SOUZA, L. C. P.; REISSMANN, C. B. 2009. Metais pesados em solos de área de mineração e metalurgia de chumbo. I - Fitoextração. Revista Brasileira Ciência do Solo, Viçosa, v. 33, n. 6, p. 1879-1888.

ARAÚJO, J. B. S.; PINTO, J. L. O. F. 2010. Identificação de fontes poluidoras de metais pesados nos solos da bacia hidrográfica do rio Apodi - Mossoró/RN, na área urbana de Mossoró-RN. Revista Verde de Agroecologia e Desenvolvimento Sustentável, Mossoró-RN, v. 5, n. 2, p. 80-94.

ASSOCIAÇÃO BRASILEIRA DE NORMAS TECNICAS - ABNT. Disponível em: $<$ http://www.abntcatalogo.com.br/norma $>$. Acesso em: 05/10/2009.

ASSOCIAÇÃO BRASILEIRA DE NORMAS TECNICAS - ABNT/NBR 154951:2007. Versão Corrigida 2: 2009 . Disponível em: $<$ http://www.abntcatalogo.com.br/norma.aspx?ID=40214 >. Acesso em: 22 fev. 2011.

BEGNINI. R.M. 2008. O.Jerivá - Syagrus romanzoffiana (Cham.) Glassman (Arecaceae) - fenologia e interações com a fauna no Parque Municipal da Lagoa do Peri. Trabalho de conclusão de curso, Florianópolis, p.103.

BERNACCI, L. C.; MARTINS, F. R.; SANTOS, F. A. M. 2008. Estrutura de estádios ontogenéticos em população nativa de palmeira Syagrus romansoffiana (Cham.). Glassman (Arecaceae). Acta Botanica Brasilica, São Paulo, v. 22, n.1, p.119-130.

BERTONCINI, E. I.; MATTIAZZO, M. E. 1999. Lixiviação de metais pesados em solos tratados com lodo de esgoto. Revista Brasileira Ciência do Solo, Viçosa, v. 23, p. $737-744$.

BOWEN, J. E. 1969. Absorption of copper, zinc and manganese by sugarcane leaf tissues. Plant Physiol, v. 44, pp. 245 -261.

BROOKS. R.R. 1983. Biological Methods of Prospecting for minerals, New York: Wiley, $322 \mathrm{p}$.

BROOKS. R.R. 2000. Plants that hyperaccumulate heavy metals: their role in phytoremediation, microbiology, archaeology, mineral exploration and phytomining. Oxford: CAB International; ill., maps. Edited by Robert R. Brooks New York, $380 \mathrm{p}$. 
CARNEIRO, M. A. C.; SIQUEIRA, J. O.; MOREIRA, F. M. S. 2002. Comportamento de espécies herbáceas em misturas de solo com diferentes graus de contaminação com metais pesados. Pesquisa Agropecuária Brasileira, Brasília, v. 37, n. 11, p. 1629-1638.

CARVALHO, L. A 2003. Condutividade hidráulica do solo no campo: as simplificações do método do perfil instantâneo. Dissertação de Mestrado, Escola Superior de Agricultura "Luiz de Queiroz", Piracicaba, 89 p.

CESTESB. 2001 Manual de gerenciamento de áreas contaminadas. CETESB, GTZ. 2ed. São Paulo.

CETESB Companhia de Tecnologia de Saneamento Ambiental (2009). Solo. www.cetesb.sp.gov.br. Consultado em outubro de 2009.

CHANEY, R.L.; BROWN, J.C.; TIFFIN. 2009. Obligatory reduction of ferric chelates in iron uptake by soybeans Plant Physiol. Colorado, v 50, p. $208-213$.

CHANEY, J.C.; BROWN TIFFIN, L. O. 1972. Obligatory reduction of ferric chelates in iron uptake by soybeans. Pant Physiol, v. 50 pp. $208-213$.

COUTINHO, H. D.; BARBOSA, A. R. 2007. Fitorremediação: considerações gerais e características de utilização. Silva Lusitana: Lisboa, v. 15, n. 1, p. 103117.

DAVIDSON, C. M.; THOMAS, R. P.; MCVEY, S. E.; PERALA, R.; LITTLEJOHN, D.; URE, M. A.; 1994. Evaluation of a sequential extraction procedure for the speciation of heavy metals in sediments. Analytica Chimica Acta, Amsterdam, v. 291, n. 3, p. 277-286.

DOS ANJOS, A. R.; MATTIAZZO, M. E. 2001. Extratores para Cd, $\mathrm{Cu}, \mathrm{Cr}, \mathrm{Mn}$, $\mathrm{Ni}, \mathrm{Pb}$ e $\mathrm{Zn}$ em Latossolos tratados com bossólidos e cultivados com milho. Scientia Agricola, Piracicaba, v. 58, n. 2, p. 337-344.

ELZAM. O. E; HODGES. T. K. 1967. Plant Physiol. v.42: p. 1483 - 1488.

FAQUIM, V. 2005. Nutrição mineral de plantas; Curso de Pós Graduação Lato Sensu (Especialização a Distancia: Solos e Meio Ambiente) - Universidade Federal de Lavras, Lavras. $186 \mathrm{p}$.

FEACHEM, R.; CAIRNCROSS, S. 1993. Environmental Health Enginnering in the Tropics. 2 nd ed. New York: John Wiley \& Sond, 306 p.

FERRARI, L. C. K. M. 2006. Modelagem tridimensional de fluxo de águas subterrâneas em um aqüifero livre e raso: aplicação no Parque Ecológico do Tietê - Tese Doutorado - Instituto de Geociências, Universidade de São Paulo, São Paulo, 206 p.. 
FERRAZ, A. V.; 2009. Ciclagem de nutrientes e metais pesados em plantas de Eucalyptus grandis adubados com lodos de esgoto produzidos em diferentes estações de tratamento da região metropolitana de São Paulo. Dissertação de Mestrado, Escola Superior de Agricultura "Luiz de Queiroz", Universidade de São Paulo, Piracicaba, 120 p.

GIOMBINI.M.; BRAVO.S.P.; MARTINEZ.M.F. 2009. Seed Dispersal of the Syagrus romanzoffiana by Tapirs in the Semi-deciduous Atlantic Forest of Argentina. Biotropica, v.41 n.4, p. 408-413.

GOLDEN SOFTWARE. Icn. Surfer version 8. Golden Inc. Software: Colorado. 2002, October.

GONÇALVES, K. D.; GOMIDE FILHO, N. O.; SILVEIRA, P. C. M.; INCHAUSPE, R. C. L.; SOUZA, W. R. 2009. Tratamentos de esgotos pluviais mistos através da fitorremediação em sistema de drenagem na estação de bombeamento do sistema de proteção contra as cheias de Porto Alegre, Casa de bombas $n^{\circ} 12$. Parque Marinha do Brasil. Porto Alegre: Centro Universitário Leonardo da Vinci, $55 \mathrm{p}$.

GRIMME, H. 1974. Potassium release in relation to crop production. Proc 10 th. Int. Colloquium, Potash Institute, Bern, Switzerland, pp. 131 - 136.

HENRIQUES, A. R. 2005. O uso do sphagnum no biomonitoramento da poluição aérea por cádmio. Monografia ( Bacharel em ciências biológicas ) Universidade Federal de Pelotas, Pelotas, p. 79.

IMBERNON.R. A. L. 1993. Evolução geoquímica e mineralógica dos produtos de alteração sobre as rochas do complexo alcalino-carbonatítico de Catalão. Disertação de Mestrado, Universidade de São Paulo, São Paulo, 132 p.

JIMENEZ, R. S.; BOSCO, S. M. D.; CARVALHO, W. A. 2004. Remoção de metais pesados de efluentes aquosos pela zeólita natural escolecita - influência da temperatura e do $\mathrm{pH}$ na adsorção em sistemas monoelementares. Química Nova, São Paulo, v. 27, n. 5, p. 34-738.

KABATA-PENDIAS, A.; PENDIAS, H. 2001. Trace Elements in Soils and plant. 3rd. ed. Florida: CRC Press, $432 \mathrm{p}$.

KÖPPEN, W. P. 1948. Climatologia: con un estudio de los climas de la Tierra. Version directa de Pedro R. Hendrichs Perez. Mexico: Fondo de Cultura Economica, p. 478.

LARIZZATTI. J. H. 2002. Ouro e elementos indicadores, regolito do garimpo Fazenda Pison: processos de dispersão e implicações para prospecção. Tese de Doutorado, Universidade de São Paulo, 224 p..

LIMA e CUNHA, M. C.; LIGHT, O. A. B.; MELLO, C. S. B.; SILVA, C. R. 2007. Métodos biológicos de prospecção mineral. In: Prospecção Geoquímica Deposito Metálicos, não Metálicos, Óleo e Gás. Imprinta Express Gráfica e Editora, Rio de Janeiro, p. 333 - 344. 
LIMA e CUNHA, M. C.; PEREIRA, V. P.; MENEGOTTO, E.; BASTOS NETO, A. C.; OLIVEIRA, L. D.; FORMOSO, M. L. L. 2008. Biogeochemical behavior of Ampeloziyphus amazonicus Ducke in the Pitinga mining district, Amazon, Brazil. Environmental Geology, New York, v. 55, n. 6, p. 1355-1362.

LOPES, D. 2010. Plantas nativas do cerrado, uma alternativa para fitorremediação. Estudos, Goiânia, v. 37, n. 3/4, 437 p.

LORENZI, H.; SOUZA, H.M.; CERQUEIRA, L.S.C.; COSTA, J.T.M.; FERREIRA, E. 2004. Palmeiras brasileiras e exóticas cultivadas. Nova Odessa: Plantarum, $432 \mathrm{p}$.

MALAVOLTA. E. 1980. Elementos de nutrição mineral de plantas. Editora Agronômica Ceres, São Paulo, p 251.

MAPA DO PARQUE ECOLÓGICO DO TIETÊ E ARREDORES. Disponível em: $<$ www.googleearth.com.br >. Acesso em: 23 fev. 2010.

MARQUES, M.; AGUIAR, C. R. C.; SILVA, J. J. L. S. 2011. Desafios técnicos e barreiras sociais, econômicas e regulatórias na fitorremediação de solos contaminados. Revista Brasileira de Ciência do Solo, Viçosa, v. 35, n. 1, p. 111.

McGRATH, J. M.; JANCSO, M. M.; PICHERSKY, E. 1993. Duplicate sequences with a similarity to expressed genes in the genome of Arabidopsis thaliana. Theor, Washington. v. 86, p. 880-888.

MICROSOFT 2008. Microsoft Office Excel, parte do Microsoft Office Professional Plus 2007- 1 CD-RO, Redmond, Washington.

MONDIM, M. 2005. Avaliação e quantificação do processo de recarga do aqüífero livre e raso no Parque Ecológico do Tietê. Dissertação de Mestrado Universidade de São Paulo, São Paulo, 115 p.

MORENO, F. N.; CHRIS, W. N.; ANDERSON, C. W. N.; BRETT, H.; ROBINSON, B. H.; MEECH, J. A.; SÍGOLO, J. B. 2008. Eco-gold gerando retorno econômico na remediação de passivos ambientais por meio da fitoextração. In: MOERI, E.; RODRIGUES, D.; ANDREAS, N. (Org.). Áreas contaminadas: remediação e revitalização. São Paulo: Instituto Ekos; Editora Signus, v. 1, p. 79-83.

MORENO, F. N.; SIGOLO, J. B. 2007. Fitoestabilização controlada: proposta de processo de revitalização para passivos de areias de fundição. In: MOERI, E.; COELHO, R.; MARKER, A. (Org.). Remediação e Revitalização de áreas contaminadas: aspectos técnicos, legais e financeiros. São Paulo: Editora Signus, v. 1, p. 115-126.

PAOLIELLO, M. M. B.; De CAPITANI, E. M. 2003. Chumbo. In: AZEVEDO, F. A.; CHASIN, A. A. M. (Ed.). Metais - Gerenciamento da Toxicidade. São Paulo: Atheneu, $554 \mathrm{p}$. 
PAVANELLI, L. C.; PIRES, M, A. F; SILVA, C. S. 2004. Avaliação preliminar da contaminação no solo por metais $\mathrm{Cd}, \mathrm{Pb}$, $\mathrm{Ni}$ e $\mathrm{Mn} \mathrm{Np}$ pólo industrial de fundição em Loanda. Química Nova, Paraná, p. 113-122.

PEREIRA, A. J. 2002. Contaminação por metais pesados saúde pública e medicina ortomolecular, São Paulo, $132 \mathrm{p}$.

PEREIRA. B. F. 2005. Potencial fitorremediador das culturas de feijão-deporco, girassol e milho cultivadas em Latossolo vermelho contaminado com chumbo; Dissertação de Mestrado Instituto Agronômico Campinas, São Paulo, $68 \mathrm{p}$.

PILON SMITS.; 2005. Phytoremediation. annual review of plant biology, 56, pp. $15-39$.

PIRES, F. R.; SOUZA, C. M.; SILVA, A. A.; PROCÓPIO, S. O.; FERREIRA, L. R. 2003. Fitorremediação de solos contaminados com herbicidas. Planta Daninha, Viçosa, v. 21, n. 2, p. 335-340.

PLETSCH, M.; CHARLWOOD, B. V.; ARAUJO, B. S. 1999. Fitorremediação de águas e solos poluídos. Biotecnologia Ciências \& Desenvolvimento, São Paulo, v. 2 , n. 11 , p. $26-29$.

PREFEITURA DO MUNÍCIPIO DE SÃO PAULO.; SECRETARIA DE INFRAESTRUTURA URBANA.; CENTRO DE GERENCIA DE EMERGÊNCIA. 2010. Boletim pluviométrico mensal.

REIMANN. C.; ÄYRÄS M.; CHEKUSHIN. I. V.; BOGATYREV, R. B.; CARIATAT. P.; 1998. Environmental geochemical atlas of the central barents region, Geological Survey of Norway, ISBN 82-7385-176-1 NGU-GTK-CKE Special Publication, $77 \mathrm{p}$.

RÖMHELD. V; MARSCHNER. H.; 1983. In vivo measurement of root-induced $\mathrm{pH}$ changes at the soil-root interface: Effect of plant species and nitrogen source. Z. Pflanzenphysiol; v. 111: p. 241-251.

ROSS, S. D. 1991 Hydrogeological study of river connected aquifers in greater São Paulo, Brazil. Dissertação de Mestrado, University of Waterloo, Waterloo, p. 187.

SCHÜTZENDÜBEL, A.; POLLE, A. 2002. Plant responses to abitic stresses: heavy metal-induced oxidative stress and protection by mycorrhization. Journal of Expermental Botany, Oxford, v. 53, n. 372, p. 1351-1365.

SORIANO, R. J.; REIS, F. A. G. V. 2005. Análise comparativa entre métodos de amostragem de águas subterrânea. Engenharia Ambiental, Espírito Santo do Pinhal, v. 2, n. 1, p. 149-167.

SPOSITO, G. 1976. An Introduction to Classical Dynamics. John Wiley \& Sons, New York, $426 \mathrm{p}$. 
StatSoft Statistica versão 2007 versão 7.0 Oklahoma USA

STRAHLER, A. N. 1963. The Earth Sciences. Harper \& Row, New York, 681 p.

TAKENO, N. 2005. Atlas of Eh-pH diagrams. Report. Japan, Geological Surveu of Japan Open File Report, 419 p.

TEMPERATURA MENSAL DA CIDADE DE SÃO PAULO. Disponível em: $<$ http://br.weather.com/weather/climatology/BRXX0232?dayofyear $=32>$. Acesso em: 22 fev. 2011.

TERAMUSSI, T. M. 2008. Percepção Ambiental de estudantes sobre o Parque Ecológico do Tietê, São Paulo. Dissertação de Mestrado, Universidade de São Paulo, São Paulo, 102 p.

TROPPMAIR, H.; 1976. Carta de solo da planície aluvial do rio tiete trecho Parque Ecológico do Tietê.

TROPPMAIR, H.; MELO. V.F. B; MARX. R.B; AB` SÁBER. A.N; Relatório de Criação do Parque Ecológico do Tietê v.3. São Paulo, 77 p..

VARNIER, C. L. 2001. O efeito do nitrogênio proveniente de sistemas de saneamento "in situ" na qualidade das águas subterrâneas em aqüiferos livres e rasos. Dissertação de Mestrado, Universidade de São Paulo, São Paulo, 150 p.

VARNIER, C. L; HIRATA. R. 2000. Nitogen impacts from a septic system in an unconfined aquifer in São Paulo, Brazil, Groundwater and Human Development, p. 86 - 90.

VETTORAZZI, C. A.; FERRAZ. S. F. B. 2000. Silvicultura de precisão: uma nova perspectiva para o gerenciamento de atividades florestais. In: BOREM, A.; GIUDICE, M. P.; QUEIROZ, D. M. Agricultura de Precisão, Viçosa, p.65 - 75.

ZEITOUNI, C. F.; BERTONI, R. S.; ABREU, C. A. 2007. Fitoextração de cádmio e zinco de um latossolo vermelho-amarelo contaminado com metais pesados. Bragantia, Campinas, v. 66, n. 4, p. 649-657. 


\section{ANEXOS}

Planilhas com valores das análises do solo e da água subterrânea $e$ Coeficientes de absorção calculados. 


\section{Tabela 1 - Comparação dos resultados obtidos para água com a portaria 518 do Ministério da Saúde}

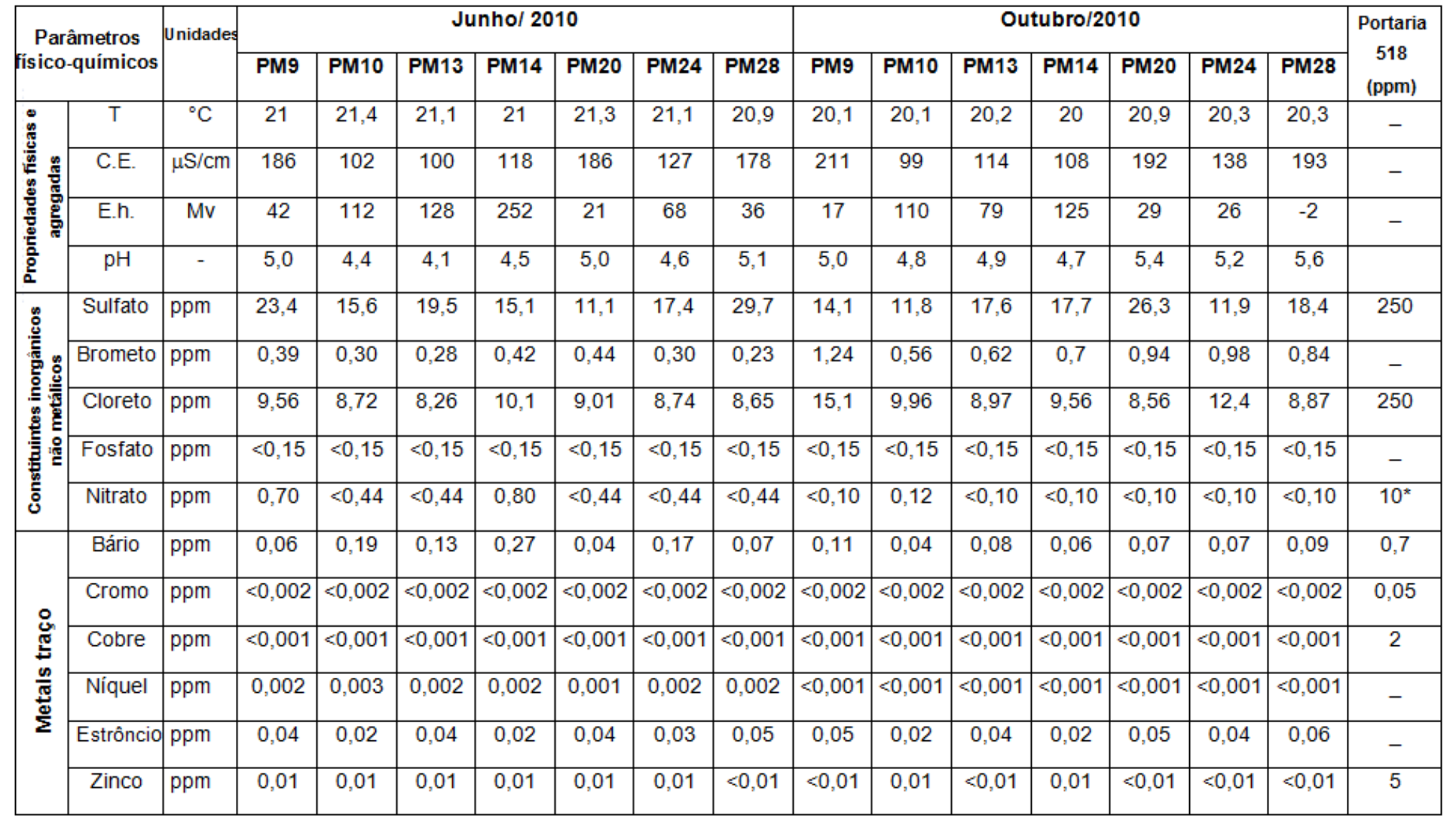

* valor de nitrogênio. 
Tabela 2 - Dados geoquímicos das amostras de solos do PET, comparados aos valores orientadores para solos e águas subterrâneas do estado de São Paulo (CETESB № 195-2005-E).

\begin{tabular}{|c|c|c|c|c|c|c|c|c|c|}
\hline \multirow{3}{*}{ Metais } & \multirow{3}{*}{ Unidade } & \multicolumn{7}{|c|}{ Amostras } & \multirow{3}{*}{$\begin{array}{c}\text { CETESB } \\
\text { No 195-2005-E } \\
\begin{array}{c}\text { Valores de } \\
\text { Qualidade para } \\
\text { o solo }\end{array}\end{array}$} \\
\hline & & \multicolumn{2}{|c|}{ F1 } & \multicolumn{2}{|c|}{ F2 } & \multicolumn{2}{|c|}{ F3 } & \multirow{2}{*}{$\begin{array}{c}\text { F4 } \\
\text { Branco }\end{array}$} & \\
\hline & & A & B & A & B & A & B & & \\
\hline Bário & $\mu g / g$ & 1337 & 480 & 1349 & 1151 & 1354 & 753 & $<37$ & 700 \\
\hline Cobalto & $\mu g / g$ & 31 & 18 & 34 & 25 & 40 & 17 & $<6$ & 5 \\
\hline Cromo & $\mu g / g$ & 38 & 60 & 40 & 35 & 34 & 81 & 17 & 50 \\
\hline Cobre & $\mu g / g$ & 16 & 25 & 16 & 21 & 15 & 92 & $<5$ & 2000 \\
\hline Lantânio & $\mu g / g$ & 119 & 130 & 136 & 105 & 138 & 101 & $<28$ & - \\
\hline Níquel & $\mu g / g$ & 19 & 24 & 20 & 20 & 20 & 24 & $<5$ & 20 \\
\hline Escândio & $\mu g / g$ & 14 & 15 & 14 & 14 & 14 & 14 & $<14$ & - \\
\hline Estrôncio & $\mu g / g$ & 265 & 64 & 240 & 207 & 29 & 130 & 9 & - \\
\hline Vanádio & $\mu g / g$ & 74 & 129 & 74 & 76 & 77 & 86 & 30 & - \\
\hline İtrio & $\mu g / g$ & 94 & 59 & 95 & 69 & 97 & 61 & 6 & - \\
\hline Zinco & $\mu g / g$ & 100 & 74 & 102 & 11 & 108 & 259 & 7 & 5000 \\
\hline Zircônio & $\mu g / g$ & 285 & 160 & 288 & 263 & 337 & 267 & 374 & - \\
\hline
\end{tabular}


Tabela 3 - Dados obtidos para amostras de solo na área do PET (F1A, F1B, F2A, F2B, F3A, F3B), amostra de solo referência (F4) e limite de detecção do método de análise (LD).

\begin{tabular}{|c|c|c|c|c|c|c|c|c|}
\hline$\%$ & F $1 \mathrm{~A}$ & F 1 B & F $2 \mathrm{~A}$ & F 2 B & F 3 A & F 3 B & F 4 & LD \\
\hline $\mathrm{SiO}_{2}$ & 62,79 & 45,08 & 59,51 & 62,59 & 63,42 & 55,32 & 93,74 & 0,03 \\
\hline $\mathrm{TiO}_{2}$ & 0,878 & 0,780 & 0,913 & 0,890 & 0,895 & 0,833 & 0,743 & 0,003 \\
\hline $\mathrm{Al}_{2} \mathrm{O}_{3}$ & 18,93 & 25,29 & 20,74 & 19,11 & 18,98 & 20,56 & 0,86 & 0,02 \\
\hline $\mathrm{Fe}_{2} \mathrm{O}_{3}$ & 4,81 & 4,47 & 4,80 & 4,87 & 4,73 & 4,95 & 0,58 & 0,01 \\
\hline MnO & 0,079 & 0,046 & 0,068 & 0,127 & 0,124 & 0,064 & 0,016 & 0,002 \\
\hline $\mathrm{MgO}$ & 0,93 & 0,31 & 0,87 & 0,93 & 0,89 & 0,50 & 0,04 & 0,01 \\
\hline $\mathrm{CaO}$ & 0,20 & 0,02 & 0,13 & 0,12 & 0,15 & 0,28 & 0,08 & 0,01 \\
\hline $\mathrm{Na}_{2} \mathrm{O}$ & 0,33 & $<0,02$ & 0,20 & 0,20 & 0,21 & 0,14 & $<0,02$ & 0,02 \\
\hline $\mathrm{K}_{2} \mathrm{O}$ & 3,91 & 1,24 & 3,65 & 3,83 & 3,79 & 2,12 & 0,09 & 0,01 \\
\hline $\mathrm{P}_{2} \mathrm{O}_{5}$ & 0,108 & 0,378 & 0,131 & 0,103 & 0,100 & 0,264 & 0,029 & 0,003 \\
\hline PF & 6,43 & 22,57 & 9,05 & 6,54 & 6,74 & 15,14 & 3,36 & 0,01 \\
\hline TOTAL & 93,69 & 77,94 & 91,40 & 93,19 & 93,69 & 85,42 & 96,31 & - \\
\hline ppm & F $1 \mathrm{~A}$ & F 1 B & F $2 \mathrm{~A}$ & F 2 B & F 3 A & F 3 B & F 4 & LD \\
\hline $\mathrm{Ba}$ & 1377 & 480 & 1151 & 1349 & 1343 & 753 & $<37$ & 37 \\
\hline $\mathrm{Ce}$ & 102 & 265 & 153 & 93 & 120 & 143 & 35 & 35 \\
\hline Co & 31 & 18 & 25 & 34 & 40 & 17 & 6 & 6 \\
\hline $\mathrm{Cr}$ & 38 & 60 & 35 & 40 & 31 & 81 & 17 & 13 \\
\hline $\mathrm{Cu}$ & 16 & 25 & 21 & 16 & 16 & 92 & 5 & 5 \\
\hline $\mathrm{Ga}$ & 27 & 36 & 28 & 26 & 26 & 27 & 9 & 9 \\
\hline La & 119 & 130 & 105 & 136 & 149 & 101 & 28 & 28 \\
\hline $\mathrm{Nb}$ & 21 & 18 & 22 & 22 & 22 & 20 & 11 & 9 \\
\hline Nd & 87 & 91 & 83 & 104 & 102 & 72 & 14 & 14 \\
\hline $\mathbf{N i}$ & 19 & 24 & 20 & 20 & 21 & 24 & 5 & 5 \\
\hline $\mathrm{Pb}$ & 15 & 15 & 19 & 16 & 21 & 65 & 4 & 4 \\
\hline $\mathbf{R b}$ & 157 & 59 & 150 & 157 & 157 & 93 & 3 & 3 \\
\hline Sc & $<14$ & 15 & $<14$ & $<14$ & $<14$ & $<14$ & $<14$ & 14 \\
\hline $\mathrm{Sr}$ & 265 & 64 & 207 & 240 & 229 & 130 & 9 & 2 \\
\hline Th & 17 & 29 & 18 & 15 & 16 & 21 & 7 & 7 \\
\hline U & 4 & 10 & 5 & 6 & 4 & 4 & 3 & 3 \\
\hline V & 74 & 129 & 76 & 74 & 82 & 86 & 30 & 9 \\
\hline $\mathbf{Y}$ & 94 & 59 & 69 & 95 & 98 & 61 & 6 & 2 \\
\hline $\mathrm{Zn}$ & 100 & 74 & 111 & 102 & 109 & 259 & 7 & 2 \\
\hline $\mathrm{Zr}$ & 285 & 160 & 263 & 288 & 339 & 267 & 374 & 2 \\
\hline $\mathrm{Cl}$ & $<50$ & $<50$ & $<50$ & $<50$ & $<50$ & $<50$ & $<50$ & 50 \\
\hline $\mathbf{F}$ & 1392 & 588 & 1304 & 1408 & 1092 & 1008 & 500 & 500 \\
\hline s & $<550$ & 762 & $<550$ & $<550$ & $<550$ & 575 & $<550$ & 550 \\
\hline
\end{tabular}


Tabela 4 - Dados recalculados dos elementos maiores, em função da perda ao fogo (PF).

\begin{tabular}{|c|ccccccc|}
\hline \% & F 1 A & F 1 B & F 2 A & F 2 B & F 3 A & F 3 B & F 4 \\
\hline $\mathrm{SiO}_{\mathbf{2}}$ & 67,21 & 57,84 & 65,09 & 67,14 & 67,67 & 64,76 & 97,31 \\
$\mathrm{TiO}_{\mathbf{2}}$ & 0,94 & 1,00 & 1,00 & 0,95 & 0,95 & 0,98 & 0,77 \\
$\mathbf{A l}_{2} \mathbf{O}_{\mathbf{3}}$ & 20,26 & 32,45 & 22,68 & 20,50 & 20,25 & 24,07 & 0,89 \\
$\mathrm{Fe}_{2} \mathbf{O}_{\mathbf{3}}$ & 5,15 & 5,74 & 5,25 & 5,22 & 5,05 & 5,79 & 0,60 \\
$\mathbf{M n O}$ & 0,08 & 0,06 & 0,07 & 0,14 & 0,13 & 0,07 & 0,02 \\
$\mathbf{M g O}$ & 1,00 & 0,40 & 0,95 & 1,00 & 0,95 & 0,59 & 0,04 \\
$\mathbf{C a O}$ & 0,21 & 0,03 & 0,14 & 0,13 & 0,16 & 0,33 & 0,08 \\
$\mathrm{Na}_{\mathbf{2}} \mathbf{O}$ & 0,35 & 0,01 & 0,22 & 0,21 & 0,22 & 0,16 & 0,01 \\
$\mathbf{K}_{\mathbf{2}} \mathbf{O}$ & 4,19 & 1,59 & 3,99 & 4,11 & 4,04 & 2,48 & 0,09 \\
$\mathbf{P}_{\mathbf{2}} \mathbf{O}_{\mathbf{5}}$ & 0,12 & 0,49 & 0,14 & 0,11 & 0,11 & 0,31 & 0,03 \\
\hline $\mathrm{TOTAL}_{\mathbf{O}}$ & $\mathbf{1 0 0 , 0 0}$ & $\mathbf{1 0 0 , 0 0}$ & $\mathbf{1 0 0 , 0 0}$ & $\mathbf{1 0 0 , 0 0}$ & $\mathbf{1 0 0 , 0 0}$ & $\mathbf{1 0 0 , 0 0}$ & $\mathbf{1 0 0 , 0 0}$ \\
\hline
\end{tabular}


Tabela 5 - Sumário estatístico para os dados geoquímicos das amostras de solo na área do PET (F1A, F1B, F2A, F2B, F3A, F3B):

(a) elementos maiores, (b) elementos menores e traços.

(a)

\begin{tabular}{|c|c|c|c|c|c|c|c|c|c|c|}
\hline$\%$ & $\mathrm{SiO}_{2}$ & $\mathrm{TiO}_{2}$ & $\mathrm{Al}_{2} \mathrm{O}_{3}$ & $\mathrm{Fe}_{2} \mathrm{O}_{3}$ & $\mathrm{MnO}$ & $\mathrm{MgO}$ & $\mathrm{CaO}$ & $\mathrm{Na}_{2} \mathrm{O}$ & $\mathrm{K}_{2} \mathrm{O}$ & $\mathbf{P}_{2} \mathrm{O}_{5}$ \\
\hline Média & 64,97 & 0,97 & 23,33 & 5,37 & 0,10 & 0,81 & 0,17 & 0,20 & 3,40 & 0,21 \\
\hline Mediana & 66,11 & 0,97 & 21,59 & 5,24 & 0,08 & 0,96 & 0,16 & 0,22 & 4,03 & 0,13 \\
\hline Desvio Pad & 3,70 & 0,02 & 4,74 & 0,32 & 0,04 & 0,26 & 0,10 & 0,11 & 1,10 & 0,15 \\
\hline Mínimo & 57,84 & 0,94 & 20,03 & 5,05 & 0,06 & 0,40 & 0,03 & 0,01 & 1,59 & 0,10 \\
\hline Máximo & 67,80 & 1,00 & 32,45 & 5,79 & 0,14 & 1,00 & 0,33 & 0,35 & 4,19 & 0,49 \\
\hline
\end{tabular}

(b)

\begin{tabular}{|c|ccccccccccccccccccccccccccccccccccc}
\hline $\boldsymbol{\mu g} / \mathbf{g}$ & $\mathbf{B a}$ & $\mathbf{C e}$ & $\mathbf{C o}$ & $\mathbf{C r}$ & $\mathbf{C u}$ & $\mathbf{G a}$ & $\mathbf{L a}$ & $\mathbf{N b}$ & $\mathbf{N d}$ & $\mathbf{N i}$ & $\mathbf{P b}$ & $\mathbf{R b}$ & $\mathbf{S c}$ & $\mathbf{S r}$ & $\mathbf{T h}$ & $\mathbf{U}$ & $\mathbf{V}$ & $\mathbf{Y}$ & $\mathbf{Z n}$ & $\mathbf{Z r}$ & $\mathbf{C l}$ & $\mathbf{F}$ & $\mathbf{S}$ \\
Média & 1187 & 164 & 31 & 55 & 35 & 32 & 137 & 23 & 103 & 24 & 28 & 142 & 10 & 208 & 22 & 7 & 98 & 88 & 142 & 296 & 28 & 1307 & 473 \\
Mediana & 1353 & 138 & 30 & 42 & 20 & 30 & 137 & 23 & 102 & 22 & 20 & 164 & 8 & 236 & 19 & 6 & 83 & 88 & 113 & 307 & 27 & 1454 & 298 \\
Desvio Pad & 359 & 93 & 8 & 25 & 36 & 7 & 20 & 1 & 15 & 4 & 24 & 40 & 5 & 76 & 8 & 3 & 34 & 15 & 80 & 51 & 2 & 297 & 290 \\
Mínimo & 615 & 98 & 20 & 36 & 16 & 28 & 115 & 22 & 85 & 20 & 16 & 76 & 7 & 82 & 15 & 4 & 80 & 72 & 94 & 205 & 27 & 754 & 294 \\
Máximo & 1474 & 341 & 42 & 95 & 108 & 47 & 167 & 24 & 119 & 30 & 76 & 168 & 19 & 284 & 37 & 12 & 166 & 104 & 303 & 360 & 32 & 1511 & 978 \\
\hline
\end{tabular}


Tabela 6 - Descrição dos dados estatísticos para água nos períodos de Junho e Outubro.

\begin{tabular}{|c|c|c|c|c|c|c|c|c|c|c|c|c|c|c|c|c|c|c|c|c|c|}
\hline Junho & Al & $\mathrm{Ba}$ & $\mathrm{Ca}$ & $\mathrm{Cr}$ & $\mathrm{Cu}$ & $\mathrm{Fe}$ & $\mathrm{K}$ & Mg & Mn & $\mathrm{Na}$ & $\mathbf{N i}$ & $\mathrm{PO}_{4}{ }^{3-}$ & Sr & $\mathrm{Zn}$ & & & & & & En & \\
\hline PM -9 & 0,06 & \begin{tabular}{|l|l|}
0,109 \\
\end{tabular} & 4,1 & 0,002 & 0,001 & 20,4 & 2,7 & 1,8 & 0,22 & 11 & 0,002 & 0,2 & 0,046 & 0,01 & 0,16 & 9,56 & 0,39 & 23,4 & 5,010 & 42 & 186,2 \\
\hline PM - 10 & 0,19 & 0,050 & 1,9 & 0,002 & 0,001 & 6,22 & 1,8 & 0,8 & 0,10 & 5,9 & 0,003 & 0,2 & 0,023 & 0,01 & 0,10 & 8,72 & 0,30 & 15,6 & 4,433 & 112 & 102,0 \\
\hline PM -13 & 0,13 & \begin{tabular}{|l|l|}
0,076 \\
\end{tabular} & 4,4 & 0,002 & 0,001 & 4,36 & 1,6 & 1,1 & 0,13 & 8,7 & 0,002 & 0,2 & 0,040 & 0,01 & 0,10 & 8,26 & 0,28 & 19,5 & 4,552 & \begin{tabular}{|l|}
128 \\
\end{tabular} & 118,4 \\
\hline PM -14 & 0,27 & \begin{tabular}{|l|}
0,063 \\
\end{tabular} & 2,1 & 0,002 & \begin{tabular}{|l|}
0,001 \\
\end{tabular} & 4,40 & 1,9 & 1,2 & 0,13 & 6,7 & 0,002 & 0,2 & 0,028 & 0,01 & 0,18 & 10,1 & 0,42 & 15,1 & 4,180 & 252 & 100,9 \\
\hline PM -20 & 0,04 & \begin{tabular}{|l|l|}
0,078 \\
\end{tabular} & 5,1 & 0,002 & 0,001 & 17,5 & 2,1 & 1,9 & 0,27 & 13 & 0,001 & 0,3 & 0,048 & 0,01 & 0,10 & 9,01 & 0,44 & 11,1 & 5,035 & 21 & \begin{tabular}{|l|}
186,7 \\
\end{tabular} \\
\hline PM - 24 & 0,17 & 0,053 & 2,5 & 0,002 & 0,001 & 11,6 & 2,4 & 1,5 & 0,14 & 7,3 & 0,002 & 0,2 & 0,030 & 0,01 & 0,10 & 8,74 & 0,30 & $\mid 17,4$ & 4,611 & \begin{tabular}{|l|}
68 \\
\end{tabular} & 127,0 \\
\hline PM - 28 & 0,07 & 0,090 & 7,6 & 0,002 & 0,001 & 12,9 & 4,7 & 2,1 & 0,17 & 9,3 & 0,002 & 0,3 & 0,056 & 0,01 & 0,10 & 8,56 & 0,23 & 29,7 & 5,155 & 36 & 178,5 \\
\hline Média & $\begin{array}{c}0,132 \\
9 \\
\end{array}$ & $\begin{array}{c}0,074 \\
2\end{array}$ & $\begin{array}{c}3,931 \\
8 \\
1074\end{array}$ & $\begin{array}{c}0,001 \\
0\end{array}$ & $\begin{array}{c}0,000 \\
5\end{array}$ & $\begin{array}{c}11,05 \\
96\end{array}$ & $\begin{array}{c}2,473 \\
7\end{array}$ & $\begin{array}{l}1,488 \\
7\end{array}$ & $\begin{array}{c}0,165 \\
9\end{array}$ & $\begin{array}{c}8,830 \\
3\end{array}$ & $\begin{array}{c}0,002 \\
0\end{array}$ & $\begin{array}{c}0,116 \\
0\end{array}$ & $\begin{array}{c}0,038 \\
9\end{array}$ & $\begin{array}{c}0,009 \\
0\end{array}$ & $\begin{array}{c}0,528 \\
6 \\
\end{array}$ & $\begin{array}{r}9,005 \\
7\end{array}$ & $\begin{array}{c}0,337 \\
1\end{array}$ & \begin{tabular}{|c|}
18,82 \\
86
\end{tabular} & $\begin{array}{c}4,708 \\
6\end{array}$ & $\begin{array}{c}94,142 \\
9\end{array}$ & $\begin{array}{c}142,85 \\
71\end{array}$ \\
\hline Minimo & $\begin{array}{c}0,040 \\
1\end{array}$ & $\begin{array}{c}0,050 \\
0\end{array}$ & $\begin{array}{c}1,874 \\
1\end{array}$ & $\begin{array}{c}0,001 \\
0\end{array}$ & $\begin{array}{c}0,000 \\
5\end{array}$ & $\begin{array}{c}4,359 \\
5\end{array}$ & $\begin{array}{c}1,620 \\
8\end{array}$ & $\begin{array}{c}0,840 \\
6\end{array}$ & $\begin{array}{c}0,102 \\
2\end{array}$ & $\begin{array}{c}5,856 \\
4\end{array}$ & $\begin{array}{c}0,001 \\
3\end{array}$ & $\begin{array}{c}0,010 \\
0\end{array}$ & $\begin{array}{c}0,023 \\
1\end{array}$ & $\begin{array}{c}0,005 \\
0\end{array}$ & $\begin{array}{c}0,440 \\
0\end{array}$ & $\begin{array}{c}8,260 \\
0\end{array}$ & $\begin{array}{c}0,230 \\
0\end{array}$ & $\begin{array}{c}11,10 \\
00\end{array}$ & $\begin{array}{c}4,180 \\
0\end{array}$ & $\begin{array}{c}21,000 \\
0\end{array}$ & $\begin{array}{c}101,00 \\
00\end{array}$ \\
\hline Máximo & $\begin{array}{l}0,272 \\
7\end{array}$ & $\begin{array}{c}0,109 \\
5\end{array}$ & $\begin{array}{c}7,585 \\
0\end{array}$ & $\begin{array}{l}0,001 \\
0\end{array}$ & 0,000 & $\begin{array}{c}20,44 \\
93\end{array}$ & $\begin{array}{r}4,732 \\
2\end{array}$ & $\begin{array}{c}2,105 \\
9\end{array}$ & $\begin{array}{l}0,270 \\
8\end{array}$ & $\begin{array}{c}13,12 \\
47\end{array}$ & 0,003 & $\begin{array}{l}0,332 \\
2\end{array}$ & $\begin{array}{l}0,056 \\
2\end{array}$ & $\begin{array}{r}0,011 \\
8\end{array}$ & $\begin{array}{l}0,800 \\
0\end{array}$ & $\begin{array}{c}10,10 \\
00\end{array}$ & 0,440 & $\begin{array}{c}29,70 \\
00\end{array}$ & $\begin{array}{l}5,150 \\
0\end{array}$ & $\begin{array}{c}252,00 \\
00\end{array}$ & $\begin{array}{c}187,00 \\
00\end{array}$ \\
\hline $\begin{array}{c}\text { Variânci } \\
\text { a }\end{array}$ & 0,007 & 0,000 & 4,212 & 0,000 & 0,000 & $\begin{array}{c}40,96 \\
6\end{array}$ & 1,122 & 0,214 & 0,003 & 6,402 & 0,000 & 0,020 & 0,000 & 0,000 & 0,024 & 0,390 & 0,006 & $\begin{array}{c}37,60 \\
6\end{array}$ & 0,130 & $\begin{array}{c}6419,4 \\
76\end{array}$ & $\begin{array}{c}1567,8 \\
10\end{array}$ \\
\hline $\begin{array}{l}\text { Desv. } \\
\text { Pad. }\end{array}$ & $\begin{array}{c}0,083 \\
37\end{array}$ & $\begin{array}{c}0,021 \\
13\end{array}$ & $\begin{array}{c}2,052 \\
27\end{array}$ & $\begin{array}{c}0,000 \\
00\end{array}$ & $\begin{array}{c}0,000 \\
00\end{array}$ & $\begin{array}{c}6,400 \\
44\end{array}$ & $\begin{array}{c}1,059 \\
18\end{array}$ & $\begin{array}{c}0,462 \\
29\end{array}$ & $\begin{array}{c}0,059 \\
04\end{array}$ & $\begin{array}{c}2,530 \\
28\end{array}$ & $\begin{array}{c}0,000 \\
52\end{array}$ & $\begin{array}{c}0,141 \\
76\end{array}$ & $\begin{array}{c}0,012 \\
22\end{array}$ & $\begin{array}{c}0,002 \\
23\end{array}$ & $\begin{array}{c}0,153 \\
99\end{array}$ & $\begin{array}{c}0,624 \\
44\end{array}$ & $\begin{array}{c}0,079 \\
31\end{array}$ & $\begin{array}{c}6,132 \\
35\end{array}$ & $\begin{array}{c}0,360 \\
76\end{array}$ & $\begin{array}{c}80,121 \\
63\end{array}$ & $\begin{array}{c}39,595 \\
57\end{array}$ \\
\hline
\end{tabular}

\begin{tabular}{|c|c|c|c|c|c|c|c|c|c|c|c|c|c|c|c|c|c|c|c|c|c|}
\hline Outubro & Al & $\mathrm{Ba}$ & $\mathrm{Ca}$ & $\mathrm{Cr}$ & $\mathrm{Cu}$ & $\mathrm{Fe}$ & $\mathrm{K}$ & Mg & Mn & $\mathrm{Na}$ & $\mathrm{Ni}$ & $\mathrm{PO}_{4}{ }^{3-}$ & $\mathbf{S r}$ & $Z \mathbf{n}$ & $\mathrm{NO} 3$ & $\mathrm{Cl}$ & $\mathrm{Br}$ & SO4 & $\mathrm{pH}$ & Eh & $E$ \\
\hline PM-9 & 0,03 & 0,114 & 5,6 & $\begin{array}{c}0,001 \\
0\end{array}$ & $\begin{array}{c}0,000 \\
5\end{array}$ & 21,4 & 3,2 & 2,0 & 0,25 & 11 & $\begin{array}{c}0,000 \\
5\end{array}$ & 0,2 & 0,054 & 0,005 & 0,1 & 15,1 & 1,24 & 14,1 & 5,07 & 17 & 211 \\
\hline PM-10 & 0,13 & 0,049 & 1,8 & $\begin{array}{c}0,00 \\
0\end{array}$ & $\begin{array}{c}0,000 \\
5\end{array}$ & 6,87 & 1,9 & 0,8 & 0,10 & 5,7 & $\begin{array}{r}0,0 \\
5\end{array}$ & 0,1 & 0,023 & 0,01 & 0,12 & 9,96 & 0,56 & 11,8 & 4,83 & 110 & 98,5 \\
\hline PM-13 & 0,13 & 0,081 & 4,6 & $\begin{array}{c}0,00 \\
0\end{array}$ & $\begin{array}{c}0,000 \\
5\end{array}$ & 3,90 & 1,8 & 1,2 & 0,15 & 8,7 & 0,0 & 0,1 & 0,043 & 0,005 & 0,1 & 8,97 & 0.62 & 17,6 & 4.93 & 79 & 114 \\
\hline PM-14 & 0,22 & 0,061 & 2,2 & $\begin{array}{c}0,00 \\
0\end{array}$ & $\begin{array}{c}0,000 \\
5\end{array}$ & 5,67 & 2,1 & 1,3 & 0,14 & 7,0 & & 0,1 & 0,029 & 0,010 & 0,1 & 9,56 & 0,7 & 17,7 & 4,79 & 125 & 109 \\
\hline PM-20 & 0,02 & 0,077 & 5,2 & $\begin{array}{c}0,001 \\
0\end{array}$ & $\frac{0,000}{5}$ & 17,5 & 2,2 & 2,0 & 0,28 & 13 & $\begin{array}{r}0,0 \\
5\end{array}$ & 0,3 & 0,050 & 0,005 & 0.1 & 8,56 & 0,94 & 26,3 & 5,46 & 29 & 193 \\
\hline PM-24 & 0,12 & 0,070 & 3,8 & $\begin{array}{c}0,001 \\
0\end{array}$ & $\begin{array}{c}0,000 \\
5\end{array}$ & 11,1 & 2,8 & 2,0 & 0,16 & 8,0 & $\begin{array}{c}0,00 \\
5\end{array}$ & 0,1 & 0,041 & 0,005 & 0,1 & 12,4 & 0.98 & 11,9 & 5,2 & 26 & 138 \\
\hline PM-28 & 0 , & 99 & 8,5 & $\begin{array}{c}0,001 \\
0\end{array}$ & $\begin{array}{c}0,000 \\
5\end{array}$ & 12 & 6,2 & 2,3 & 018 & 12 & $0,0 C$ & 0,3 & 2 & 005 & 0 & 8,87 & 0,84 & 184 & 5, & -2 & 193 \\
\hline Média & $\begin{array}{c}0,098 \\
0\end{array}$ & $\begin{array}{l}0,078 \\
7\end{array}$ & $\begin{array}{l}4,532 \\
4\end{array}$ & 0,001 & $\begin{array}{l}0,000 \\
5\end{array}$ & $\begin{array}{c}11,29 \\
05\end{array}$ & 2, & $\begin{array}{c}1,64 \\
8\end{array}$ & 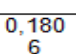 & 5 & $\begin{array}{l}0,000 \\
5\end{array}$ & 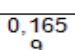 & 0, & 0,0066 & 0,102 & $\begin{array}{l}10,48 \\
86\end{array}$ & 0,840 & 2 & 5,134 & 54,8571 & 150,928 \\
\hline Mínimo & 0,024 & $\frac{1}{0,048}$ & $\begin{array}{c}1,778 \\
6\end{array}$ & 0,001 & $\begin{array}{c}5 \\
0,000 \\
5\end{array}$ & $\begin{array}{c}3,903 \\
8\end{array}$ & & $\begin{array}{c}0,802 \\
0\end{array}$ & $\begin{array}{l}\frac{6}{0,102} \\
5\end{array}$ & $\frac{8}{5,686}$ & $\begin{array}{l}\frac{5}{0,000} \\
5\end{array}$ & $\frac{9}{0,100}$ & , & 0,0050 & $\frac{9}{0,100}$ & $\begin{array}{c}86 \\
8,560 \\
0\end{array}$ & $\frac{0}{0,560}$ & $\frac{86}{11,80} 0$ & $\frac{3}{4,790}$ & $-2,0000$ & $\begin{array}{c}6 \\
98,5000\end{array}$ \\
\hline ximo & 0,222 & 0,113 & 8,469 & 0,001 & 0,000 & 21,38 & 6,183 & 2,256 & 0,282 & 12,65 & 0,000 & 0,277 & 0,061 & 8 & 0,120 & 15,10 & 1,240 & 26,30 & 5,660 & 000 & 211,000 \\
\hline Variânci & $\frac{0}{0,005}$ & $\frac{9}{0,000}$ & $\frac{3}{5,110}$ & 0,000 & $\frac{5}{0,000}$ & $\begin{array}{c}64 \\
41,31 \\
48\end{array}$ & $\frac{1}{2,379}$ & $\frac{1}{0,302}$ & $\frac{7}{0,004}$ & $\begin{array}{l}65 \\
7,151 \\
5\end{array}$ & $\frac{5}{0,000}$ & $\frac{1}{0,007}$ & $\frac{1}{0,000}$ & & 000 & $\frac{00}{5,784}$ & $\frac{0}{0,056}$ & 25,09 & $\frac{0}{0,107}$ & 2451,80 & $\begin{array}{l}7,70 \\
74\end{array}$ \\
\hline $\begin{array}{l}\text { Desv. } \\
\text { Pad. }\end{array}$ & $\begin{array}{c}\frac{4}{0,073} \\
52\end{array}$ & 0,022 & 2,260 & $\begin{array}{c}0,000 \\
00\end{array}$ & $\begin{array}{c}0,000 \\
00\end{array}$ & $\begin{array}{l}6,427 \\
66\end{array}$ & $\begin{array}{c}1,542 \\
70\end{array}$ & $\begin{array}{c}0,549 \\
55\end{array}$ & 0,063 & 2,674 & $\frac{0}{0,000}$ & $\begin{array}{c}1 \\
0,084 \\
24\end{array}$ & $\frac{2}{0,013}$ & $\begin{array}{c}0,0026 \\
9\end{array}$ & $\frac{1}{0,007}$ & $\frac{3}{2,405}$ & $\frac{0}{0,236}$ & $\begin{array}{c}24 \\
5,009 \\
23\end{array}$ & $\frac{3}{0,327}$ & $\frac{95}{49,5157}$ & $\frac{24}{46,8796}$ \\
\hline
\end{tabular}


Tabela 7 - Resultados dos elementos maiores, menores e traços das folhas obtidos no período de Junho.

\begin{tabular}{|lllllllllllll|}
\hline \multicolumn{10}{c|}{ JUNHO } \\
\hline FOLHAS & J-1 & J-2 & J-3 & J-4 & J-5 & PECíOLOS & PJ-1 & PJ-2 & PJ-3 & PJ-4 & PJ-5 \\
SiO2 \% & 48,06 & 45,00 & 61,00 & 49,57 & 61,44 & SiO2 \% & 19,26 & 43,47 & 50,15 & 36,37 & 29,03 \\
TiO2 \% & 0,04 & 0,02 & 0,04 & 0,05 & 0,06 & TiO2 \% & 0,01 & 0,01 & 0,01 & 0,01 & 0,03 \\
Al2O3 \% & 0,43 & 0,31 & 0,55 & 0,46 & 0,84 & Al2O3 \% & 0,10 & 0,11 & 0,08 & 0,08 & 0,21 \\
Fe2O3 \% & 0,47 & 0,43 & 0,50 & 0,96 & 0,73 & Fe2O3 \% & 0,04 & 0,10 & 0,07 & 0,03 & 0,18 \\
MnO \% & 1,45 & 1,45 & 1,56 & 1,87 & 1,27 & MnO \% & 0,46 & 0,61 & 0,47 & 0,55 & 0,77 \\
MgO \% & 4,68 & 6,41 & 3,88 & 4,57 & 3,05 & MgO \% & 1,03 & 2,43 & 1,61 & 1,84 & 3,38 \\
CaO \% & 7,47 & 6,70 & 6,21 & 6,90 & 5,83 & CaO \% & 2,18 & 4,55 & 3,52 & 4,83 & 6,10 \\
Na2O \% & 0,49 & 0,53 & 0,34 & 0,34 & 0,64 & Na2O \% & 0,41 & 0,93 & 0,33 & 0,41 & 0,59 \\
K2O \% & 25,59 & 26,81 & 17,66 & 26,41 & 18,88 & K2O \% & 10,57 & 29,89 & 26,45 & 27,53 & 44,25 \\
P2O5 \% & 7,78 & 8,47 & 5,16 & 6,54 & 5,37 & P2O5 \% & 1,10 & 8,45 & 7,41 & 2,30 & 8,23 \\
Total \% & 100,00 & 100,00 & 100,00 & 100,00 & 100,00 & Total \% & 100,00 & 100,00 & 100,00 & 100,00 & 100,00 \\
Ba ppm & 41 & 23 & 66 & 47 & 66 & Ba ppm & $<10$ & $<10$ & $<10$ & $<10$ & 12 \\
Be ppm & $<2$ & $<2$ & $<2$ & $<2$ & $<2$ & Be ppm & $<2$ & $<2$ & $<2$ & $<2$ & $<2$ \\
Co ppm & $<15$ & $<15$ & $<15$ & 16 & $<15$ & Co ppm & 17 & 19 & 16 & $<15$ & 18 \\
Cr ppm & 18 & 15 & $<15$ & 31 & 15 & Cr ppm & $<15$ & 17 & 32 & $<15$ & $<15$ \\
Cu ppm & 148 & 172 & 113 & 95 & 162 & Cu ppm & 46 & 85 & 41 & 31 & 101 \\
La ppm & 10 & 33 & 36 & 30 & 25 & La ppm & 28 & 66 & 64 & 38 & 56 \\
Ni ppm & 77 & 74 & 91 & 88 & 119 & Ni ppm & $<15$ & 23 & 22 & $<15$ & 34 \\
Sc ppm & $<10$ & $<10$ & $<10$ & $<10$ & $<10$ & Sc ppm & $<10$ & $<10$ & $<10$ & $<10$ & $<10$ \\
Sr ppm & 80 & 31 & 77 & 50 & 46 & Sr ppm & 30 & 69 & 49 & 92 & 68 \\
V ppm & $<15$ & 16 & $<15$ & 35 & 26 & V ppm & 42 & $<15$ & 34 & $<15$ & 40 \\
Y ppm & 34 & 76 & 107 & 94 & 64 & Y ppm & 13 & 16 & 17 & 17 & 15 \\
Zn ppm & 406 & 418 & 341 & 397 & 438 & Zn ppm & 23 & 107 & 191 & 144 & 476 \\
Zr ppm & $<25$ & $<25$ & $<25$ & 36 & $<25$ & Zr ppm & $<25$ & 91 & 28 & $<25$ & 32 \\
\hline & & & & & & & & & & & \\
\hline
\end{tabular}


Tabela 8 - Resultados dos elementos maiores, menores e traços das folhas obtidos no período de Outubro.

\begin{tabular}{|c|c|c|c|c|c|c|c|c|c|c|c|c|c|}
\hline \multicolumn{14}{|c|}{ OUTUBRO } \\
\hline FOLHAS & J1 & J2 & J3 & J4 & J5 & J6 & PECÍOLOS & PJ1 & PJ2 & PJ3 & PJ4 & PJ5 & PJ6 \\
\hline SiO2 \% & 66,52 & 45,35 & 67,26 & 60,70 & 60,53 & 18,24 & SiO2 \% & 68,72 & 30,45 & 56,56 & 66,28 & 63,03 & 15,99 \\
\hline TiO2 \% & 0,05 & 0,06 & 0,05 & 0,03 & 0,04 & 0,05 & TiO2 \% & 0,01 & 0,01 & 0,01 & 0,04 & 0,01 & 0,01 \\
\hline Al203 \% & 0,89 & 0,67 & 0,82 & 0,56 & 0,67 & 0,55 & Al203 \% & 0,31 & 1,28 & 1,32 & 0,58 & 1,11 & 0,11 \\
\hline Fe2O3 \% & 0,71 & 0,34 & 0,65 & 0,48 & 0,62 & 0,53 & Fe2O3 \% & 0,08 & 0,14 & 0,18 & 0,36 & 0,11 & 0,16 \\
\hline MnO \% & 4,54 & 9,50 & 4,63 & 4,61 & 5,85 & 12,45 & MnO \% & 1,12 & 7,97 & 6,97 & 1,64 & 2,22 & 5,69 \\
\hline MgO \% & 4,62 & 6,96 & 3,16 & 4,61 & 3,20 & 14,74 & MgO \% & 2,44 & 5,70 & 1,50 & 2,91 & 2,42 & 15,37 \\
\hline $\mathrm{CaO} \%$ & 7,55 & 8,20 & 5,82 & 7,10 & 5,66 & 10,21 & $\mathrm{CaO} \%$ & 6,73 & 10,30 & 3,77 & 6,23 & 3,94 & 10,90 \\
\hline $\mathrm{Na2O} \%$ & 1,03 & 1,54 & 1,20 & 1,21 & 1,14 & 5,59 & $\mathrm{Na2O} \%$ & 1,50 & 1,76 & 1,51 & 2,09 & 1,46 & 6,36 \\
\hline K2O \% & 11,04 & 25,72 & 14,31 & 17,33 & 20,48 & 37,04 & K2O \% & 18,42 & 40,97 & 27,45 & 18,40 & 24,92 & 44,98 \\
\hline P2O5 \% & 2,32 & 1,25 & 1,55 & 2,51 & 1,32 & 0,44 & P2O5 \% & 0,56 & 1,07 & 0,51 & 1,09 & 0,57 & 0,30 \\
\hline Total \% & 100,00 & 100,00 & 100,00 & 100,00 & 100,00 & 100,00 & Total \% & 100,00 & 100,00 & 100,00 & 100,00 & 100,00 & 100,00 \\
\hline $\mathrm{Ba}(\mathrm{ppm})$ & 62 & 44 & 52 & 30 & 35 & $<10$ & $\mathrm{Ba}$ (ppm) & 11 & 75 & 13 & $<10$ & $<10$ & 21 \\
\hline $\mathrm{Be}$ (ppm) & $<2$ & $<2$ & $<2$ & $<2$ & $<2$ & $<2$ & $\mathrm{Be}$ (ppm) & $<2$ & $<2$ & $<2$ & $<2$ & 2,9 & 3,0 \\
\hline Co (ppm) & $<15$ & $<15$ & $<15$ & $<15$ & $<15$ & $<15$ & Co (ppm) & $<15$ & $<15$ & $<15$ & $<15$ & $<15$ & $<15$ \\
\hline $\mathrm{Cr}$ (ppm) & 18 & 89 & $<15$ & $<15$ & $<15$ & $<2$ & $\mathrm{Cr}$ (ppm) & $<15$ & 16 & 30 & $<15$ & 23 & $<15$ \\
\hline Cu (ppm) & 214 & 336 & 234 & 174 & 171 & 428 & Cu (ppm) & 87 & 245 & 132 & 123 & 49 & 237 \\
\hline La (ppm) & 36 & 21 & 60 & 44 & 36 & 21 & La (ppm) & 15 & $<15$ & 37 & 30 & 17 & $<15$ \\
\hline $\mathrm{Ni}(\mathrm{ppm})$ & 96 & 51 & 100 & 88 & 97 & $<15$ & Ni (ppm) & $<15$ & $<15$ & $<15$ & $<15$ & $<15$ & $<15$ \\
\hline Sc (ppm) & $<10$ & $<10$ & $<10$ & $<10$ & $<10$ & $<10$ & Sc (ppm) & $<10$ & $<10$ & $<10$ & $<10$ & $<10$ & $<10$ \\
\hline Sr (ppm) & 64 & 65 & 70 & 40 & 38 & $<5$ & Sr (ppm) & 99 & 168 & 85 & 33 & 42 & 169 \\
\hline V (ppm) & 16 & $<15$ & 18 & $<15$ & $<15$ & $<15$ & V (ppm) & $<15$ & 29 & $<15$ & $<15$ & $<15$ & $<15$ \\
\hline$Y(p p m)$ & 45 & 8 & 110 & 80 & 48 & $<10$ & $Y(p p m)$ & $<10$ & $<10$ & $<10$ & $<10$ & $<10$ & $<10$ \\
\hline Zn (ppm) & 124 & 506 & 129 & 182 & 245 & $<10$ & Zn (ppm) & 101 & 531 & 44 & 39 & 138 & $<10$ \\
\hline $\mathrm{Zr}$ (ppm) & $<25$ & $<25$ & $<25$ & $<25$ & $<25$ & $<25$ & $\mathrm{Zr}$ (ppm) & $<25$ & $<25$ & $<25$ & $<25$ & $<25$ & $<25$ \\
\hline
\end{tabular}


Tabela 9 - Resultados obtidos através dos cálculos dos coeficientes de absorção biológica (CAB), para os nomofilos e pecíolos nos horizonte $\mathrm{s} A$ e $\mathrm{B}$ nos meses de junho e outubro.

BAC - Coeficiente de Absorção Biológica
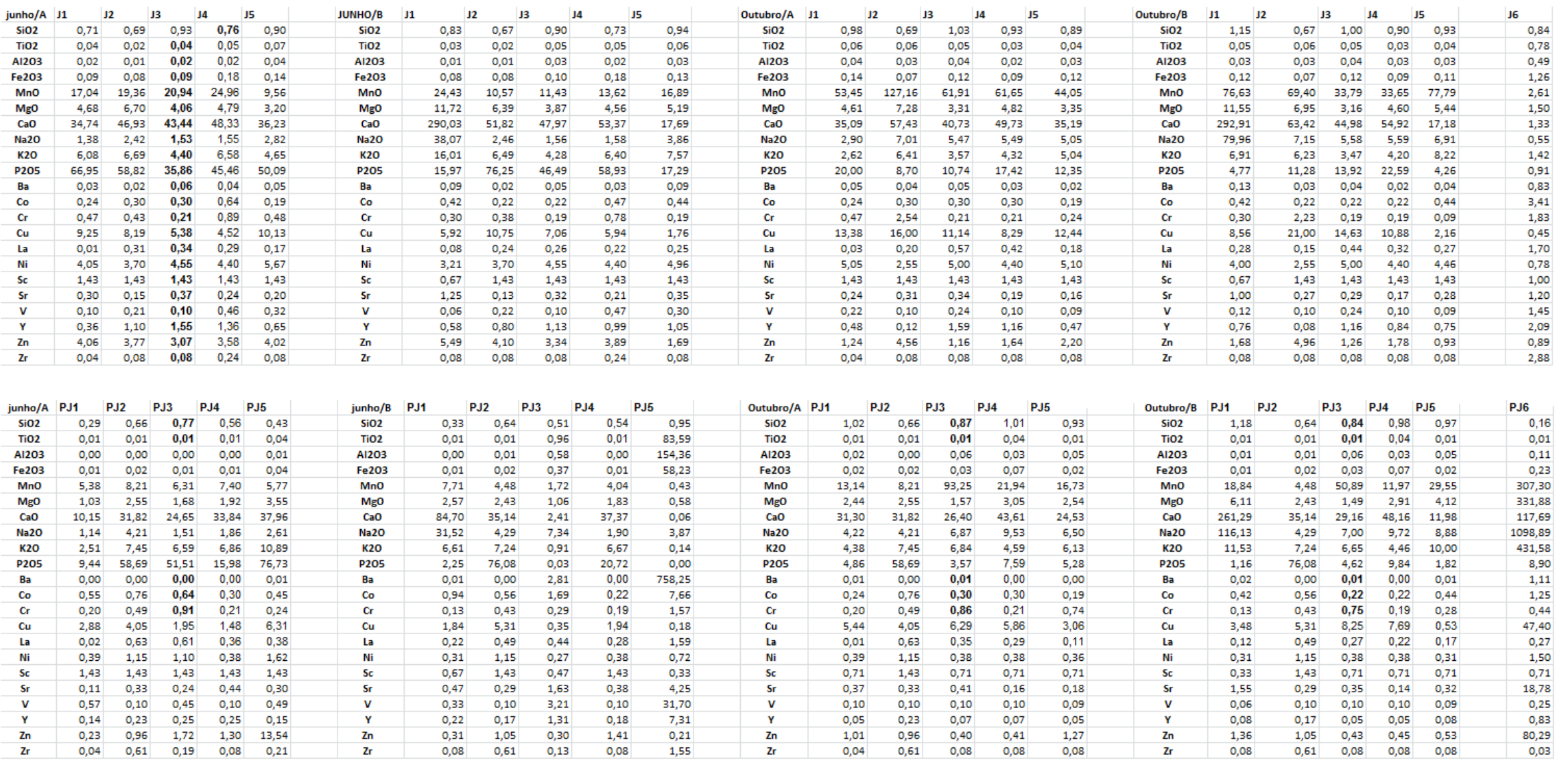
Tabela 10 - Resultados obtidos através dos cálculos dos coeficientes de absorção temporal (CAT), para os nomofilos e pecíolos.

TAC - Coeficiente de Absorção Temporal

\begin{tabular}{|c|c|c|c|c|c|c|c|c|c|c|c|}
\hline & J1 & $J 2$ & J3 & J4 & 15 & & PJ1 & PJ2 & PJ3 & PJ4 & PJ5 \\
\hline $\mathrm{SiO} 2$ & 0,72 & 0,99 & 0,91 & 0,82 & 1,02 & SiO2 & 0,28 & 1,43 & 0,89 & 0,55 & 0,46 \\
\hline TiO2 & 0,67 & 0,41 & 0,84 & 1,60 & 1,54 & TiO2 & 1,76 & 1,69 & 1,92 & 0,30 & 6,57 \\
\hline $\mathrm{Al} 2 \mathrm{O3}$ & 0,48 & 0,46 & 0,68 & 0,83 & 1,24 & $\mathrm{Al} 203$ & 0,33 & 0,09 & 0,06 & 0,13 & 0,19 \\
\hline $\mathrm{Fe} 2 \mathrm{O} 3$ & 0,65 & 1,25 & 0,77 & 1,98 & 1,18 & $\mathrm{Fe} 2 \mathrm{O} 3$ & 0,50 & 0,71 & 0,39 & 0,09 & 1,59 \\
\hline $\mathrm{MnO}$ & 0,32 & 0,15 & 0,34 & 0,40 & 0,22 & $\mathrm{MnO}$ & 0,41 & 0,08 & 0,07 & 0,34 & 0,34 \\
\hline $\mathrm{MgO}$ & 1,01 & 0,92 & 1,23 & 0,99 & 0,95 & MgO & 0,42 & 0,43 & 1,07 & 0,63 & 1,40 \\
\hline $\mathrm{CaO}$ & 0,99 & 0,82 & 1,07 & 0,97 & 1,03 & $\mathrm{CaO}$ & 0,32 & 0,44 & 0,93 & 0,78 & 1,55 \\
\hline $\mathrm{Na} 2 \mathrm{O}$ & 0,48 & 0,34 & 0,28 & 0,28 & 0,56 & $\mathrm{Na} 2 \mathrm{O}$ & 0,27 & 0,53 & 0,22 & 0,20 & 0,40 \\
\hline K2O & 2,32 & 1,04 & 1,23 & 1,52 & 0,92 & $\mathrm{~K} 2 \mathrm{O}$ & 0,57 & 0,73 & 0,96 & 1,50 & 1,78 \\
\hline P2O5 & 3,35 & 6,76 & 3,34 & 2,61 & 4,06 & P2O5 & 1,94 & 7,90 & 14,44 & 2,11 & 14,52 \\
\hline $\mathrm{Ba}$ & 0,66 & 0,52 & 1,27 & 1,57 & 2,06 & $\mathrm{Ba}$ & 0,45 & 0,07 & 0,38 & 1,00 & 2,40 \\
\hline Co & 1,00 & 1,00 & 1,00 & 2,13 & 1,00 & Co & 2,27 & 2,53 & 2,13 & 1,00 & 2,40 \\
\hline $\mathrm{Cr}$ & 1,00 & 0,17 & 1,00 & 4,13 & 2,00 & $\mathrm{Cr}$ & 1,00 & 1,06 & 1,07 & 1,00 & 0,33 \\
\hline $\mathrm{Cu}$ & 0,69 & 0,51 & 0,48 & 0,55 & 0,81 & $\mathrm{Cu}$ & 0,53 & 0,35 & 0,31 & 0,25 & 2,06 \\
\hline La & 0,28 & 1,57 & 0,60 & 0,68 & 0,93 & La & 1,87 & 8,80 & 1,73 & 1,27 & 3,29 \\
\hline $\mathrm{Ni}$ & 0,80 & 1,45 & 0,91 & 1,00 & 1,11 & $\mathrm{Ni}$ & 1,00 & 3,07 & 2,93 & 1,00 & 4,53 \\
\hline Sc & 1,00 & 1,00 & 1,00 & 1,00 & 1,00 & Sc & 2,00 & 2,00 & 2,00 & 2,00 & 2,00 \\
\hline $\mathrm{Sr}$ & 1,25 & 0,48 & 1,10 & 1,25 & 1,24 & Sr & 0,30 & 0,41 & 0,58 & 2,79 & 1,62 \\
\hline v & 0,47 & 2,13 & 0,42 & 4,67 & 3,47 & V & 5,60 & 0,26 & 4,53 & 1,00 & 5,33 \\
\hline $\mathbf{Y}$ & 0,76 & 9,50 & 0,97 & 1,18 & 1,39 & $\mathbf{Y}$ & 2,60 & 3,20 & 3,40 & 3,40 & 3,00 \\
\hline $\mathrm{Zn}$ & 3,27 & 0,83 & 2,64 & 2,18 & 1,83 & $\mathrm{Zn}$ & 0,23 & 0,20 & 4,34 & 3,13 & 10,70 \\
\hline $\mathrm{Zr}$ & 1,00 & 1,00 & 1,00 & 2,88 & 1,00 & $\mathrm{Zr}$ & 1,00 & 7,28 & 2,24 & 1,00 & 2,56 \\
\hline
\end{tabular}


Tabela 11 - Resultados obtidos através dos cálculos dos coeficientes de absorção acropetal (AC), para os nomofilos e pecíolos.

\section{AC - Coeficiente Acropetal}

\begin{tabular}{|c|c|c|c|c|c|c|c|c|c|c|c|}
\hline Junho & J1 & $J 2$ & 13 & 14 & 15 & Outubro & J1 & $J 2$ & 13 & $J 4$ & 15 \\
\hline $\mathrm{SiO} 2$ & 2,63 & 2,47 & 3,34 & 2,72 & 3,37 & $\mathrm{SiO} 2$ & 3,65 & 2,49 & 3,69 & 3,33 & 3,32 \\
\hline TiO2 & 0,70 & 0,45 & 0,86 & 1,02 & 1,26 & TiO2 & 1,04 & 1,10 & 1,03 & 0,64 & 0,82 \\
\hline Al2O3 & 0,78 & 0,55 & 1,00 & 0,84 & 1,51 & Al2O3 & 1,61 & 1,20 & 1,48 & 1,01 & 1,21 \\
\hline $\mathrm{Fe} 2 \mathrm{O} 3$ & 0,88 & 0,81 & 0,94 & 1,81 & 1,38 & $\mathrm{Fe} 2 \mathrm{O} 3$ & 1,35 & 0,65 & 1,23 & 0,92 & 1,17 \\
\hline $\mathrm{MnO}$ & 0,12 & 0,12 & 0,13 & 0,15 & 0,10 & $\mathrm{MnO}$ & 0,36 & 0,76 & 0,37 & 0,37 & 0,47 \\
\hline MgO & 0,32 & 0,43 & 0,26 & 0,31 & 0,21 & MgO & 0,31 & 0,47 & 0,21 & 0,31 & 0,22 \\
\hline $\mathrm{CaO}$ & 0,73 & 0,66 & 0,61 & 0,68 & 0,57 & $\mathrm{CaO}$ & 0,74 & 0,80 & 0,57 & 0,70 & 0,55 \\
\hline $\mathrm{Na} 2 \mathrm{O}$ & 0,09 & 0,09 & 0,06 & 0,06 & 0,11 & $\mathrm{Na} 2 \mathrm{O}$ & 0,18 & 0,28 & 0,22 & 0,22 & 0,20 \\
\hline K2O & 0,69 & 0,72 & 0,48 & 0,71 & 0,51 & K2O & 0,30 & 0,69 & 0,39 & 0,47 & 0,55 \\
\hline P205 & 17,64 & 19,20 & 11,71 & 14,84 & 12,18 & P2O5 & 5,27 & 2,84 & 3,50 & 5,69 & 3,00 \\
\hline Ba & 8,20 & 4,60 & 13,20 & 9,40 & 13,20 & Ba & 12,40 & 8,80 & 10,40 & 6,00 & 6,40 \\
\hline Co & 1,00 & 1,00 & 1,00 & 2,13 & 1,00 & Co & 1,00 & 1,00 & 1,00 & 1,00 & 1,00 \\
\hline $\mathrm{Cr}$ & 2,40 & 2,00 & 1,00 & 4,13 & 2,00 & $\mathrm{Cr}$ & 2,40 & 11,87 & 1,00 & 1,00 & 1,00 \\
\hline $\mathrm{Cu}$ & 0,35 & 0,40 & 0,26 & 0,22 & 0,38 & $\mathrm{Cu}$ & 0,50 & 0,79 & 0,55 & 0,41 & 0,46 \\
\hline La & 0,48 & 1,57 & 1,71 & 1,43 & 1,19 & La & 1,71 & 1,00 & 2,86 & 2,10 & 1,29 \\
\hline $\mathrm{Ni}$ & 10,27 & 9,87 & 12,13 & 11,73 & 15,87 & $\mathrm{Ni}$ & 12,80 & 6,80 & 13,33 & 11,73 & 14,27 \\
\hline Sc & 2,00 & 2,00 & 2,00 & 2,00 & 2,00 & Sc & 2,00 & 2,00 & 2,00 & 2,00 & 2,00 \\
\hline $\mathrm{Sr}$ & 0,71 & 0,28 & 0,69 & 0,45 & 0,41 & $\mathrm{Sr}$ & 0,57 & 0,58 & 0,63 & 0,36 & 0,33 \\
\hline v & 0,50 & 1,07 & 0,50 & 2,33 & 1,73 & v & 1,07 & 0,50 & 1,20 & 0,50 & 0,50 \\
\hline Y & 6,80 & 15,20 & 21,40 & 18,80 & 12,80 & $\mathbf{Y}$ & 9,00 & 1,60 & 22,00 & 16,00 & 9,20 \\
\hline $\mathrm{Zn}$ & 0,64 & 0,66 & 0,54 & 0,62 & 0,69 & $\mathrm{Zn}$ & 0,19 & 0,80 & 0,20 & 0,29 & 0,38 \\
\hline $\mathrm{Zr}$ & 1,00 & 1,00 & 1,00 & 2,88 & 1,00 & $\mathrm{Zr}$ & 1,00 & 1,00 & 1,00 & 1,00 & 1,00 \\
\hline Junho & PJ1 & PJ2 & PJ3 & PJ4 & PJ5 & Outubro & PJ1 & PJ2 & PJ3 & PJ4 & PJ5 \\
\hline $\mathrm{SiO} 2$ & 1,20 & 2,72 & 3,14 & 2,28 & 1,82 & $\mathrm{SiO} 2$ & 4,30 & 1,90 & 3,54 & 4,15 & 3,94 \\
\hline TiO2 & 1,43 & 1,41 & 1,41 & 1,55 & 4,76 & TiO2 & 0,81 & 0,83 & 0,74 & 5,12 & 0,72 \\
\hline Al2O3 & 0,89 & 0,97 & 0,70 & 0,68 & 1,88 & $\mathrm{Al} 203$ & 2,73 & 11,26 & 11,59 & 5,12 & 9,77 \\
\hline $\mathrm{Fe} 2 \mathrm{O} 3$ & 0,26 & 0,64 & 0,45 & 0,21 & 1,15 & $\mathrm{Fe} 2 \mathrm{O} 3$ & 0,51 & 0,91 & 1,14 & 2,31 & 0,72 \\
\hline $\mathrm{MnO}$ & 0,08 & 0,11 & 0,08 & 0,10 & 0,13 & $\mathrm{MnO}$ & 0,20 & 1,40 & 1,22 & 0,29 & 0,39 \\
\hline MgO & 0,07 & 0,16 & 0,10 & 0,12 & 0,22 & MgO & 0,16 & 0,37 & 0,10 & 0,19 & 0,16 \\
\hline $\mathrm{CaO}$ & 0,20 & 0,42 & 0,32 & 0,44 & 0,56 & $\mathrm{CaO}$ & 0,62 & 0,94 & 0,35 & 0,57 & 0,36 \\
\hline $\mathrm{Na} 2 \mathrm{O}$ & 0,06 & 0,15 & 0,05 & 0,06 & 0,09 & $\mathrm{Na} 2 \mathrm{O}$ & 0,24 & 0,28 & 0,24 & 0,33 & 0,23 \\
\hline K2O & 0,23 & 0,66 & 0,59 & 0,61 & 0,98 & K2O & 0,41 & 0,91 & 0,61 & 0,41 & 0,55 \\
\hline P2O5 & 3,67 & 28,26 & 24,80 & 7,70 & 27,52 & P2O5 & 1,89 & 3,58 & 1,72 & 3,66 & 1,89 \\
\hline $\mathrm{Ba}$ & 0,24 & 0,24 & 0,24 & 0,24 & 0,57 & $\mathrm{Ba}$ & 0,52 & 3,57 & 0,62 & 0,24 & 0,24 \\
\hline Co & 2,27 & 2,53 & 2,13 & 1,00 & 2,40 & Co & 1,00 & 1,00 & 1,00 & 1,00 & 1,00 \\
\hline $\mathrm{Cr}$ & 1,00 & 2,27 & 4,27 & 1,00 & 1,00 & $\mathrm{Cr}$ & 1,00 & 2,13 & 4,00 & 1,00 & 3,07 \\
\hline $\mathrm{Cu}$ & 0,19 & 0,36 & 0,17 & 0,13 & 0,43 & $\mathrm{Cu}$ & 0,37 & 1,03 & 0,56 & 0,52 & 0,21 \\
\hline La & 3,73 & 8,80 & 8,53 & 5,07 & 7,47 & La & 2,00 & 1,00 & 4,93 & 4,00 & 2,27 \\
\hline $\mathrm{Ni}$ & 1,00 & 3,07 & 2,93 & 1,00 & 4,53 & $\mathrm{Ni}$ & 1,00 & 1,00 & 1,00 & 1,00 & 1,00 \\
\hline Sc & 2,00 & 2,00 & 2,00 & 2,00 & 2,00 & Sc & 1,00 & 1,00 & 1,00 & 1,00 & 1,00 \\
\hline $\mathrm{Sr}$ & 0,18 & 0,41 & 0,29 & 0,54 & 0,40 & $\mathrm{Sr}$ & 0,59 & 0,99 & 0,50 & 0,20 & 0,25 \\
\hline v & 5,60 & 1,00 & 4,53 & 1,00 & 5,33 & v & 1,00 & 3,87 & 1,00 & 1,00 & 1,00 \\
\hline $\mathbf{Y}$ & 2,60 & 3,20 & 3,40 & 3,40 & 3,00 & $Y$ & 1,00 & 1,00 & 1,00 & 1,00 & 1,00 \\
\hline $\mathrm{Zn}$ & 0,04 & 0,19 & 0,34 & 0,26 & 2,63 & $\mathrm{Zn}$ & 0,18 & 0,94 & 0,08 & 0,08 & 0,25 \\
\hline $\mathrm{Zr}$ & 1,00 & 7,28 & 2,24 & 1,00 & 2,56 & $\mathrm{Zr}$ & 1,00 & 1,00 & 1,00 & 1,00 & 1,00 \\
\hline
\end{tabular}

